Portland State University

PDXScholar

$1-1-1984$

\title{
The relation of economic diversity to levels, growth rates, and stability of unemployment and income
}

Mohsen Attaran

Portland State University

Follow this and additional works at: https://pdxscholar.library.pdx.edu/open_access_etds Let us know how access to this document benefits you.

\section{Recommended Citation}

Attaran, Mohsen, "The relation of economic diversity to levels, growth rates, and stability of unemployment and income" (1984). Dissertations and Theses. Paper 542.

https://doi.org/10.15760/etd.542

This Dissertation is brought to you for free and open access. It has been accepted for inclusion in Dissertations and Theses by an authorized administrator of PDXScholar. Please contact us if we can make this document more accessible: pdxscholar@pdx.edu. 


\title{
THE RELATION OF ECONOMIC DIVERSITY TO LEVELS, GROWTH RATES, AND STABILITY \\ OF UNEMPLOYMENT AND INCOME
}

by

MOHSEN ATTARAN

A dissertation submitted in partial fulfillment of the requirements for the degree of

\author{
DOCTOR OF PHILOSOPHY \\ in \\ SYSTEMS SCIENCE
}

Portland State University

(C) 1984 Mohsen Attaran 
TO THE OFFICE OF GRADUATE STUDIES AND RESEARCH:

The members of the Committee approve the dissertation of Mohsen Attaran presented November 26, 1984 .
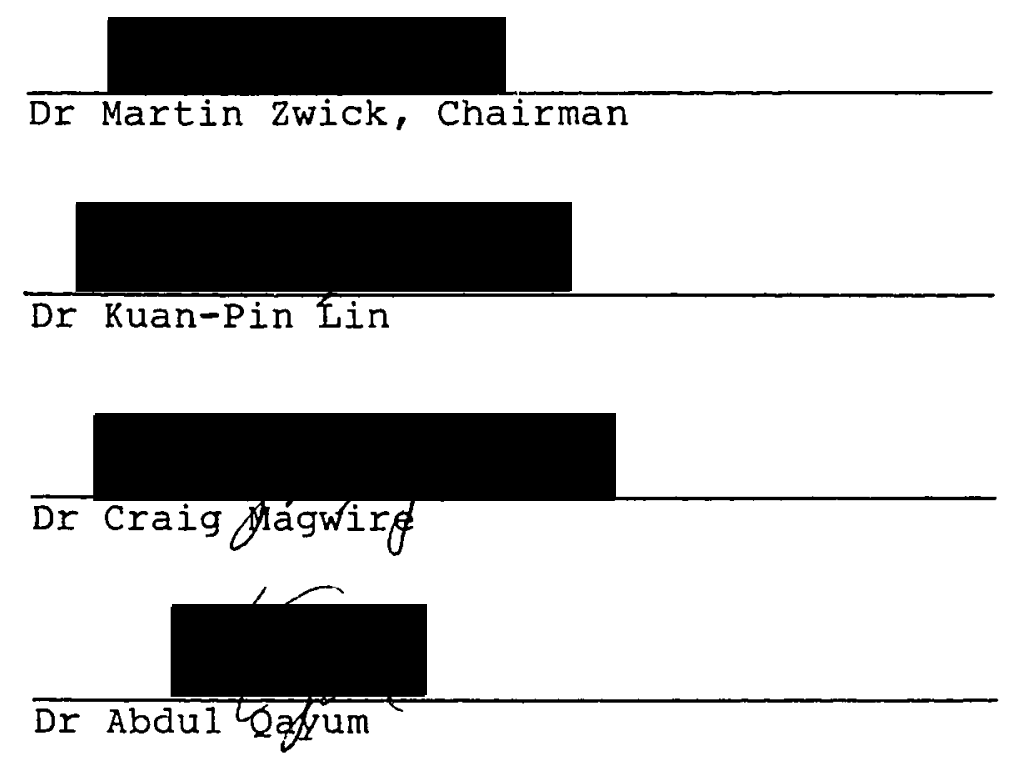

$\therefore P P R O V E D$ :

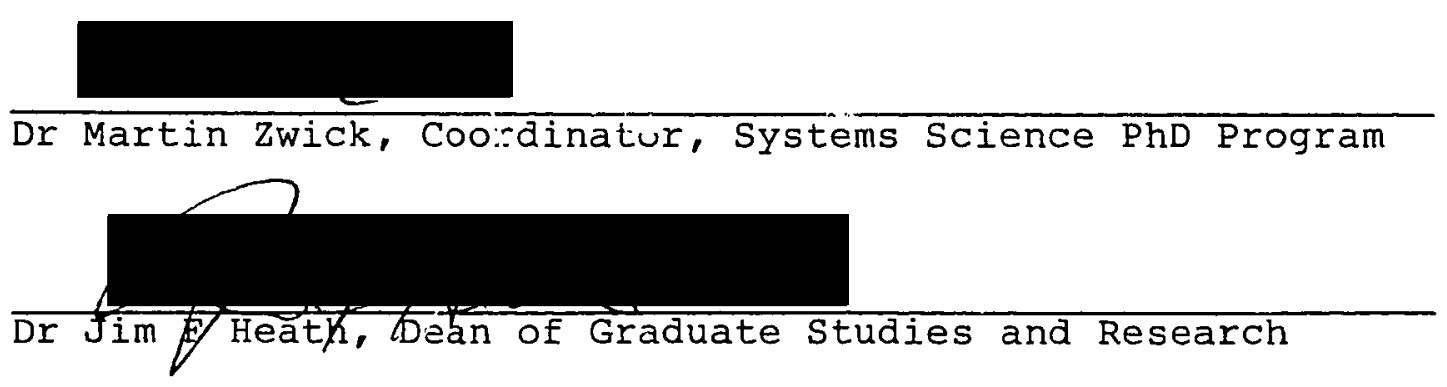


AN ABSTRACT OF THE DISSERTATION OF Mohsen Attaran for the Doctor of Philosophy in Systems Science presented November 26,1984 .

Title: The Relation of Economic Diversity to Levels, Growth Rates, and Stability of Unemployment and Income.

APPROVED BY MEMBERS OF THE DISSERTATION COMMITTEE:
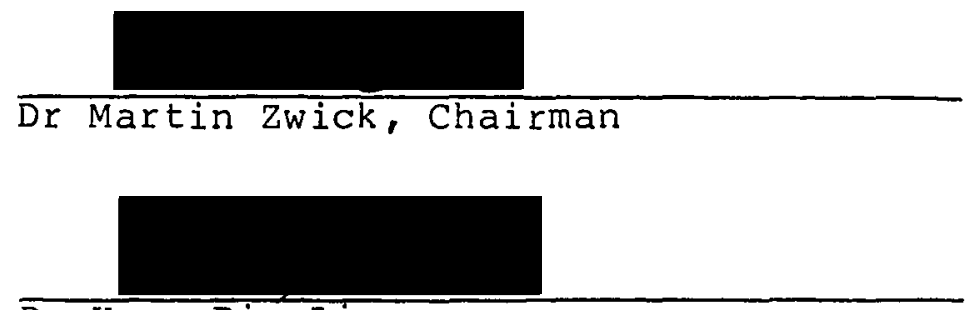

Dr Kuan-Pin Lin
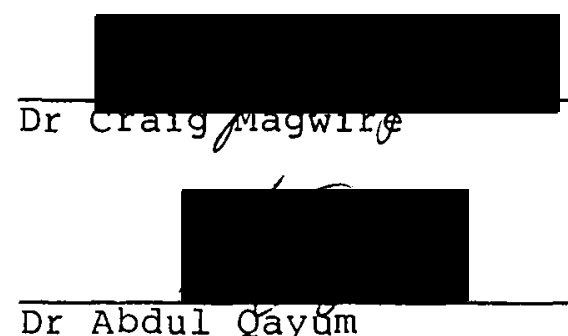

The purpose of this study is to investigate some widely-held assumptions regarding the value of diversification as an economic strategy. It has often been suggested 
that economic diversity enhances economic performance, either by promoting higher levels of economic well-being or by improving the ability of regions to cushion the adverse effects of economic cycles. This is the conventional wisdom, but it has not been adequately tested, although some attempts have been made to relate measures of diversity to other economic indicators (e.g., Rodgers, MacLaughlin, Conkling). The current study explores this particular issue, and the results obtained should be of interest to economists, regional scientists, and development planners and policymakers.

Shannon's entropy function, applied to the distribution of employment in different economic sectors, was used as an index of diversity. This measure allows not only comparison of changes in diversity over time, but also, through its decomposition properties, a means of analyzing the nature of such changes. Economic performance was assessed in terms of unemployment and per capita income, considered in four ways: the level of the variable, its rate of change over time, the degree of instability of the level, and the degree of instability of its rate of change. Eight hypotheses were formulated and tested with data from the counties of Oregon for the ten-year period from 1972 to 1981. To provide a comparative perspective for the Oregon investigation, a U.S. study was also 
conducted for the same period.

Calculations of both studies revealed diversity to be negatively but very weakly correlated with unemployment; the oregon finding, however, did not quite satisfy the $5 \%$ significance standard used throughout this research. While a weak positive association was found between diversity and per capita income of oregon counties, a larger negative association was observed between the two variables in the U.S. study. These results can be explained either as an effect of differing levels of geographic aggregation or in terms of differences among the particular specializations of low diversity counties and states. For Oregon, relations between the variables for nonrecession years were stronger than for recession years.

The study further showed that diversified counties of Oregon were more stable in unemployment and per capita income and showed lower rates of growth of unemployment and higher rates of growth of per capita income than the more specialized counties. None of these associations, however, was particularly strong. For the U.S. study, no evidence was found for any relation between diversity and either growth rates or stability. In general, correlations between diversity and income-based measures were larger than between diversity and unemployment-based measures; 
also, percentage changes associated with differences in diversity were considerably greater for the income-based measures.

Although expected patterns of relationship were thus found to hold, if weakly, for the counties of Oregon, comparison with the national study suggests that results may not be generalizable to other, especially larger, geographic units. Whether diversification is useful for regional development depends at least partially on the specific character of the industries in the region's economy 


\section{ACKNOWLEDGMENTS}

Grateful appreciation is extended to the members of my dissertation committee: first, to my Chairman, Dr Martin Zwick, for providing the initial inspiration and encouragement for undertaking this project and for his unfailing help through all its phases, which generated many of the ideas presented; to Dr Kuan-Pin Lin, who made valuable suggestions for improvement; to Dr Abdul Qayum for his advice, encouragement, and helpful insights; and to Dr Craig Magwire for his kindness and support throughout the project.

I wish to thank my parents, whose sincere belief in education has motivated me to continue my education and whose financial support made it possible for me to reach this goal.

No words can express my gratitude and appreciation to my family--my beloved wife, Fariba, who provided the moral support which sustained me during this experience and without whose dedication and support I would have found it impossible to continue my education; and my beautiful daughter, sharmin, for the joy she brings to my life. My final thank-you is to two special friends, Jamshid Hosseini, for his preparation of several of the 
graphs presented in this study, and sally Lopez, whose help with every aspect of the preparation of this manuscript created order in what often seemed to be an unmanageable project. 
TABLE OF CONTENTS

PAGE

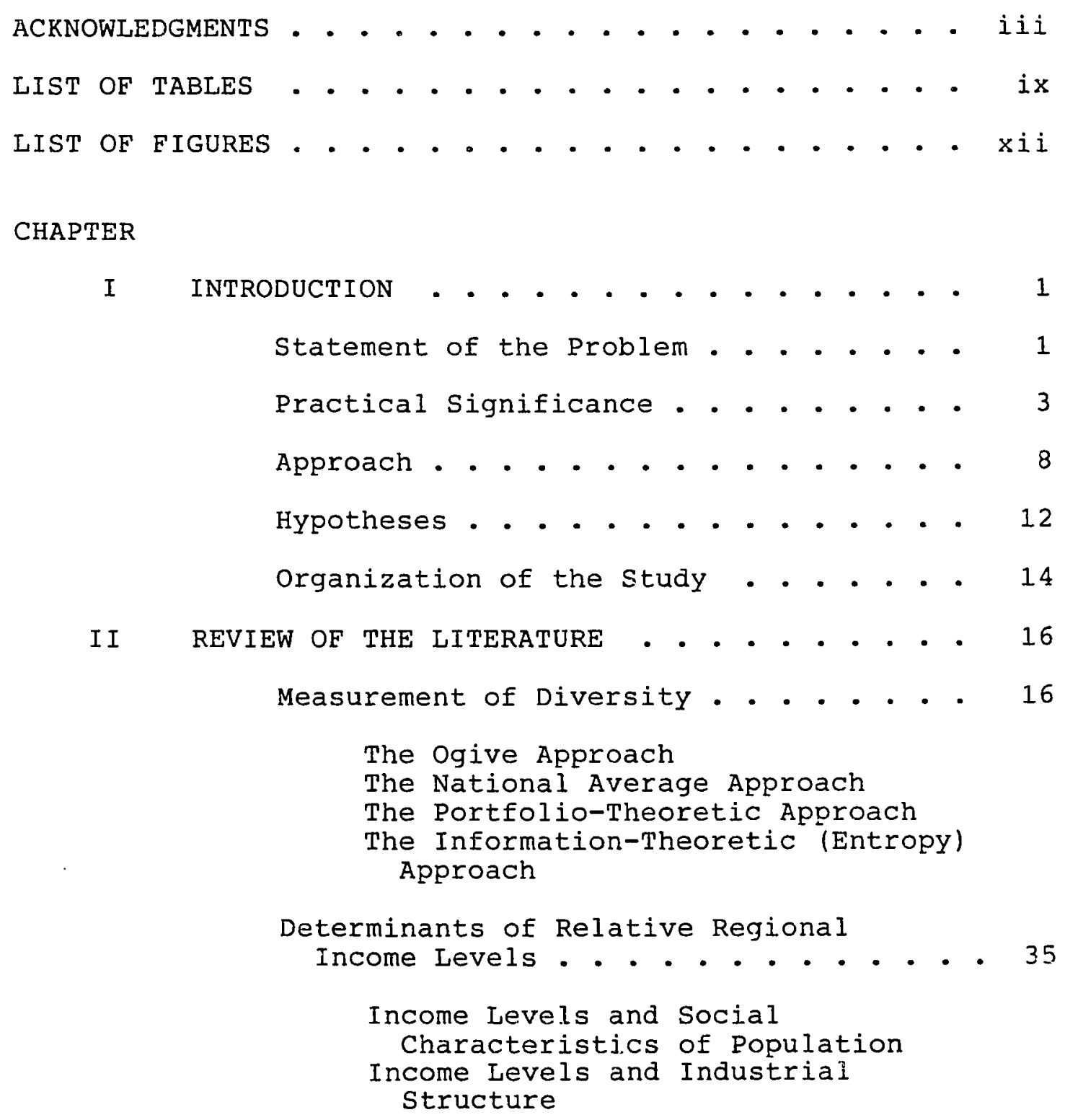


Summary • • • • • • • • • • • • 39

II RESEARCH METHODOLOGY . . . . . . . . . 41

Source of Data. . . . . . . . . . 41

Measures of Diversity and Dependent

Variables ...... . . . . . 43

Statistical-Treatment of the Data . . 50

Null and Alternative Hypotheses . . . 52

Hypothesis Testing . . . . . . 53

Level of Significance . . . . . . 55

IV ECONOMIC TRENDS OF THE LAST DECADE • • • . . 58

Economic Review and Outlook, 1972-1981. 59

The 1970's: Years of Inflation

The Effects of Inflation on

Economic Sectors

oregon, A Hard-Hit state

Oregon's Economy, A Closer Look . . . 68

Nonfarm Wage and Salary

Employment

Manufacturing Employment

Unemployment Characteristics

Per Capita Income Variation

Oregon vs. U.S.: A Comparative

Perspective . . . . . . . . 77

Employment Growth and Stability

Unemployment

Employment-Population Ratio

Growth and Stability: Per Capita

Income 
vii

CHAPTER

PAGE

V FINDINGS : THE OREGON STUDY . . . . . . . - 88

Variation in Diversity within Oregon . - 88

The Difficulty of Accurately Measuring Diversity .............. 94

Changes Over Time in Diversity Patterns 98

Extent and Pattern of Diversification Between and Within Industries . . 100

Factors Associated Diversity

(Hypotheses 1 and 2)....... 105

Unemployment

Per Capita Income

The Effect of Recession on the Strength of Relations............ . 112

The Recession Years

The Nonrecession Years

Summary Tests of Hypotheses 1 and 2

Diversity, Growth and Cyclical

Instability . . . . . . . . . . 123

Levels and Rate of Growth

(Hypotheses 1-4)

Cyclical Fluctuations

(Hypotheses 5-8)

Summary . . . . . . . . . . 130

VI FINDINGS: THE U.S. STUDY . . • . . • • . 133

Factors Associated Diversity

(Hypotheses 1 and 2)........ 135

Unemployment

Per Capita Income 
viii

CHAPTER

PAGE

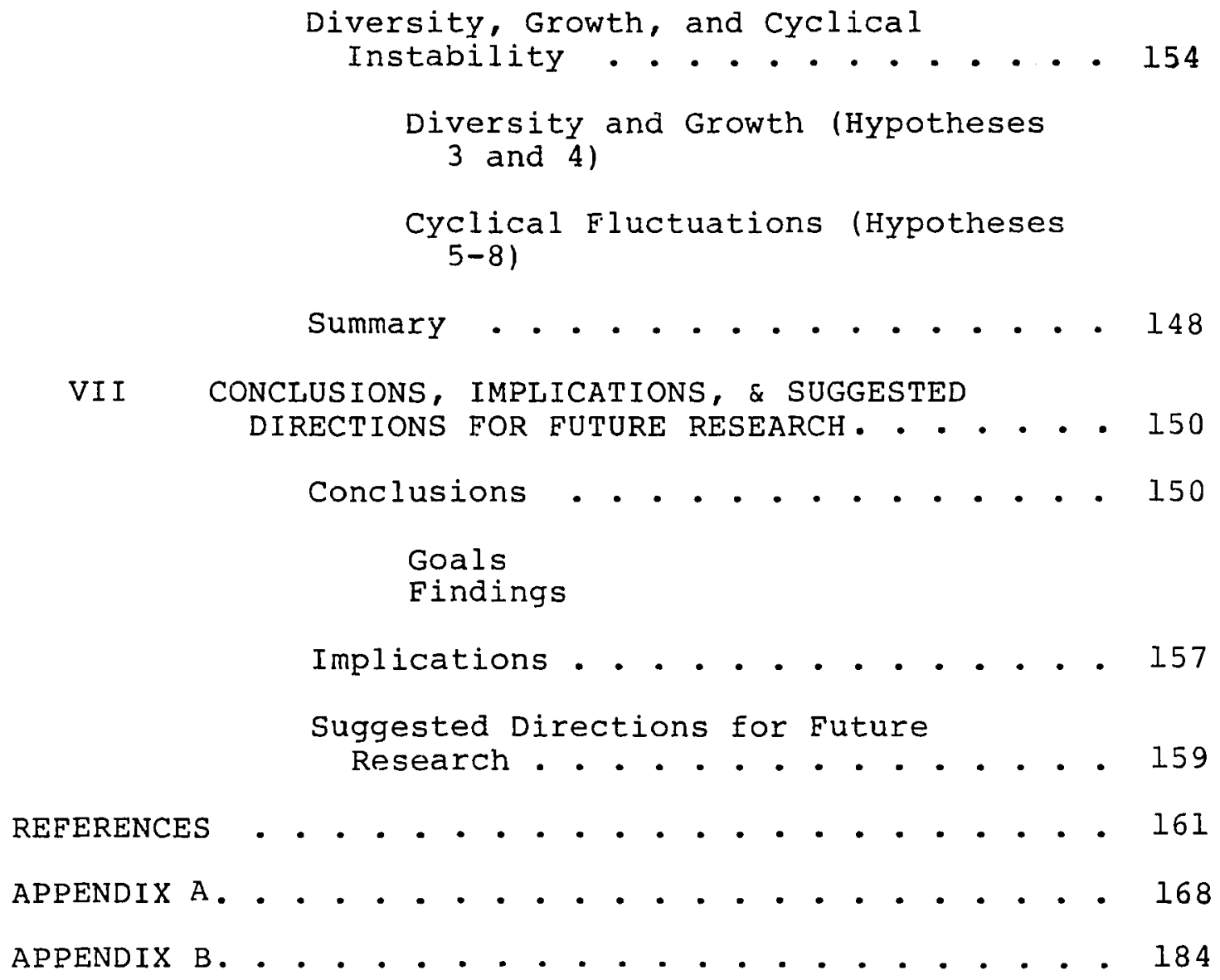




\section{LIST OF TABLES}

TABLE

PAGE

I Correlations Among Employment in Different

Sectors . . . . . . . . . . 96

I Correlations Among Fractional Employment in

Different Sectors . . . . . . . 97

II Employment Diversification Indices for

Oregon, 1972-1981 . . . . . . . . 100

IV A Disaggregated Entropy Measure of Employment

Diversity, Oregon, 1972-1981 . . . . 102

$\mathrm{V}$ Correlation Coefficient of Diversity With

Unemployment for Oregon Counties,

$1972-1981$. . . . . . . . 106

VI Correlation Coefficients of Diversity with

Logarithms of Real Per Capita Income

For the Counties of Oregon, 1972-1981 . 110

VII Summary of Hypotheses 1 and 2: Level

Studies For Recession, Nonrecession, and Total Study Period . . . . . . 119

VII Correlation Results of Diversity and Level

and Rate of Growth for Oregon Counties, $1972-1981$. . . . . . . . . . . 125 
IX Correlation Results of Diversity and Cyclical Instability of Levels and Growth Rates for the Counties of Oregon, 1972-1981 . 129

X Summary of Main Results for Oregon . . . . 132

XI The Correlation Coefficients of Diversity With Unemployment: The United States, $1972-1981$. . . . . . . . . 136

XII The Correlation Coefficients of Diversity With Logarithm of Per Capita Income: The United States, 1972-1981 . . . . 140

XIII Relative Importance of Various Employment Categories in the Five States with the Lowest Mean Diversity . . . . . . . 144 XIV Relative Importance of Various Employment Categories in the Five Oregon Counties With the Lowest Mean Diversity . . . . 145 XV Correlation Results of Diversity and Cyclical Instability, U.S. Studies . . . . . 147

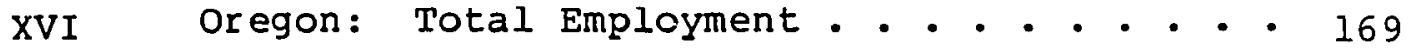
XVII Oregon Unemployment Rates by County, 1972$1981 \ldots 179$ XVIII Oregon Per Capita Income by County and place of Residence, 1972-1981 . . . . . . 180 


\section{TABLE}

PAGE

XIX Oregon Indices of Diversity . . . . . . . 181

XX U.S.: Total Employment . . . . . . . 185

XXI U.S. Unemployment Rates by States, 1972-1981. 195

XXII U.S. Per Capita Income by State, 1972-1981 • 196

XXIII Consumer Price Indexes, by Major Groups,

$1972-1981$. . . . . . . . . . 597

XXIV U.S. Indices of Diversity . . . . . . . . 198 


\section{LIST OF FIGURES}

FIGURE

PAGE

i. Annual, average consumer price index, U.S. and Portland SMSC, 1972-1981 . . . . 62

2. Oregon lumber and wood product employment compared with U.S. housing starts, $1972-1981$. . . . . . . . . . 66

3. Oregon nonagricultural wage \& salary employment, 1972 and 1981 . . . . 69

4. Manufacturing employment, percent distribution . . . . . . . . 71

5. Employment: U.S. and Oregon, 1970-1982 •. 78

6. Average unemployment rates (in calendar years), Oregon and U.S. . . . . 81

7. Real per capita income: U.S. \& Oregon, $1970-1981$. . . . . . . . . 85

8. Oregon diversification indices...... . 89

9. Histogram for diversity indices of oregon counties, averaged for the period 1972-1981 . . . . . . . . . . 93

10. Unemployment vs. diversity, 1972-1981, oregon ............ 107 
xiii

F IGURE

PAGE

11. Per capita income vs. diversity: 1972-191, Oregon . . . . . . . . . . . . . 111

12. Unemployment vs. diversity, recessionary years, oregon ........... . 113

13. Per capita income vs. diversity, recessionary years, Oregon . . . . 115

14. Unemployment vs. diversity, nonrecessionary years, oregon . . . . . . . . . 116

15. Per capita income vs. diversity, nonrecessionary years, Oregon . . . . 117

16. Average diversification indices, $1972-1981$. . . . . . . . . . 134

17. Unemployment vs. diversity, 1972-1981, U.S. 137 18. Per capita income vs. diversity, 1972-1981, U.S. ................ 141 
CHAPTER I

INTRODUCTION

STATEMENT OF THE PROBLEM

One of the major outcomes of the depression of the thirties was a drive toward diversification of industrial activity in many areas of this country. Diversification became an important policy consideration because of the belief that specialization was a dangerous liability which could lead to periodic high unemployment and instability of income. A 1937 statement from a government publication illustrates the extreme nature of this belief:

\begin{abstract}
A poorly balanced industrial structure throws the entire industrial front out of joint by causing migration of labor, unemployment, lower wages, curtailed purchasing power, less trading business, lower living standards, high cost of relief, high taxes, tax delinquency, untenanted property, stagnation of building enterprises, obsolescence of community plants, and depreciation of industrial equipment.
\end{abstract}

(National Resource Planning Board, 1937: 62)

The advantages of diversity have been argued and analyzed in the regional economics literature (Hoover, Mclaughlin). Specifically, regional business cycle theorists have debated the thesis that as a region's industrial structure becomes more diversified, its economy 
becomes less responsive to fluctuation caused by changes in extraregional economic factors (Nourse, Richardson). Hoover and Fisher wrote that

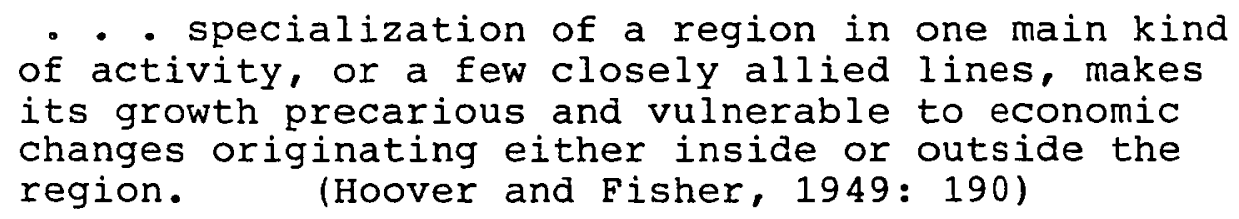

The suggested disadvantages of specialization are that a region's market for its specialty might be undercut by the discovery of new and cheaper supply sources, by improvements in production elsewhere, by improvement in transportation, or by shifts in demand.

It is also suggested that the less specialized an area is (i.e., the greater the degree to which it is diversified), the greater its ability will be to cushion adverse cyclical effects. This view is closely related to the widely-held assumption that economic diversity enhances economic performance, the latter being measured by growth rate, per capita income, unemployment rate, or other indicators.

For years now, economic planners have assumed that diversification in the economic activity of a region increases the aggregate level of regional income or income per capita, reduces unemployment rates, increases growth rates, and stabilizes (in the sense of reducing fluctuations 
over time) the levels of aggregate income, employment, or other regional economic characteristics (Conroy, 1975a).

These assumptions are the "conventional wisdom," but in fact may not be true. While attempts have been made to relate the index of diversity to certain indicators of economic performance (McLaughlin, Rodgers, Conkling), the issue has not been adequately explored; thus, the nature and significance of diversity is not fully understood. We do not as yet really know whether measures of diversity have explanatory or predictive value in relation to levels, rates of growth and instability of per capita income, unemployment, and other economic variables.

This study undertakes an investigation of the various aspects of economic diversity to determine whether support can be found for some of the generally-held assumptions regarding its value. These assumptions are tested with data from the counties of oregon and the states of the United States for the ten-year period, 1972-1981.

\section{PRACTICAL SIGNIFICANCE}

The interest in economic diversification is a nationwide phenomenon, but it has been particularly felt in Oregon. Many of Oregon's 36 counties rely heavily on the timber industry, which provides 80,000 jobs throughout the state. In 1980, the lumber and wood product industries 
employed one out of three workers in several oregon counties such as Crook, Harney, Grant, and Lake. Heavy reliance in these counties on logging and mill payrolls makes them vulnerable to downturns in the national business cycle. In the recent recession, for example, the lumber and wood products industry in oregon was severely afflicted. By midMay 1980, nearly 17,000 of the industry's workers in the state had been laid off.

Industries related to the lumber and wood products sector were also deeply affected by the recession and its aftermath. Within construction, for example, special trades contractors were especially hard-hit. Employment in this sector fell nearly 148 in 1980 , a loss of approximately 7,300 jobs.

The impact of the housing slump on some counties has been particularly severe. During the recession's peak in 1980, Harney county registered an unemployment rate of nearly 30\%. Crook registered 20.8\%, Grant 18.0\%, Baker 17.08, and fifteen other counties listed jobless rates of from 10 to 158 . The majority of these counties were located within two regions: northeastern Oregon and the area from Eugene to the California border.

The areas of the state which perhaps suffered least from the recession were the metropolitan areas of Portland and Salem, presumably because these two areas have 
relatively diversified economies and are therefore less dependent on the wood products-related industries.

Mr. Tom Brennen of the Oregonian staff has pointed out these unemployment differences among oregon counties:

In this recession, as in previous ones, there are two Oregons. One is called the Portland Standard Metropolitan Statistical Area; the other is the rest of the state. . . There is almost that kind of disparity between the jobless rates for the Portland area and the rest of the state, which is recession-prone because of its heavy dependence on timber industry payrolls. Portland is recessionresistant because of its high degree of diversification. . Take the latest unemployment figures, for the month of May. The state average was 8.6 percent of the labor force. . That rate in the Portland area was 5.7 percent. But in the other Oregon, it was a fraction below 11 percent, or 93 percent higher than in Portland... Portland and the rest of the state each have almost exactly one-half of the jobs in the state. But in May, Portland had only one-third of the unemployment, while the rest of the state had the other two-thirds. (Brennen, 1980: D11)

Mr. Brennen is here clearly alluding to the widely-held assumption that the greater the diversification in an area, the greater the area's ability to cushion adverse cyclical effects.

During the past several years, state programs in oregon have attempted to promote economic diversification by attracting new industry. For instance, during the 1975 to 1980 period, the state approved $\$ 245 \mathrm{million}$ in economic development revenue bonds for the purpose of financing new industries. From 1976 to 1984 , Oregon issued 72 industrial 
development revenue bonds for a total of $\$ 201.59$ million. The above revenue saved a total of 670 jobs and created 4830 new ones (Industrial development bonds issued, 1976-1874, Economic Development Department). Governor Atiyeh, a long-time advocate of regional economic diversification, has repeatedly stressed the plight of the region in terms of economic diversity. On Wednesday, June 20, 1984, Governor Atiyeh described a proposed alternative to the unitary method of taxation in a speech to the World Affairs Council in Portland. Oregon is one of the 13 states which uses the unitary method in computing taxes on foreign businesses. This method taxes foreign corporations at a rate based on their worldwide earnings. Some companies have cited it as a reason not to locate new plants in Oregon. The Governor's speech pointed out that

If we wish to hold onto Oregon's attractiveness as a place to live, as a place to work. . . and as a place to rear the next generation of Oregonians, we must diversity our economy. We have lived through a recession that was more severe, more troubling, and more damaging to our spirit because so many of our hopes have been tied to a single industry. That industry is lumber and wood products . . . . But this heavy reliance on a single industry and the resulting cycles of boom and despair cannot continue. Oregon must diversity its economy . . . But these engines for economic growth and expansion in our state continue to be braked by one factor - . the unitary method of taxing the worldwide income of multinational corporations. Today I am proposing a modification of our corporate tax structure that will fine-tune oregon's business climate, polish Oregon's image internationally, and position Oregon to attract thousands more payrolls. (Atiyeh, 1984: 2-3) 
The interest in economic diversification is not limited to Oregon, but has been a nationwide phenomenon for some time. Development planning agencies of local governments have attempted to reap the benefits of additional economic activities by adopting policies which stimulate the location of new or relocated activities within a specific region. These policies might range from providing information on locational characteristics of an area to tax exemptions for newly locating or expanding industries. As noted by conroy (1975):

The magnitude of such interventions in the spatial
allocation of economic activity within the United
States is somewhat surprising. - . As of 1971 ,
there were no fewer than 4,513 different
organizations actively involved in 'industrial
develofment.' The vast majority of them seeking to
attract riow or expanded industry to specific, very
limited geographic areas. (Conroy, $1975 \mathrm{~b}$ : xii)

Conroy additionally points out that 42 of the 50 states approved revenue bonds for financing new industries. In 42 states, there existed city- and/or county-owned industrial parks; in 21 states, corporate income cax exemptions were available to new industries; and in 12 states, cities and counties provided free lands to newcomers.

An understanding of the relationship of economic diversity to the economic health of an area is essential to effective economic planning. In view of the present (198084) economic crisis in oregon and the importance of a 
diversification policy in the country, an improved understanding of the nature and significance of diversity would clearly be of practical importance.

The purpose of this study is to investigate economic diversity as an economic strategy to determine whether there is support for some of the generally-held assumptions regarding its value. Such an investigation should provide insight into the patterns of growth and sources of cyclical instability of the units (counties, states) during the period of study. This, in turn, may offer both a conceptual and an historical perspective for decisionmakers responsible for formulating policies for economic recovery.

\section{APPROACH}

The term diversification has been used in many contexts. In its broadest sense, diversification has been defined as the extent to which the economic activity of a region is dispersed among a great many employment fields.

The earliest attempt to compare ordinally the industrial diversity of urban areas was undertaken by Mclaughlin in 1930. Since that initial study, many other measures of diversification have been developed; they may be broadly grouped into four categories, each of which has been used in one or more empirical attempts to calculate the index of diversity. 
The first class of measures, the ogive approach, detines a maximally-diversified economy as one with equal percentages in each industrial group into which it is disaggregated. The works of McLaughlin (1930), Tress (1938), Rodgers (1957), Conkling (1963), Shear (1965), and Gratton (1979), sought to relate differences in instability to deviation from such a uniform distribution across industries.

A second class of measures, the national average approach, defines a maximally diversified regional economy as one in which the proportion of employment, or value added, in each industry is identical to that of the national economic pattern. Studies by Florence (1943), Steigenga (1955), and Borts (1961), are representative of this approach.

A third class of measures, the portfolio-theoretic approach, is derived from the works of Conroy (1974), Barth, Kraft and wiest (1975), and St. Louis (1980). These authors drew concepts and techniques from the literature on the diversification of stock portfolios to suggest that industrial diversification is an analogous process. This method assumes that allocation of the limited resources of a region among various industries to maximize benefits could be compared with the portfolio of stocks for a given investor. Their measure, "industrial portfolio variance," 
serves as an aggregate measure of the instability that may be associated with the industrial structure of a region.

A fourth and final class of measures of diversification uses information-theoretic entropy as a measure of diversity. As in the ogive approach, the information-theoretic entropy measure is maximum for equiproportional distribution of employment among all sectors. The works of Paulson and Garrison (1973), Garrison (1974) and Hackbart and Anderson (1975), are representative of this approach. This is the method analyzed in the current study.

The above-mentioned approaches and the specific reasons for the employment of the entropy measure in the present study are discussed in detail in Chapter II.

With a view toward providing a better understanding of the nature and significance of economic diversity, this study has the following as its specific goals:

1. To provide an economic overview and a comparative perspective by examining the economic trends of both oregon and the nation as a whole during the 1970's.

2. To calculate diversity indices based upon employment data for oregon's twenty-nine counties and three multi-county areas for a 
ten-year perioả from 1972 through 1981. For

the same period, the entropy measures of diversity are also calculated for the United States $(50$ states and the District of Columbia). In the U.S. study, the states are considered as the regional units, and the relative position of oregon in the U.S. is determined; in the oregon study, counties are considered as the regional units, and the relative position of the tri-county area is analyzed.

3. To determine the extent to which diversity indices vary within the regional units and to analyze the reasons for the above variations.

4. To disaggregate entropy into its within-set and between-set aspects so that various patterns of interindustry diversification within a region over time may be examined.

5. To study the association of economic diversity with economic performance of the various regional units (counties and states). This is the main objective of the current study; the hypotheses associated with this objective are formulated on pages 12-13. 
6. To study the effect of the recession on the strength of the relationship between the level of economic diversity and unemployment and/or per capita income.

\section{HYPOTHESES}

The major aim of this study is to gain a better understanding of the significance for oregon of economic diversity, more specifically to determine whether diversity is statistically correlated with improved economic performance.

Economic performance will be assessed in terms of two economic variables, namely unemployment and per capita income, considered in four different ways: the level of the variable, its rate of change over time, the degree of instability of the variable, and the degree of instability of the rate of change. There are thus eight hypotheses to be tested:

1. There is a negative correlation between the level of economic diversity and the level of unemployment.

2. There is a positive correlation between the level of economic diversity and the level of per capita income. 
3. There is a negative correlation between the level of economic diversity and the rate of growth of unemployment.

4. There is a positive correlation between the level of economic diversity and the rate of growth of per capita income.

5. There is a negative correlation between the level of economic diversity and instability (cyclical fluctuations) of the level of unemployment.

6. There is a negative correlation between the level of economic diversity and instability (cyclical fluctuations) of the level of per capita income.

7. There is a negative correlation between the level of economic diversity and the instability of the rate of growth of unemployment.

8. There is a negative correlation between the level of economic diversity and the instability of the rate of growth of per capita income.

The above hypotheses will be tested with data from the counties of oregon for the ten-year study period. To provide a comparative perspective for the oregon study, a U.S. study has also been conducted, but this study is only 
preliminary; definitive results on the national ievel need further investigation. Such an examination may offer both a conceptual and an historical perspective for decisionmakers responsible for formulating strategies and policies for economic recovery.

\section{ORGANIZATION OF THE STUDY}

Chapter II presents a review of the literature and a derivation of the theoretical and operational definitions of economic diversity. The chapter begins with a general definition of economic diversity, followed by a review of various measures that have been developed over the past fifty years to measure it. The chapter concludes with a review of the literature available on the role of diversification in regional economic performance.

Chapter III presents the method of research employed in this study. Included in this chapter are the nature and sources of the raw data, a derivation of the entropy measure of diversity, the manipulation and analysis of the data, and the statistical treatment of the data.

Chapter IV provides a brief economic overview and a comparative perspective by examining the economic trends of both oregon and the nation as a whole during the 1970's. Chapters V and VI present the results of the Oregon and U.S. studies, respectively. Statistical results are 
presented in tabular and graphical form, and the numerical data are analyzed. Further details may be found in the appendices.

Chapter VII presents conclusions, discusses the limitations of this study, and suggests some directions for further research. 
CHAPTER II

REVIEW OF LITERAIURE

In the academic literature, the subject of diversification has been hindered by the problem of defining regional diversity in a theoretically meaningful way and then of measuring and expressing relative diversity quantitatively. Diversity has been defined as "the presence in an area of a great number of different types of industries" (Rodgers, 1957: 16), or as "the extent to which the economic activity of a region is distributed among a number of categories" (Parr, 1965: 22).

\section{MEASUREMENT OF DIVERSITY}

The earliest diversity measurement was attempted by Mclaughlin in 1930. He tested the strength of relationship between the degree of industrial concentration in a given city and the severity of the cyclical, as well as the seasonal, economic fluctuations which that city experienced. Using the Federal Biennial Census of Manufacturers' Data, he computed concentration ratios for 14 U.S. cities based on the percentage of total value added by manufacture for each city derived from both the first five and the first twenty largest manufacturing industries in each area. He divided 
the value added by manufacture in the leading twenty industries in each city into two groups: consumers' goods and producers' goods. Then "the percentage of prociucers' goods in each of the cities for 1919 was paired with the corresponding cyclical decrease in value added from 1919 to 1921 adjusted for trend" (McLaughlin, 1930: 149). The two series were tested for correlation with a resulting significant coefficient of linear correlation of .88 . Similarly, the percentages in producers' goods in 1921 produced a coefficient of linear correlation of .93. He also found a significant association between concentration and severity of seasonal variation, the latter being measured on the basis of month-to-month variations in manufacturing employment.

Since then, economists and regional scientists have developed other ways of measuring diversity: the ogive approach, the national average approach, the portfoliotheoretic approach, and the information-theoretic (entropy) approach

\section{The Ogive Approach}

A common measure of diversity is the ogive index, which represents the deviation from equal distribution of employment in all industrial sectors (Tress, 1938; Rodgers, 1957; Conkling, 1963; Shear, 1965; Gratton, 1979; Bahl, et al) 1971). 
Consider a set of $n$ industrial classes, and let $P$ ( $i$ $i$ $=1,2,3, \ldots$. n) denote the percent of employment in the ith industry class. Then the concentration index, (C), is computed by

$$
C\left(P_{1}, P_{2}, \cdots \cdot P_{n}\right)=n \sum_{i=1}^{n}\left(P_{i}-1 / n\right)^{2}
$$

The minimum value of $C$ is attained when employment is equally distributed among industries.

Tress constructed an index of diversity of this type for England and Wales based on 1931 employment in 12 industrial classes (basically, one-digit SIC), thus expecting $1 / 12=8.38$ employment for each industry in each city for perfectly balanced or greatest possible diversity. Rodgers effectively used an identical technique to calculate the diversity indices of 93 standard metropolitan areas of the U.S., based on 1950 employment percentages of 22 manufacturing groups. His method was essentially a modification of the measure developed by Tress. The approach is identical in that

\footnotetext{
- - the distribution of manufacturing employment by manufacturing groups for individual areas is compared with the average distribution for all of the industrial areas studied, with the latter considered a norm or reference level. (Rodgers, 1957: 19).
}

Turning to another aspect of the problem of 
diversification, Rodgers tried to measure the effects of diversification on the economic health of an area. The monthly employment data of 82 industrial areas of the U.S. for the period 1949-1954 were treated with the method of moving average, which eliminates seasonal and irregular fluctuations. The average deviations of the sasscral indices were then correlated with the diversity indices of the 82 industrial areas with a resulting coefficient of linear correlation of $.243\left(\mathrm{r}^{2}=.0593\right)$. This indicates that there was only a very weak statistical relationship between diversification and seasonal variation in industrial employment.

With regard to cyclical employment variation, Rodgers first calculated the standard deviation of employment of 12 highly varied industrial areas from 1926 to 1950. The above data were correlated with corresponding indices of diversity, and the resulting correlations were equally weak $(r=.223, r=.0545)$. Correlation of the 1940 diversity indices of the 76 industrial areas with their overall percentage change in employment for the 28-year period (1919-1947) were still weaker $\left(r=.0574, r^{2}=.0033\right)$. Several years later, Conkling (1963) calculated the diversity indices on three area levels: national (the island of Great Britain), regional (South Wales and Monmouthshire), local (52 employment exchange areas) for the 
years 1931, 1951, and for each year from 1949 through 1959. He then studied the factors associated with changes in employment diversity in South Wales, Great Britain.

He founò a correlation coefficient of $(r=0.666, r$ $=.444$ ) between the 1959 diversity indices of the 52 employment exchange areas and the proportion of work force in each engaged in mining and quarrying. This indicates that diversity varied inversely with the relative size of the mining proportion.

Between the 1959 unemployment rates of the 52 employment exchange areas and their diversity indices, he obtained an $r^{2}$ of only 0.026, indicating that "there is virtually no statistical relationship between the two, apparently contradicting the widely-held view on this subject" (Conkling, 1963: 270).

Other factors correlated with indices of diversity are 2 percentage of women workers $(r=.31)$, size of the labor force $\left(r_{2}^{2}=0.253\right)$, percentage of employment in the service trades $(r=0.309)$, and percentage of workers in light manufacturing $\left(r^{2}=0.311\right)$. He concluded that

The results of the atove correlations, together with others not reported here, may be said to confirm generally-held beliefs, though with one important exception, namely the relationship between diversification and the employment rate. (Conkling, 1963: 270) 
The National Average Approach

This class of measures has used the U.S. national average employment or value-added figures in each industry as the benchmark for the measurement of employment diversity (Florence, 1943; Steigenga, 1955; Borts, 1961; Bahl et al, 1971) .

Consider a set of $\mathrm{n}$ industrial classes, and let $\mathrm{P}_{i}=$ the proportion of total employment in the ith industry class; $\mathrm{M}_{i}$ = national average employment in the ith industry, and $\alpha=$ the power to which deviations will be raised $(\alpha=1$, for Florence, $\alpha=2$ for Steigenga and Borts). Then the concentration index (C) is computed by

$$
C\left(P_{1}, P_{2}, \cdots P_{n}\right)=\sum_{i=1}^{n} \frac{\left(P_{i}-M_{i}\right)^{\alpha}}{M_{i}}
$$

Sargent Florence (1943) calculated the diversity indices of each state comparing the percentage distribution of employment in all economic activity on a state level with the equivalent percentage for the nation.

Borts (1961) also used the national percentage distribution of employment among industries as a norm. As noted by Conroy (1975a: 71), Borts studied the relationship between relative state employment fluctuations for three periods of business contraction and expansion during 19191953 and the respective industrial structure of 33 states. 
To standardize the state pattern, he calculated for each state the cycle the nation would have had over those periods if it had had the state's industrial composition. He then compared those cycles based on individual state industrial composition with those known for the nation. He concluded that the most variable states, e.g., the states whose industrial composition would have given the nation the greatest fluctuations, were those characterized by a high proportion of durable goods manufacture, specialty transportation equipment, primary and fabricated metal products, machinery and lumber. The least variable states are characterized by a high proportion of nondurable goods manufacture (textiles, shoes, apparel, tobacco, and food products).

Steigenga (1955) calculated the standard deviation of percentage distribution of employment across 25 employment classes for 53 towns in The Netherlands. A standard deviation was computed for each area as an indicator of diversity; a high standard deviation indicated a serious lack of diversity, and a low standard deviation indicated a high level of diversity.

In this method, perfect diversification consisted of just duplicating the national average. It may well be, however, that by some criterion, a given area has a better industrial mix than the nation as a whole. In this case, 
movement toward duplicating the national proportion may worsen the area's stability or rate of growth. The national average measure suffers from an additional difficulty. Because the norm (national average) is not fixed, this measure will not distinguish whether the industrial distribution within the region itself has become more or less diversified over time.

The Portfolio-Theoretic Approach

In the recent past, portfolio theory has played an important role in the area of financial asset selection (Markowitz, 1952, 1959; Tobin, 1958; Sharpe, 1970). The concept of diversified investment portfolios was first introduced by Markowitz $(1952,1959)$ to the process of stock selection for investors. His aim was to provide maximum return with minimum variance of return. Based largely on this concept, a new method of measuring industrial diversity, namely the portfolio-theoretic approach, emerged (Conroy, 1972, 1975; Barth et al, 1975; St. Louis, 1980; El-Himus, 1982). Michael E Conroy was the first to employ this technique to examine the effect of industrial diversification on the stability of a region's employment (Conroy, 1974, 1975). In Conroy's view, 
If each industry in an economy may be characterized as an individual community investment, then the set of industries which any given economy has acquired at a point in time may be considered a 'portfolio' of community investments among which some or all of the region's economic factor resources are distributed (Conroy, 1975c: 495)

Financial analysis refers to such sets of financial assets as an individual's "portfolio of securities." Conroy refers to the industry structure of a region as a community "industrial portfolio."

Following Conroy, every region expects a stream of returns in the form of employment, income, or a weighted subset of these from investment of factor resources to individual industries. Those expected returns are considered essentially stochastic whose variance may serve as a measure of the fluctuations or "risk." An aggregate measure of risk that may be associated with the industrial structure of a region is called "portfolio variance" and is defined, in terms of the present notation, as:

$$
\sigma_{p}^{2}\left(P_{1}, P_{2}, \cdots, P_{n}\right)=\sum_{i=1}^{n} \sum_{j=1}^{n} P_{i} P_{j} \sigma_{i j}
$$

where small p as subscript means "portfolio" and where capital $\mathrm{P}_{i}$ and $\mathrm{P}_{j}$ are the percent of regional resources (employment, income, or outputs) allocated to industries $i$ and $j$ and where $\sigma_{j j}$ denotes the covariance of these resources (employment, income, etc) over time for the ith 
and $j$ th industries.

Conroy (1975c) utilized portfolio variance as a measure of regional industrial diversity to investigate the relationship between fluctuations in economic activity and diversity of the industrial structure of 52 U.S. Standard Metropolitan Statistical Areas (SMSA's) over the period 1958 through 1967. He first calculated the industrial portfolio variances $\left(\sigma_{p}{ }^{2}\right)$ for each SMSA using 120-month national employment time series data across 118 three-digit standard Industrial Classification (SIC) manufacturing industries. Then, for each region,

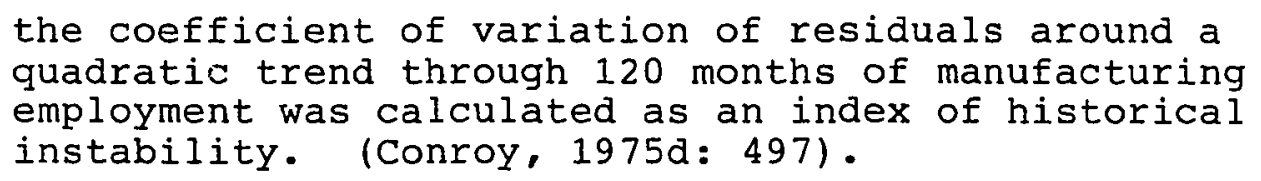

Correlation of the square root of portfolio variance (a measure of relative diversity) with indices of historical instability produced a correlation coefficient of $(r$ $=.6580, r=.422)$. This indicates that the proportion of the variation in observed instability which is explained by the diversity of industrial structure as measured by the portfolio variance is 42.28 . He also correlated the indices of diversity of the 52 regions with other structural characteristics of the regional sample (population, manufacturing employment, employment growth rate). Observing the statistics, he found that 


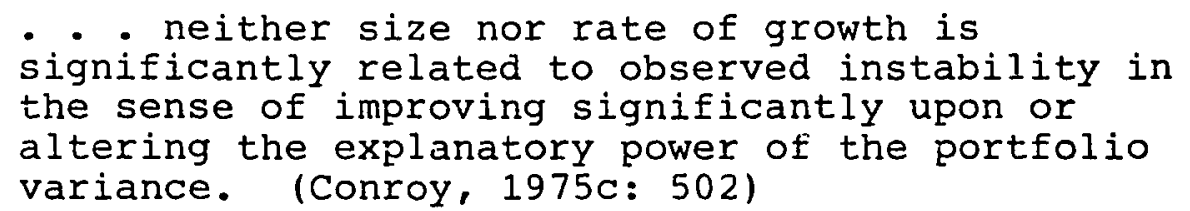

variance. (Conroy, 1975c: 502)

\begin{abstract}
In using $\sigma_{p}^{2}$ (the portfolio variance) as an index of diversity, Conroy argues that the smaller the variance, the more stable the region.

Barth et al (1975) applied the portfolio theoretic technique to investigate the relationship between the industrial mix and employment stability of Virginia during the years 1951-71. Nine industries were selected for Barth's research: contract construction, finance, insurance, and real estate, government, durable goods, mining, nondurable goods, transportation, services, and wholesale and retail trade.
\end{abstract}

The $P$ and $P$ for his study are the percentage of total labor resources employed in industries $i$ and $j$, and $\sigma_{i j}$ denotes the covariance of return (employment) among industries. Using the portfolio variance formula suggested by Conroy, Barth finds that "the estimate of employment risk has decreased from 7.38 in 1952 to 7.08 in 1971 , a 4.18 reduction in risk" (Barth et al, 1975: 13). Unlike Conroy's study, Barth's did not state what degree of fluctuation in employment is affected by diversity indices. However, he examined the impact on employment risk of changing the industrial $\mathrm{mix}$ in the region. The process 
of selecting new sectors or expansion of existing ones so as to minimize risk involves selecting those which reduce or lead to the smallest addition in total variance. For example, from the variance-covariance matrix of employment in nine sectors, Barth concluded that the addition of the service sector to the industrial mix of a region would be desirable because the service sector has a relatively small variance and the sum of the covariances of its employment with those of the existing industries is small. In contrast, expansion of the durable goods industry would add substantially to total risk because of its large variance and large positive covariance with each of the existing industries.

The latest study of this nature was El-Himus' in 1981. The method used in this study is essentially a modification of the measure developed by Conroy. El-Himus replaced the statistic $\sigma$, the covariance of return between the ith and jth industry by $r$, the coefficient of correlation, arguing that the size of covariance is a function of the measurement and "when it is used to calculate portfolio variance, it tends to bias the results in favor of large regions. Bigger regions will have a greater portfolio variance" (ElHimus, 1982: 25).

Based on this new measure of diversification, LID (Level of Industrial Dependence), El-Himus calculated the 
diversity index of the oregon counties in 1980. The diversity indices were then correlated with unemployment rates with a resulting coefficient of linear correlation of $-.528\left(r^{2}=.279\right)$. In addition, the LID index was calculated in a longitudinal study of two specially-selected counties, Morrow and Harney, for a six-year period from 1975 to 1980 . The above two counties were selected because they were two extreme cases. While Morrow enjoyed a low rate of unemployment during the study period and maintained a diversified economy, Harney claimed the highest rate of unemployment in Oregon due to heavy dependence on the timber industry. The unemployment rates of the two counties were then correlated with corresponding indices of diversity for the six-year study period, and the resulting coefficients of Iinear correlation were found to be $-.319(r=.101)$ for Morrow and $+.149\left(r^{2}=.022\right)$ for Harney. However, the relationships proved to be statistically insignificant at the .058 level of significance for both cases. El-Himus admitted that "unfortunately, we were not as successful in our longitudinal study where we measured IID over a six year period" (El-Himus, 1982: 38). Based on these findings, he ultimately concluded that "although there is a definite relationship between economic diversification and unemployment, it is not, however, as strong as previously Claimed" (El-Himus, 1982: 54). 


\section{The Information-Theoretic (Entropy) Approach}

Entropy as a measure of disorder, uncertainty, or homogeneity has been used to analyze many different phenomena. In the physical sciences, it has been used to measure the irreversible increase of "unavailable energy." In the biological and behavioral sciences, entropy has been used as a measure of organization. In communication theory, it quantifies the degree of uncertainty in a system (Shannon and Weaver, 1949). Taking the Shannon entropy as a measure of diversity yields

$$
D\left(P_{1}, P_{2}, \cdot \cdot P_{n}\right)=-\sum_{i=1}^{n} P_{i} \log _{2} P_{i}
$$

In the context of communication theory, where this measure gives the uncertainty $\mathrm{H}, \mathrm{P}_{i}$ is the probability of some event $i$. As a measure of diversity, the $P$ represents the proportion of some total quantity. For example, let $\mathrm{K}$ denote some quantity such as total employment, total output, foreign trade, or income, and $\mathrm{K}$ the amount contributed to this total by the ith entity, such as an industry in a region, a county, or a product traded. The value shares are $P_{i}=\frac{K_{i}}{K}$, and the entropy measure gives the diversity or spread of the distribution (Horowitz and Horowitz, 1976). As with the ogive index, the maximum value of $D$ is attained $\left(\log _{2} n\right)$ when all $P_{i}$ are equal. If the ith entity is the 
only contributor to $\mathrm{K}$, then $\mathrm{P}_{i}=1$, all other $\mathrm{P}_{i}=0$ and $\mathrm{D}=$ 0 .

The entropy measure has been invoked in empirical studies in economics as well as in business areas such as management, marketing, finance, and accounting. In a marketing context, entropy can represent the distribution of consumer preference for various brands (Hermiter, 1972, 1973). Hermiter uses entropy as a measure of uncertainty or disorder in the stochastic system that represents the consumer's preferences for special brands.

In the analysis of empirical data, entropy has also been used as a measure of dispersion, an alternative to the variance $\sigma$ (a measure of risk or uncertainty). For example, the use of entropy rather than variance as a measure of the risk of a securities portfolio whose components yield stochastic returns has been advocated by Philippatos and Wilson $(1972,1974)$ and Jacquemin and Berry (1979). Philippatos and Wilson suggest that entropy

can be computed for both metric and nonmetric data, including such attributes of securities as industry, name of company, exchange in which traded, and other classifications, in addition to the quantitative profile of security. (1972: 215)

They concluded that since entropy can be estimated directly from variances (when the form of prior distribution is known) and can be computed from nonmetric data, entropy is 
more general and better suited for the selection of portfolio than variance.

In the analysis of accounting data, entropy has been used to measure the loss of information from aggregation of items on financial statements, e.g., the balance sheet (Theil, 1969; Lev, 1968, 1970).

An extensive treatment of entropy-based measures in the analysis of economic data has been given by Theil, who discusses in detail the basic technical informational concepts and illustrates them with economic examples. Theil's books $(1967,1972)$ are primarily concerned with distributional issues and with decomposition analysis. In particular, he has argued that information concepts provide an appropriate measure which can be utilized in empirical studies in economics to answer such questions as: How is income distributed among the families of a nation or among the states of a nation? How are sales, total outputs or employment distributed among industries within a region and among regions? How is international trade distributed among countries?

He also showed that entropy techniques are useful, not only in providing an overall index of dispersal of economic activities over time, but also through their decomposition properties, in analyzing the nature of such a dispersal. In market structure analysis, entropy has often been 
employed as a measure of "competitiveness" of an industry (Horowitz and Horowitz, 1968). Here P represents the market shares of firms in the industry. As such, entropy varies inversely with the degree of industrial concentration. Using this measure, the Horowitz's analyzed the concentration in the brewing industry between 1944 and 1964.

Using the decomposition property of entropy, some market structure researchers were able to analyze concentration, either within or between regions, or within brands of an individual company, and between companies (Bernhardt and Mackenzie, 1968; Horowitz and Horowitz, 1970; Thiel, 1967). For example, the Horowitz's studied the industrial concentration in 21 two-digit manufacturing industries in the common market nations (Horowitz, 1970).

Along similar lines, Pulson and Garrison (1973) used entropy and a related measure to test the hypothesis that "labor-intensive" industries are less concentrated geographically than other types of industries. The results of the study supported the hypothesis.

Entropy measures of geographical concentration have also been used to examine the extent to which rural and small-town counties compete with urban areas for manufacturing employment in the Tennessee Valley region (Garrison, 1974). Here $P_{i}$ represents the relative ability 
of the ith county to attract manufacturing industries. Decomposition of entropy into its between-set and within-set components also has enabled Garrison to compare the low wage and high wage industries of the region as to the nature of their geographical dispersal over time.

He concluded that

the disaggregation of entropy indicates an increase in the strength of both the rural and small-town groups in attracting low-wage industries. But for higher wage industries, the analysis indicates very little increase in the strength of rural counties; the increase in competitiveness in the region in attracting these industries is due largely to the strength of the small-town and small-city counties.

(Garrison, 1974; 56)

Entropy has also been used to measure employment diversity (Hackbart and Anderson, 1975). Within this context, the $\mathrm{P}$ represents the ith sector share of regional employment. Entropy measures the diversity of a region as compared to a uniform distribution of employment among all sectors of the economy. Hackbard and Anderson illustrated the applicability of the entropy method by examining four river basin regions in Wyoming. They concluded that the entropy method "provides a direct means of comparing diversity in different regions or changes in diversity over time" (p. 378). However, they did not examine how their measure of diversity is associated with other economic factors such as employment, income, or other measures of the 
economic health of an area.

The entropy measure is a more flexible and analytically-powerful measure of economic diversity than the national average measure. The rectangular distribution (uniform distribution) of economic activities used as a comparative norm with the entropy measure is more objective and conceptually consistent with the intuitive notion of diversification as the absence of concentration.

The national average measure assesses the deviation of the regional distribution of economic activity from the national distribution. The use of a national pattern as a base is questionable, however, because it would require that the region deny itself its own comparative advantage. Also, since the norm (national distribution) changes over time, this measure does not determine whether the distribution of economic activity within a region itself has become more or less diversified over time. Because the uniform distribution is a comparative norm which is fixed, the entropy measure will accomplish the above objectives. The ogive and entropy measures are conceptually similar in that both approaches compare actual distribution of employment to a hypothetical uniform distribution representing "balanced" industrial composition (equal percentage in each group). However, the entropy measure is more flexible than the ogive in that the entropy measure can 
be decomposed so that the various patterns of interindustry diversification within a region over time may be examined. These patterns and changes might not be at all apparent merely from an examination of the single-unit total diversity index of diversification. As discussed earlier in this chapter, the decomposition property has permitted some useful extensions of regional analysis and market structure analysis by enabling researchers to analyze concentration and structural changes both within and between regions. Chapter $V$ illustrates the manner in which the entropy measure can be decomposed to express the extent and patterns of diversification between and within manufacturing and nonmanufacturing sectors for the counties of Oregon.

DETERMINANTS OF RELATIVE REGIONAL INCOME LEVELS

One major objective of this study is to test the strength of relations between diversity and per capita income. Before empirically testing the relationship, a study of the determinants of relative regional income levels is in order.

Empirical analyses of regional income differentials are far less abundant than analyses of regional employment characteristics. One reason might be that comparable data on income are much less readily available than employment data. 
During the past thirty years, economists have suggested several factors which might be associated with variation in the level of income of different regions (Duncan and Reiss, 1956; Kuznets, 1958; Perloff et al, 1960; Borts and Stein, 1964; Matilla and Thompson, 1968; Conroy, 1975). These factors range from social characteristics of a population (demographic and education) to the economic structure (industrial composition) of a region.

Empirical analyses of income differentials using states or urban areas as the unit of study have been made by a number of researchers since 1950. These analyses specifically addressed the following two questions:

1. To what extent are current levels of income related to social characteristics of the local population?

2. To what extent are current levels of income associated with industrial structure of the region?

Income Levels and Social Characteristics of population

Duncan and Reiss (1956) analyzed the social characteristics of all urban areas of the nation with a population of 10,000 or more in the nation as of 1950. They found that the higher-income urban areas tended to have a notably larger proportion of their population in the age bracket of twenty-one or older. Lower income areas may have 
had higher levels of fertility and, therefore, a younger population. Also, a larger proportion of nonwhites were found in the low-income areas.

Matilla and Thompson (1968) conducted an econometric analysis of income levels across 135 SMSA's for 1960. They concluded that the level of family income in the SMSA's is most closely associated with the educational level of the residents.

Income Levels and Industrial structure

Empirical analysis of regional income differentials suggests that a high level of income is related to higher manufacturing employment and lower agricultural employment. Simon Kuznets (1958) was probably the first to test such relationships. He classified the states into six groups based on per capita income levels for the years 1920, 1930, 1940, and 1950. He then divided the industrial structure of states into manufacturing and agriculture. He found that those states with large proportions of employment in agriculture generally were poorer than nonagricultural states. However, the relationship between manufacturing and income was clearly positive. He then divided the manufacturing sector into raw material industries (food, tobacco, lumber, textiles, etc) and fabricating industries (machinery, miscellaneous manufacturing). He found that those states with the lowest per capita income levels 
Erequently had the highest proportions of raw material industries and the lowest proportions of fabricating industries.

Along similar lines, Perloff et al (1960) calculated the rank correlation between state income and proportion of employment in economic sectors. They found positive correlations between income and proportion in manufacturing $(r=.33)$ and service $(r=.57)$, and negative correlations with resource-processing industries $(r=-.60)$ and agriculture $(r=-.65)$.

Mattila and Thompson (1968) also offer empirical evidence on this relationship. Their econometric model found several factors which were significantly associated with the level of family income, among them, the percent of labor force in manufacturing, the percent of labor force in durable goods, and the ratio of capital to labor.

The relationship between the industrial structure of an area and the relative income fluctuations it tended to encounter was noted by Thompson (1956). In his words

\footnotetext{
- . nothing could seem more certain, deductively, than a close causal relationship between the local industry mix and the cyclical instability of that area . - (Thompson, 1956: 16)
}

Michael Conroy suggests that 
Employment in a high-wage industry will not generate high levels of annual income if that employment is erratic. A lower wage paid in an industry with steady employment may generate higher income. For any particular wage level, the more stable the employment (i.e., the industry) over the year, the higher the income level will be. (Conroy, 1975a: 65)

Clark (1934) suggested that producer and durable goods industries are more cyclically volatile than nondurable and consumer goods industries because the expenditures for durables are far more sensitive to changes in income than expenditures for nondurable goods. Regions with a high fraction of employment in, for example, higher paying durable manufacturing industries are anticipated to generate a high level of income. But precisely because of the dominance of durable goods production, they will also be expected to exhibit a high degree of cyclical instability. On the other hand, regions which are highly specialized in stable areas such as public administration and education might be expected to exhibit stability in both employment and income.

\section{SUMMARY}

In the current study, Shannon's entropy function is used as a measure of economic diversity. This measure provides a precise definition of economic diversity and, not only a direct means of comparing changes in diversity over time, but also, through its decomposition properties, of 
evaluating the nature of such a change.

Chapter III, following, discusses further the entropy

formula as an overall index of diversity and shows how this

measure can be disaggregated into its between-set and

within-set aspects to express the extent and pattern of

diversity between and within groups of regional units. 
CHAPTER III

\section{RESEARCH METHODOLOGY}

\section{SOURCE OF DATA}

The raw data compiled and analyzed in this research report are of two types: Oregon data and U.S data. For the Oregon study, the employment data for nonagricultural economic sectors were obtained from the oregon Resident Labor Force, Unemployment and Employment, a statistical report prepared by the Research and Statistics Section of the Oregon Employment Division. It is a monthly report which provides data on annual average and monthly data on nonfarm wage and salary employment for major industries. Agricultural employment data were obtained from the State of Oregon Agricultural Employment report, a monthly statistical report provided by the Employment Division of the State of Oregon. Data are reported for workers aged 16 and over. Monthly figures are estimates only and are not taken from an actual head count. Data pertaining to per capita income and percent unemployment were obtained from Oregon County Economic Indicators, a compilation of the most commonly requested data for oregon counties, prepared annually by the Information and Research Division of the 
Economic Development Department. The sources of the data are the U.S. Department of Commerce, Bureau of Economic Analysis, and Oregon Employment Division, respectively. In addition, the following secondary sources have been utilized:

1. Annual Planning Information (API), published by the Employment Division, which provides labor market and related economic information for the state of Oregon and selected prime sponsor areas;

2. Oregon Labor Trends, a monthly letter analyzing Oregon's economic and labor force developments;

3. Annual Economic Report, which provides a summary of significant labor force and related economic trends for labor areas.

National annual employment data for each of the eight economic sectors used in the calculation of diversity index for the U.S. study were taken from the Bureau of Labor Statistics (BLS) series, Employment and Earnings, States and Areas, 1939-78, Bulletin 1370-13, and the supplement to Employment and Earnings, States and Areas, 1977-81, Bulletin $1370-16$. 
National data on per capita income were taken from the Statistical Abstracts of the United States, a national data book and guide to sources published annually by the U.S. Department of Commerce, Bureau of the Census.

The following secondary sources were also used:

1. U.S. Bureau of Economic Analysis, Survey of Current Business

2. U.S. Department of Labor, Bureau of Irabor Statistics, Geographic Profile of Employment and Unemployment, 1979

3. U.S. Department of Labor, Bureau of Labor Statistics, Handbook of Labor Statistics

MEASURES OF DIVERSITY AND DEPENDENT VARIABLES

In the present study, Shannon's entropy function is used as a measure of economic diversity. The entropy method measures diversity of a region against a uniform distribution of employment where the norm is equiproportional employment in all economic sectors. As it is applied to the Oregon estimate of employment data, the entropy measure of economic diversity $D(E, E$, - . E ) is defined as follows:

(1) $D\left(E_{1}, E_{2}, \ldots . E_{n}\right)=-\sum_{i=1}^{n} E_{i} \log _{2} E_{i}$ 
where $n=$ the number of economic sectors, and

$E_{i}=$ the proportion of total employment of the region

The most important properties of the above measure are:

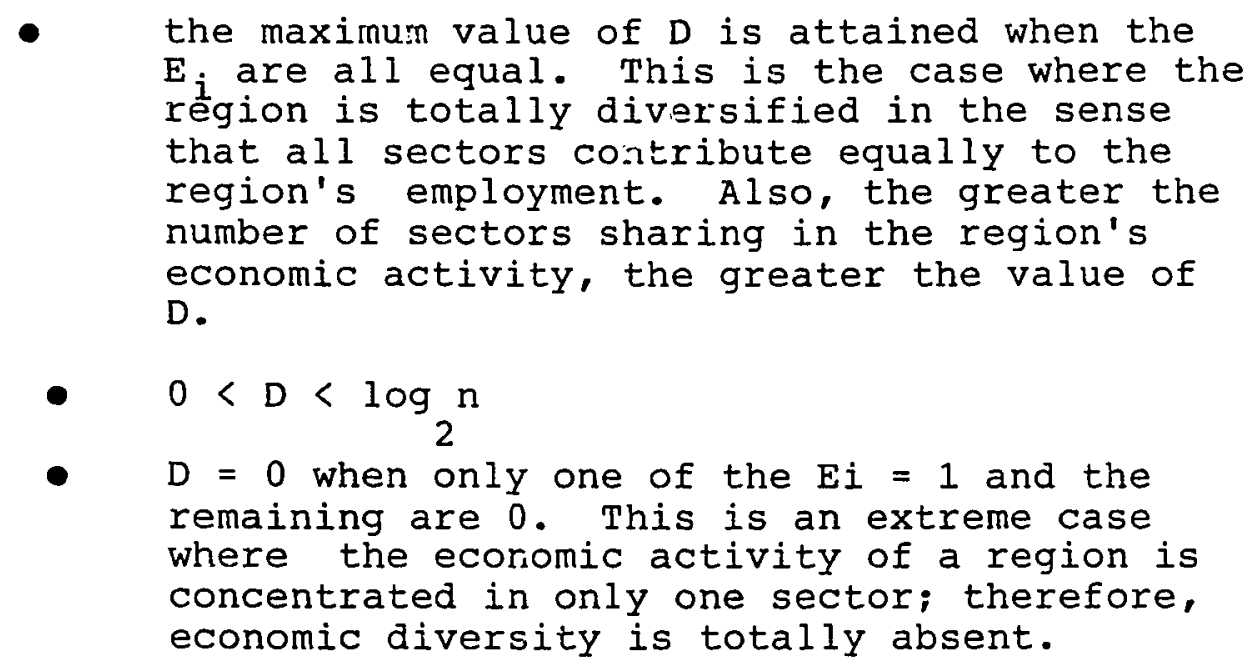

It is important to note that while two regional units having maximal diversity are identical in employment distribution (identical for purposes of this study), two regional units with minimal diversity could be quite different, depending upon the particular sector of specialization (see discussion, Chapter VI).

Using the entropy formula, diversity indices based upon employment data were calculated for Oregon's twentynine counties and three multi-county areas for a ten-year period from 1972 through 1981. Oregon's multi-county labor force areas are: the Portland SMSA (which includes Clackamas, Multnomah, and Washington counties, plus Clark 
County, Washington), the Salem SMSA (which includes Marion and Polk counties), the Eugene SMSA (which includes the Eugene and Springfield areas), and the two-county wascoSherman labor market area.

Calculation of the entropy measure for oregon counties is based on employment data from 9 sectors. These sectors are: (1) agriculture; (2) durable goods; (3) nondurable goods; (4) construction; (5) transportation, communication, and utilities; (6) trade; (7) finance, insurance, and real estate; (8) service and miscellaneous; and (9) government. The value, E, which measures the ith sector's relative share of employment for a given county, is calculated from Oregon Resident Labor Force data provided by the state of Oregon, Employment Division, Department of Human Resources. Since there are nine sectors, the maximum value of

$$
D\left(E_{1}, E_{2}, \cdot E_{9}\right)=\log _{2} 9=3.1699
$$

The diversification values would then range from 0 to 3.1699 , with a diversification value of 3.1699 denoting the greatest diversification among the 9 sectors of a county. For the national study, the diversification indices based on employment data were calculated for the 50 states and the District of Columbia for the same period (19721981). Calculation of the entropy measure is based on 
employment data from 8 nonagricultural sectors--the same sectors that were used for the oregon study.

The value $E$, which measures the ith sector's relative share of employment for a given state, is calculated from the BLS series, Employment and Earnings, States and Areas for a ten-year period from 1972 to 1981 . Since there are 8 sectors, the maximum value of

$$
\mathrm{D}\left(\mathrm{E}_{1}, \mathrm{E}_{2}, \cdots \cdot \mathrm{E}_{8}\right)=\log _{2} 8=3
$$

and observed values may be directly interpreted in this scale. The diversification values would then range from 0 to 3 , with a diversification value of 3 denoting the greatest diversification among the eight sectors of a state. The entropy technique is useful, not only in providing an overall index of economic diversity over time, but also through its decomposition properties in analyzing the nature of such a diversity (Thiel, 1967). The entropy measura as it is formulated in Equation 1 can be disaggregated into its between-set and within-set aspects to express the extent and pattern of dispersal between and within different groups or subsets of industries. Consider, for example, that industries (sectors) are combined into G sets. The employment share of set $\mathrm{S}$ is then 


$$
E_{g}=\sum_{i \in S_{g}} E_{i} \quad g=1, \cdot \cdot \cdot G
$$

The entropy index of diversity within each of the G sets can be measured by:

$$
D_{\text {within }} S_{g}=-\sum_{i \in S_{g}} \frac{E_{i}}{E_{g}} \log _{2} \frac{E_{i}}{E_{g}}
$$

The within-set measure merely represents the application of the entropy measure to different groups of industries treated independently. Representing each set's relative share of the total state employment by $\frac{E_{g}}{E_{S}}$, where $E_{S}$ is total state employment, the entropy measure of diversification between the $G$ sets may then be expressed as:

(3) $D_{\text {between }}=-\sum_{g=1}^{G} \frac{E_{g}}{E_{s}} \log _{2} \frac{E_{g}}{E_{s}}$

The between-set measure identifies the extent to which employment is distributed equally between the $G$ sets. The relative importance of each of the $G$ sets determines the contribution of its diversification to the degree of industry diversification within the total economy. Weighting 
the result of Equation 2 by the relative share of each set yields:

(4) $D_{\text {within }}=\sum_{g=1}^{G} \frac{E_{g}}{E_{S}} \quad\left(-\sum_{i \varepsilon S} \frac{E_{i}}{E_{g}} \log _{2} \frac{E_{i}}{E_{g}}\right)$

which is the total measure or summation of diversity within the $G$ sets.

The entropy measure of economic diversity for the entire economy can be obtained by summing Equations 3 and 4:

(5) $D=-\underset{g=1}{G} \frac{E_{g}}{E_{S}} \log _{2} \frac{E_{g}}{E_{S}}+\underset{g=1}{G} \frac{E_{g}}{E_{S}}\left(-\sum_{i \varepsilon S} \frac{E_{i}}{E_{g}} \log _{2} \frac{E_{i}}{E_{g}}\right)$

This disaggregation of entropy into its between-set and within-set aspects, where $G=2$ (manufacturing and nonmanufacturing) is carried out for the state of oregon, and its results are presented in Chapter $v$.

In the studies about to be discussed, the following dependent variables are considered for particular regional units and years:

1. Unemployment levels, expressed as percent of work force. Also used are unemployment levels for each regional unit, averaged over the ten-year period of study. 
2. Logarithm of per capita income in constant dollars for particular regional units and years. Data which measure the per capita income in constant dollars have been calculated by dividing the per capita income in current dollars by the Consumer Price Index (CPI). This index is often used as a cost of living index. It indicates what changes are taking place in the purchasing power of: dollars spent. To construct the CPI, the Bureau of Labor Statistics periodically surveys a large sample of families to determine what goods and services ("market basket") consumers actually buy. The CPI used in this study is expressed in terms of what the market basket cost in 1967. The Bureau of Labor Statistics is changing the base year to 1977. A new CPI series will be published in 1984. A logarithm of real per capita income was taken because, were the logarithm of per capita income to be plotted against time, a comparison of the slopes would immediately show the period in which the rate of growth would be greater. Real per capita income figures are also used for each regional unit: averaged over the ten-year study period.

3. Unemployment growth rate, measured by the slope of unemployment trend line. Using the least-squares method, the trend unit (i.e., estimated unemployment, expressed as a function of time), was derived for each regional unit over the ten-year study period. The slopes of these trend 
lines were then used as a measure of unemployment growth rates.

4. Per capita income growth rates, measured by the slope of per capita income trend lines. The slopes of these trend lines were calculated following the same procedure that was used for unemployment growth rates.

5. Unemployment instability, measured by the standard deviation of the unemployment level for each regional unit over the ten-year study period.

6. Per capita income instability, measured by the standard deviation of the real per capita income level for each regional unit over the ten-year study period.

7. Instability of (yearly) changes in unemployment, measured by the standard deviation of annual changes in unemployment for each regional unit over the ten-year study period.

8. Instability of (yearly) changes in per capita income, measured by the standard deviation of annual changes in per capita income for each regional unit over the tenyear study period.

\section{STATISTICAL TREATMENT OF THE DATA}

To investigate the effect of economic diversification 
on the economic health of an area, a series of hypotheses will be tested using the normal error regression model. This model is defined as:

$$
V=\beta_{0}+\beta_{1} D+\varepsilon
$$

where

$\mathrm{V}$ is the value of the dependent variable (e.g., unemployment),

$D$ is the value of the independent variable (diversity), $\beta_{0}$ and $\beta_{1}$ are intercept and slope, respectively, and $E$ is the error term.

This model treats $D$ as a nonrandom quantity without error or with a small degree of error, relative to the random error $(\varepsilon)$.

The linear correlation will provide a mathematical statement about the strength of the linear relationship between the variables. The Pearson Product Moment Correlation Coefficient, symbolized by $r$, is employed in this research. The square of the Pearson's $r$, denoted by 2 $r$, is a more easily interpreted measure of association when the concern is with strength of relationship rather than with direction of relationship. Its usefulness derives from the fact that $r^{2}$ is a measure of the proportion of variance in one variable "explained" by the other (McClave and 
Dietrich, 1979).

NULL AND ALTERNATIVE HYPOTHESES

The test for no relationship is expressed in a null hypothesis. It is possible to test the null hypothesis in such a way that the real value of the correlation coefficient is equal to 0 or to set up a confidence interval for the true correlation coefficient. The test to determine whether the true correlation coefficient of a population is equal to zero follows the usual parametric procedures (Hodges and Lehmann, 1979). If the null hypothesis is rejected, the implication is that the observed correlation between the variables did not occur merely by chance. Such a statistically meaningful relationship need not, of course, imply the existence of a causal relationship between the variables.

The major objective of this study is to test eight hypotheses. In a statistical sense, the null and alternative hypotheses are:

HYPOTHESIS 1. Diversity and unemployment level are negatively correlated.
$\mathrm{H}_{0}: \mathrm{B}_{1}=0$
$H_{1}: B_{1}<0$ 
HYPOTHESIS 2. Diversity and per capita income level are positively correlated.
$H_{0}: B_{1}=0$
$H_{1}: \beta_{1}>0$

HYPOTHESIS 3. Diversity and unemployment growth rate are negatively correlated.
$\mathrm{H}_{0}: B_{1}=0$
$\mathrm{H}_{1}: B_{1}<0$

HYPOTHESIS 4. Diversity and per capita income growth rate are positively correlated.
$\mathrm{H}_{0}: \beta_{1}=0$
$\mathrm{H}_{1}: \mathrm{B}_{1}>0$

HYPOTHESIS 5. Diversity and unemployment instability are negatively correlated.
$\mathrm{H}_{0}: \beta_{1}=0$
$\mathrm{H}_{1}: B_{1}<0$

HYPOTHESIS 6. Diversity and per capita income instability are negatively correlated.
$\mathrm{H}_{0}: \mathrm{B}_{1}=0$
$H_{1}: \beta_{1}<0$ 
HYPOTHESIS 7. Diversity and instability of (yearly) changes in unemployment rate are negatively correlated.

$$
\mathrm{H}_{0}: \beta_{1}=0 \quad \mathrm{H}_{1}: \beta_{1}<0
$$

HYPOTHESIS 8. Diversity and instability of (yearly) changes in per capita income are negatively correlated.

$$
\begin{array}{ll}
\mathrm{H}_{0}: & \beta_{1}=0 \\
\mathrm{H}_{1}: & \beta_{1}<0
\end{array}
$$

HYPOTHESIS TESTING

The above hypotheses can be tested using the student's $t$ distribution, as follows:

$$
t^{*}=\frac{\hat{\beta}_{1}}{S\left(\hat{\beta}_{1}\right)}
$$

where $\hat{\beta}_{1}$ is the estimate of $\beta_{1}$ and $s\left(\beta_{1}\right)$ is the standard error.

If the level of significance test is set at $\alpha$ and the critical value of $t$ is denoted by $t$, the decision rule for Hypothesis 2, for example, is of the form

$$
\begin{aligned}
& \text { If } t^{*}<t_{C}(1-\alpha ; n-2), \text { conclude } H_{0} \\
& \text { If } t^{*}>t_{C}(1-\alpha ; n-2), \text { conclude }{ }_{1}^{H}
\end{aligned}
$$


The hypothesis testing was accomplished by use of the subprogram, Pearson Correlation of the Statistical Package for the Social Sciences (SPSS) computer programs. This subprogram computes Pearson Product Moment Correlations for pairs of variables. Output from this subprogram includes the coefficient of correlation, estimates of $\beta_{0}$ and $\beta_{1}$, the test of significance, and the number of cases, $N$, upon which the coefficient of correlation is computed. Significance tests are reported for each hypothesis and are derived from the use of the $t$ test with $n-2$ degrees of freedom for the computed quantity. The user has the option of selecting a one- or two-tailed lest of significance.

In statistical analysis, the choice of the two-tailed test is normally justified when the researcher does not have an explicit hypothesis concerning expected direction of the correlation coefficient, i.e., whether it will be positive or negative. The choice in this investigation is the onetailed test, since there are rather explicit expectations regarding the direction of the relationship.

\section{LEVEL OF SIGNIFICANCE}

In the formal test procedure described in this chapter, a level of significance is chosen and a clear decision rule for rejecting the null hypothesis is formulated. This level of significance, $\alpha$, determines the probability that the null 
hypothesis will be incorrectly rejected (i.e., that a type 1 error will be made). The difficulty with that strictness is that a result can be made "significant" merely by changing the $\alpha$, which serves as the formal criterion for significance. However, it is possible to reformulate the test procedure without changing its essence. Instead of simply reporting the rejection of the hypothesis $\left(\mathrm{H}_{0}\right)$ at a given significance level, it is more informative to report the probability under $\mathrm{H}_{0}$ of obtaining a value as extreme as, or more extreme than, the observed value. This probability is called the significance probability $(\hat{P})$ of the observed result. The significance probability has the important property of showing in a single number whether or not to reject the hypothesis at any attainable levei, $\alpha$. Furthermore, it enables the reader to choose the level of sigrificance (perhaps on the basis of losses, which may be quite different from those of the person reporting the results) and to determine whether $\mathrm{H}_{0}$ would have been rejected at that level of significance.

$$
\begin{aligned}
& \text { For any value of } \alpha \text {, } \\
& \text { If } \alpha>\hat{P} \text {, reject } H_{0} \\
& \text { If } \alpha<\hat{P} \text {, accept } H_{0}
\end{aligned}
$$

A low $\alpha$, then, casts doubt upon the hypothesis $\mathrm{H}_{0}$; conversely, a high $\hat{\mathrm{P}}$ tends to support the hypothesis. 
Reporting the value of significance probability of a test (in addition to the formal decision) is a way of concisely conveying some information about what is going on in the data. For the above reason, when reporting the outcome of a statistical test, the significance probability is published, thus enabling others to perform the test at a level of their own choice. The empirically-derived significance probabilities will be demonstrated in the findings section of this research report. The level of significance, $\alpha$, chosen for this research is set to .05 .

Chapter IV, following, utilizes the formulas and research data presented in Chapter III to examine the economic trends of the last decade and to provide a brief economic overview for both oregon and the nation as a whole. 
CHAPTER IV

ECONOMIC TRENDS OF THE LAST DECADE

The 1970's witnessed a turnaround in the previously sluggish performance of the Oregon economy. Since 1970, the real value (in 1972 dollars) of the final outputs of all goods and services produced in the state has advanced at an annual average rate of $4.8 \%$, over . $8 \%$ greater than the annual average growth rates attained during the years between 1960-1970. During the 1970's, Oregon also outpaced the mean annual real growth of GNP (3.88) attained by the U.S. economy as a whole. This development of the economy increased Oregon's vitality. The favorable economic climate resulted in an expansion and growth of real personal income and employment as well as attracted large number of new residents from other states.

Recent economic and demographic trends in Oregon are definitely not unique and have occurred within a context of a larger national framework. Throughout the nation, the more sparsely settled and less industrialized states have generally experienced above average percentage gains in population, output, and income. Underlying this variation in current growth performance is the development of "amenities" as significant factors in both individual and 
corporate location decisions. People moved to these states for several reasons: to seek employment, to leave behind the problems associated with life in large, industriallymature cities (pollution, congestion, and crime), to pursue a slower-paced lifestyle, or to retire. It appears that money and job security were less important than clean air, peace of mind, recreational opportunities, and closeness to nature.

In order to provide a brief economic overview and a comparative perspective, this chapter examines the economic trends of the last decade and presents aggregate economic data for both oregon and the nation, making a comparison of relative economic performance.

ECONOMIC REVIEW AND OUTLOOK, 1972-1981

Officially, the nation experienced recessions during most of 1970, 1974-1975, and again in 1980-1982. The period 1980-1982 actually experienced two recessions, the first lasting from January to July 1980 and the second from July 1981 through at least December 1982. But the intervening recovery period was so mild that in such hard-hit states as Oregon, it proved to be virtually nonexistent. For these states, the years 1980-1982 were one long period of economic pain. 
The 1970's: Years of Inflation

Although the 1970 's contained several recessionary years, the real economic problem proved to be inflation, i.e., a rise in the general price level (or average level of prices) of all goods, services, and factors of production such as capital and wages.

Inflation imposes both macro- and microeconomic costs. At the micro level, inflation redistributes income by altering income and wealth. Because not all prices rise at the same rate during an inflationary period and not everyone buys the same goods and services, not everyone suffers equally from inflation. People on fixed incomes, firms and individuals who must borrow money at high interest rates suffer most. At the macro level, inflation threatens to reduce total output because it increases uncertainty about the future and thereby holds back economic (consumption and production) decisions.

Whichever response consumers and producers make--either decreasing or increasing their rate of expenditure--the economy is likely to suffer in the end. If they cancel their expenditure plans, the demand for goods and services will fall. On the other hand, if market participants increase their rate of expenditure in the hope of beating inflation, the result may push prices up still faster. In general, inflation impairs the nation's efficiency, growth, 
and competitiveness in the world market (Spencer, 1980: 107111) .

Figure 1a summarizes Oregon's experience with inflation since 1972, as measured by the Consumer Price Index (CPI), compiled by the U.S. Bureau of Labor Statistics. Since the Bureau does not maintain a CPI series for oregon, the Portland SMSA index is used for the Oregon figures. The base year for pricing the market basket of goods is 1967 , and the price has been set at $\$ 100$ for that year.

Figure 1a shows the movement of consumer prices in both the United States and the Portland SMSA from 1972 through 1981. Overall, the rise in prices was 117 for the nation and 1338 for the Portland SMSA. Two periods of relatively rapid increases are shown, separated by periods of relative stability. The first period of inflation was 1974-75 (recession years).

In two years, the national Consumer Price Index rose by 238 for both the nation and the Portland SMSA. During these two years, the national economy was confronted by the following adverse economic conditions: production was declining, unemployment was rising, the government deficit was increasing, and labor productivity registered the first year-to-year decline on record. From 1976 to 1978, the national consumer price index rose by $7 \%$ annually and the Portland CPI by 88 annually, a considerably slower pace than 
1a. Annual Avg CPI, Portland and U.S.

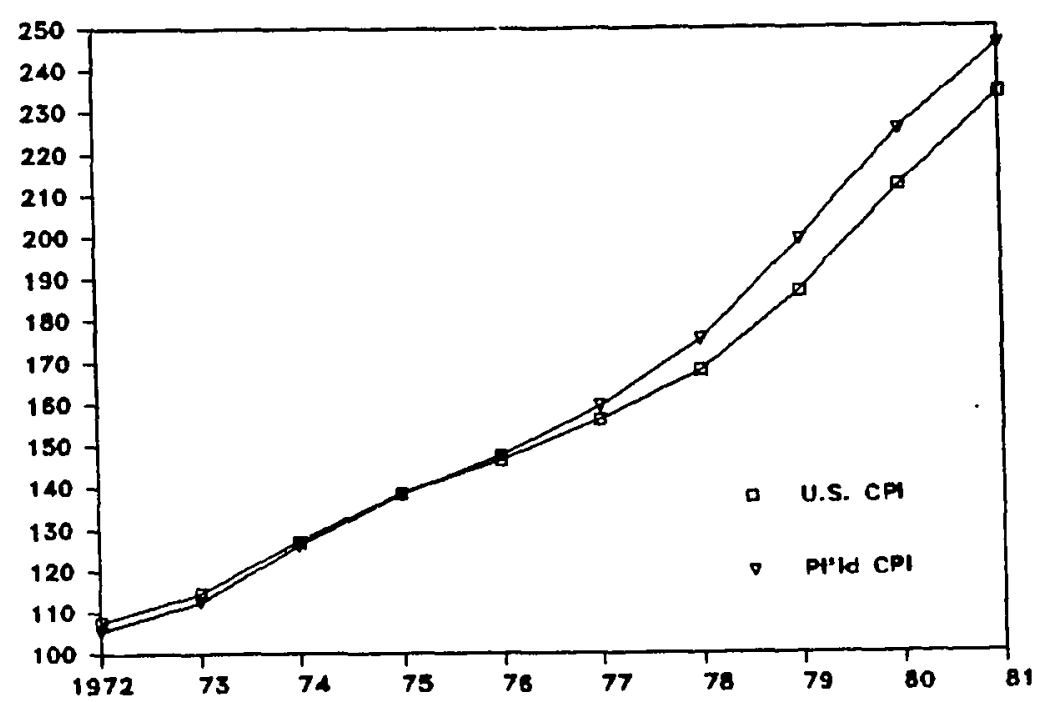

1b. Annual \& Change (Rate of Inflation) Portland SMSA and U.S.A.

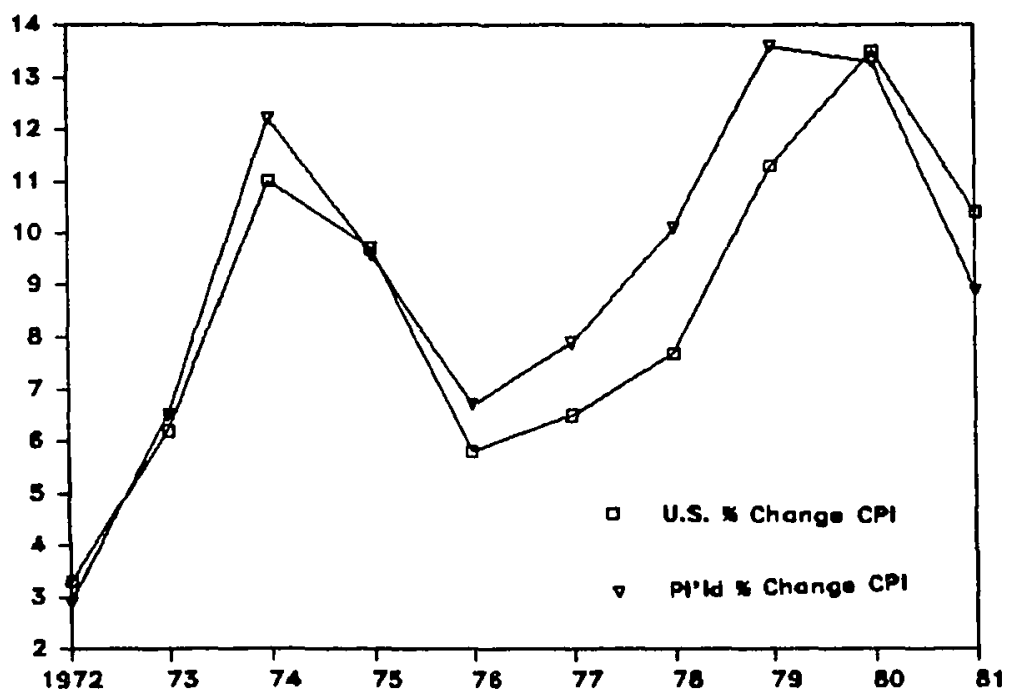

Source: U.S. Bureau of Labor Statistics

Figure 1. Annual average consumer price index, U.S. and Portland SMSA, 1972-1981. 
in the 1974-75 period.

The second period of relative rapid increase in price levels came during the 1979-81 period. In three years, the national CPI increased by over 398 and the Portland CPI by over 408 .

Figure 1b provides a convenient summary of oregon's recent inflation experience. In this figure, annual changes in the CPI have been transformed into annual percentage change (rate of inflation). Figure 1b confirms that prices have risen at least a little nearly every year, and occasionally $(1974,1979,1980)$ by very large amounts.

The Effects of Inflation on Economic Sectors

Inflation hit the housing industry particularly hard during the 1970 's. Soaring interest rates resulted from a restrictive monetary policy imposed to combat a surge in inflation. The combination of climbing housing prices and soaring interest rates during the decade squeezed an increasing percentage of families out of the new and used housing market, year to year.

Between 1977 and 1980, housing prices skyrocketed 528 . A recent estimate released by the National Association of Home Builders indicates that 438 of all families in 1970 possessed the necessary income to qualify for a home purchase. By 1980, this percentage had dropped to 16.58 (Economic Report, 1982, North Coast Area). The Housing 
Affordability Index, published by the National Association of Realtors, also indicates a levelling off of median family income compared with qualifying income for home purchase. The 1981 figures show the Index at 68.9. If the Index equalled 100, principal and interest payments on a mortgage for a median-priced resale home would have consumed exactly 25 of the nation's median gross income. The 1981 index means that a family earning the median income (i.e., midpoint) figure, had 68.98 of the income needed to qualify for the purchase of a median-priced resale home, which was $\$ 66,400$ that year (The Sunday Oregonian, May 2, 1984: D11).

As the national housing market was thrown into disarray by high interest rates, the resulting plunge in construction was in turn reflected in the lumber and wood products industry. Residential construction is the major source of demand for lumber, plywood and other wood products since an estimated 408 of all lumber and wood products are used for home construction.

Oregon, A Hard-Hit State

Lumber and wood products play a major role in Oregon's economy. Douglas fir, the major softwood harvested in Oregon, is used extensively in dimension lumber and plywood for housing construction. When housing starts are up, so is Oregon's lumber and wood products employment. A drop in housing usually leads to a drop in the work force in Oregon. 
Such a relationship is shown in Figure 2. During the recession of 1974-75, wood products employment fell from 80,900 in 1973 to 69,600 in 1975 (a 148 decrease) because of the slump in the housing market. During the recent (198082) recession, annual average employment in lumber and wood products manufacturing fell by 17,000 from 80,800 in 1979 to 63,800 in $1981--a$ drop of nearly 218 .

Oregon's economy continues to struggle through the worst recession it has experienced in several decades. Continued high interest rates and inflation manifested themselves in different ways throughout Oregon. The first industries hit were lumber and wood products and construction.

The recession also hurt the service industries. The largest service industry in oregon is probably tourism. The local price and availability of gasoline had a direct impact on tourism and the industries it helps to support. Gas shortages caused many people from other states, primarily California, to vacation closer to home. Soon, the ripple effect of recession had all of Oregon's economy in a depressed state.

Since the beginning of the current recession (1980), Oregon's economy has lost more than $10 \%$ of its nonfarm payroll jobs. In comparison, the national decline in nonfarm employment has been 1.98 during the recessionary 
2a. Oregon Lumber and Wood Products Employment

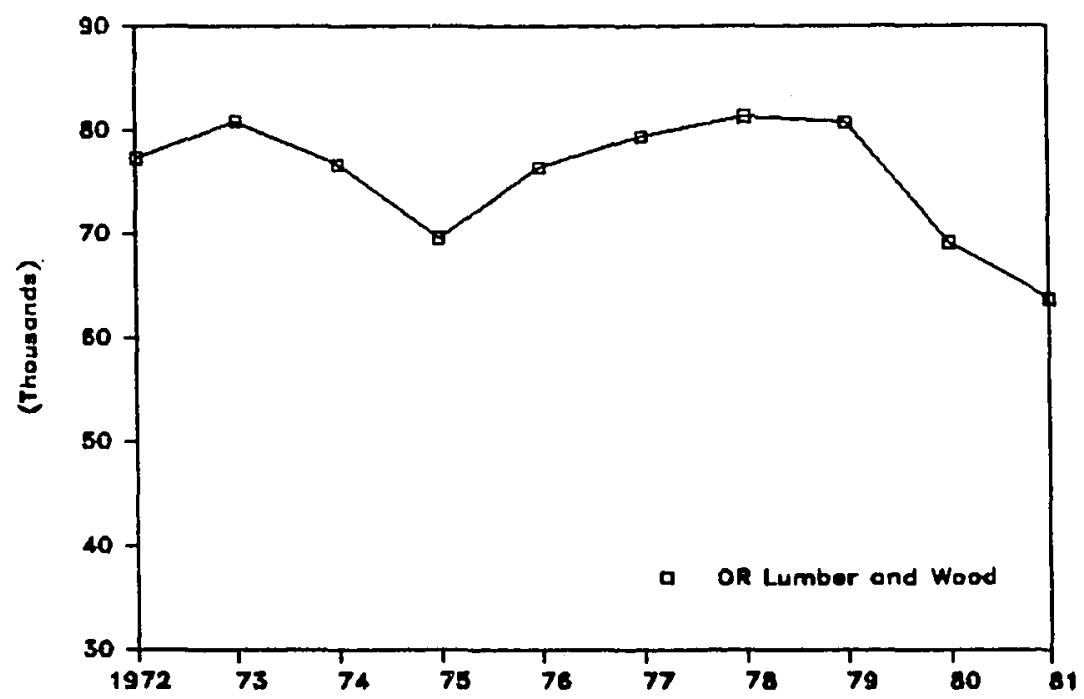

2b. U.S. Housing Starts

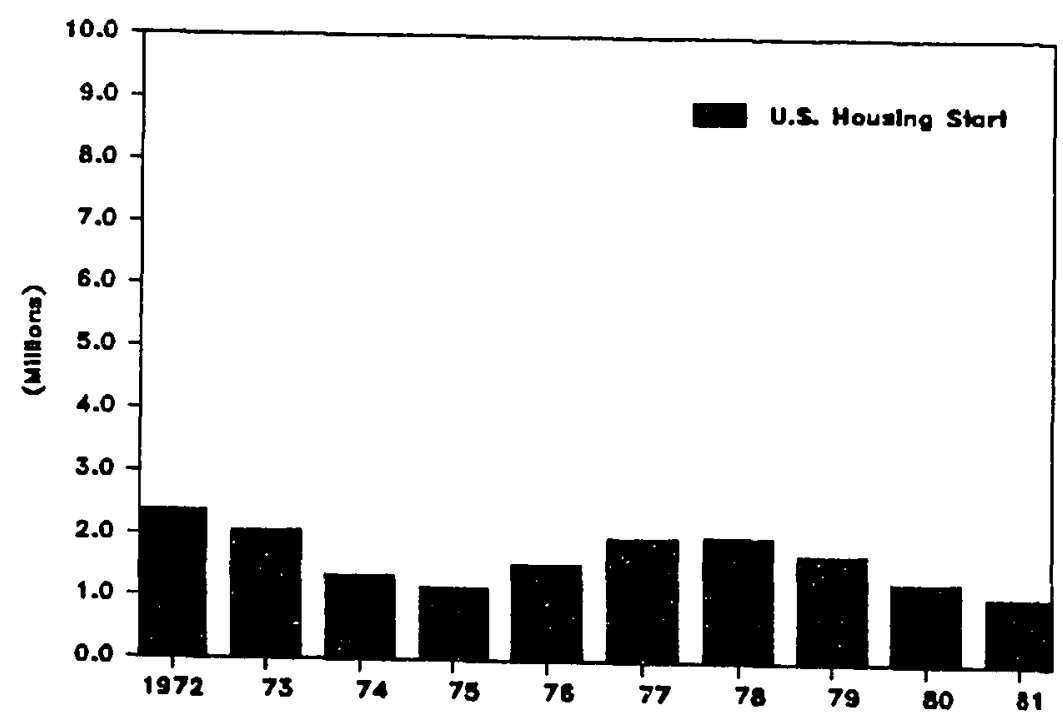

Source: Department of Human Resources, Employment Division, state of Oregon

Figure 2. Oregon lumber and wood product employment compared with U.S. housing starts, 1972-1981. 
period. Payroll employment in neighboring states has decreased by 3.78 for Washington and 7.48 for Idaho (State of Oregon, Executive Department, Oregon Economic and Revenue Forecast, v. 15, no. 4, December 1982). Oregon's substantial job loss during the recent recession has been reflected in population trends. Transitional changes in Oregon's historical economic base, led by the employment decline in the forest and food product industries, has caused a noticeable emigration from certain regions. According to the Portland State University Population Research Center, 20,000 people moved out of Oregon during the 1981-82 period. The emigration for 198283 is 40,000 (The Oregonian, Sunday, January 22, 1984, v. 203, no. 8). This figure is in sharp contrast with the 1970-1980 figures, which show a statewide increase of 541,130 people. Approximately 718 of this increase was due to immigration rather than to births (Oregon state Department of Economic Development, A Statistical Profile, 1982: 31.

The trend of outmigration from large metropolitan core areas to the urban fringe areas was common for oregon counties during the 1970's. As confirmation of this trend, 10 Oregon counties showed inmigration figures of more than 808 during the 1970-79 period. Intracounty population changes also have taken place in oregon. The outflow, or 
urban-to-rural shifts, was also common for most counties in eastern Oregon, according to the Annual Planning Information for Calendar Year 1982 ( p. 105). OREGON'S ECONOMY, A CLOSER LOOK

Nonfarm Wage and Salary Employment

The most accurate data on employment is nonfarm wage and salary employment data. These statistics count people on nonagricultural payrolls by place of work. Approximately 858 of Oregon's working populace are employed in the nonfarm wage and salary category. This category increased from 89,370 in 1972 to 120,500 in 1981, an increase of almost 358.

Employment growth during the ten-year study period did not occur evenly by industry. Nonfarm wage and salary employment is of two major types: manufacturing and nonmanufacturing, which, in turn, are subdivided into still smaller categories. The pie charts contained in Figure 3 display Oregon's major wage and salary employment categories for 1972 and 1981. Despite differing economic conditions, some general conclusions can be drawn from the study of these charts.

The bulk of all wage and salary employment is to be found in nonmanufacturing, which has displayed a greater growth rate than manufacturing has over the 1972-1981 
1972

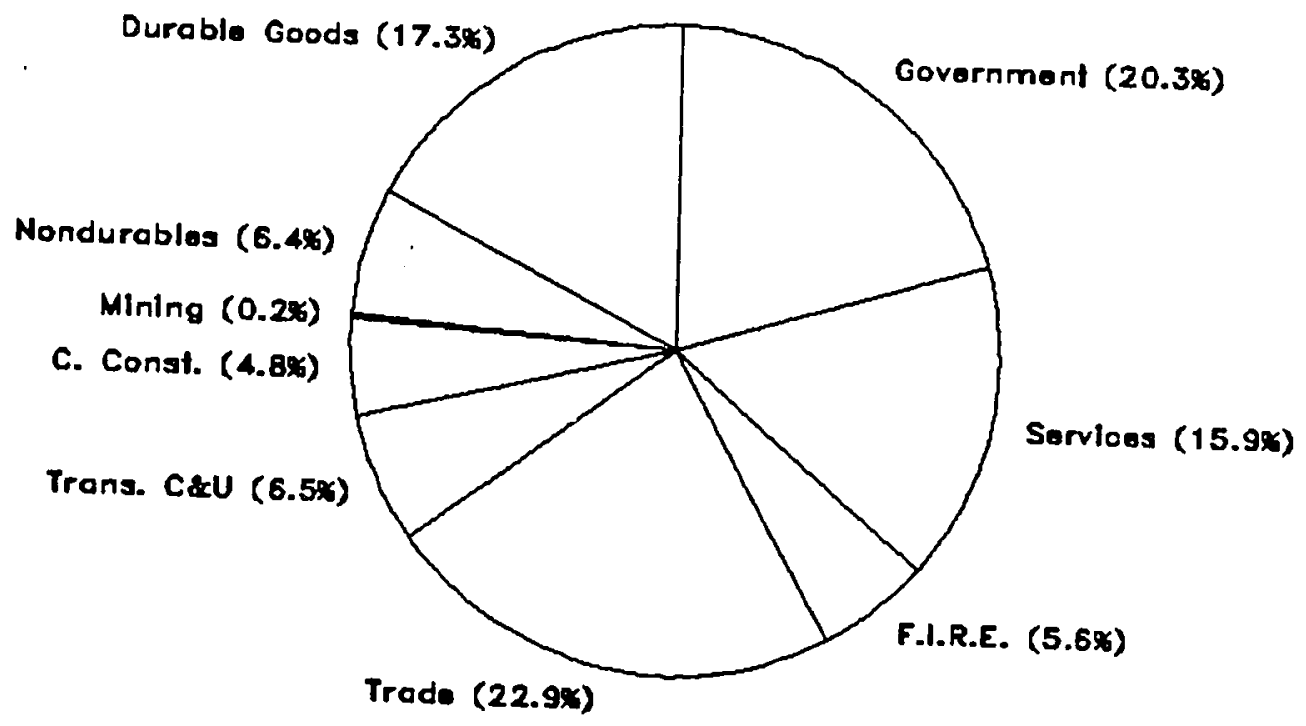

1981

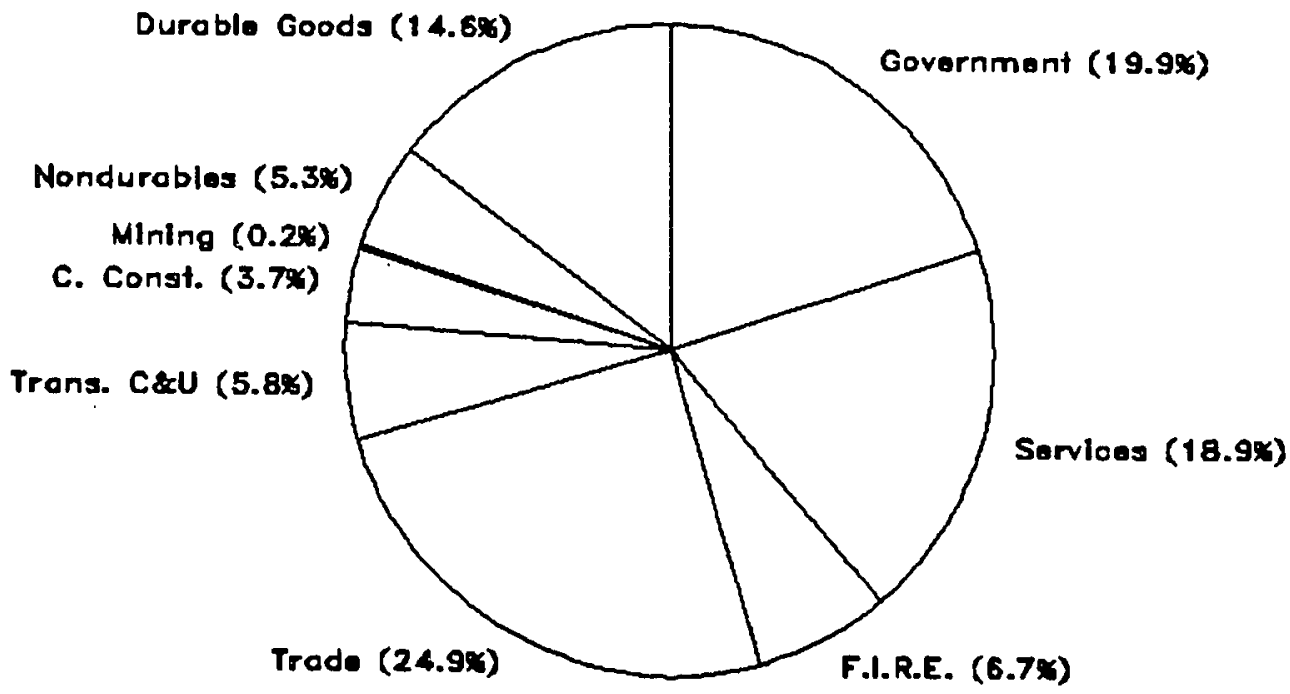

Source: Department of Human Resources, Employment Division, State of Oregon

Figure 3. Oregon nonagricultural wage \& salary employment, 1972 and 1981. 
period. Employment in the manufacturing sector rose $10.2 \%$, and the nonmanufacturing sector increased by 38.28 . Part of the explanation for the lower growth rate in the manufacturing sector rests in the fact that durable goods industries are usually considered to be more cyclically volatile than the nondurable goods and manufacturing sectors (Barts, 1960). In general, recessions have a greater diverse impact on manufacturing employment.

During the study period, several nonmanufacturing industries increased faster than the national average, notably finance, insurance, and real estate (58.6\%), services (55.98), and trade (438). Among nonmanufacturing industries, only government and transportation, communication, and utilities grew at a relatively slow pace and therefore declined as a proportion of total employment.

\section{Manufacturing Employment}

During the study period, Oregon has substantially reduced the reliance on its historical economic base, a movement away from dependence on the traditional resourceoriented industries of food and forest products. Figure 4 displays the percent distribution of manufacturing employment for 1972 and 1981. Lumber and wood products, as well as food products, grew at a relatively slow pace during the ten-year period, falling from a combined total of $54.7 \%$ to 43.28 of the total manufacturing employment. 

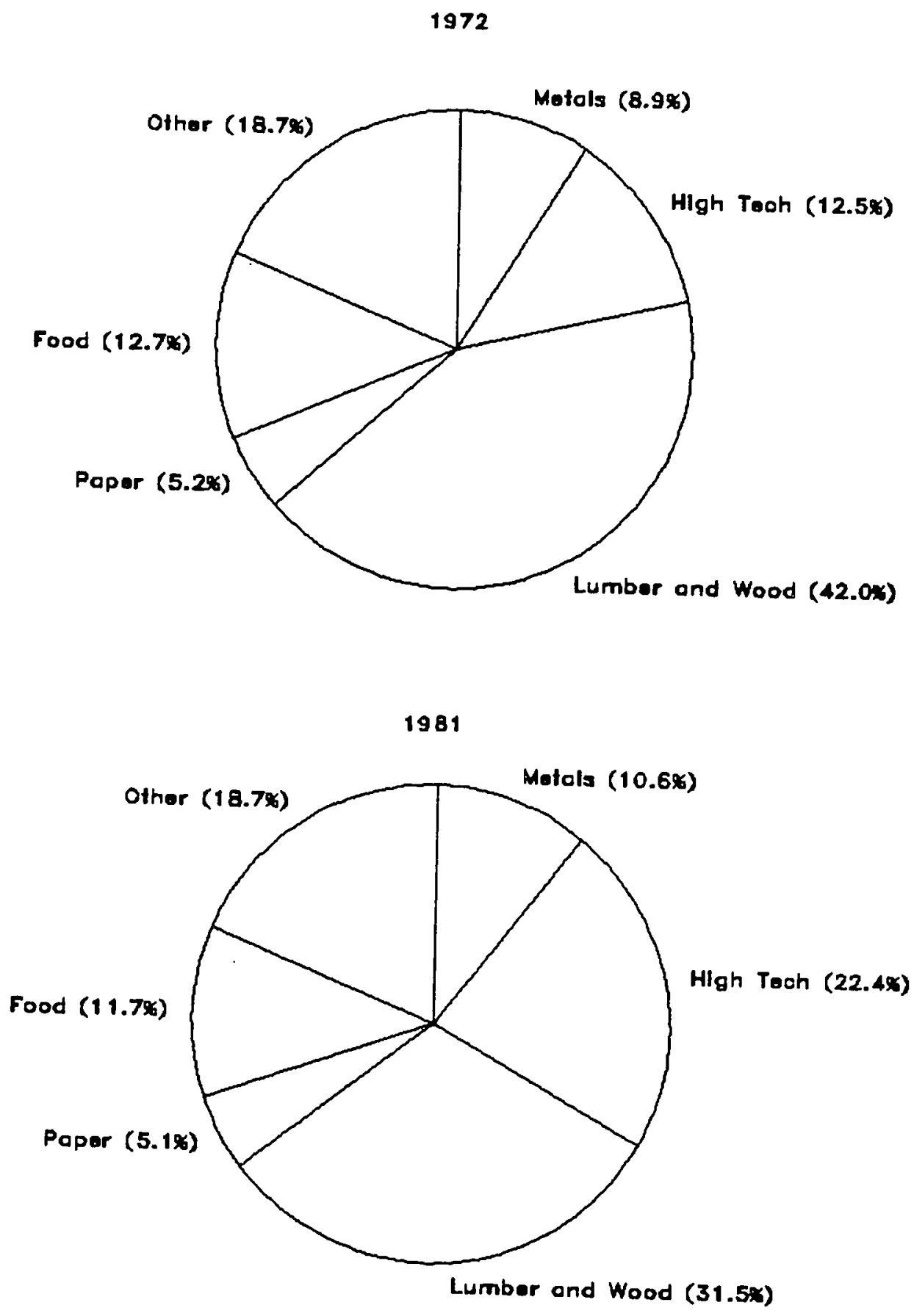

Source: Department of Human Resources, Employment Division, State of Oregon

Figure 4. Manufacturing employment, percent distribution. 
While there has been a significant movement away from dependence on the lumber and wood products industry, they still continue to dominate the manufacturing sector. Lumber and wood products account for virtually the entire economic base in many of the state's counties. During 1971, an average of 77,300 workers were employed in this industry. This figure was reduced to 63,800 by 1981 . Part of the decline in wood products industry employment resulted from adverse effects of the recession. But several structural changes were also partially responsible. For example, growing competition from Canadian and southern U.S. pine mills has forced the wood products industry to become more efficient. The application of new technology has increased worker productivity and reduced unit production costs. The overall effect of these structural changes has been to increase productive capacity without a significant increase in demand for labor inputs.

Paper and allied products, while stable employers, have shown a small steady decline. The industrial pacesetters during this period have been the high technology industries, consisting of machinery, electrical equipment and supplies, and instruments and related products. The high technology sector has increased its employment from $12.5 \%$ of total manufacturing to 22.48 between 1972 and 1981 . For the same period, total employment in this sector increased by 97.48 , 
from 23,000 in 1972 to 45,400 in 1981. Primary metals also showed a gain from 8.98 of total manufacturing to 10.68 . While aggregate figures show that oregon has substantially reduced its reliance on its historical economic base during the period of study, most of the economic diversification has been geographically concentrated in the Portland SMSA. More than 508 of the nonforest and food products employment is located in the Portland SMSA, with the balance of the state for the most part still subjected to the beating side effects of slowgrowing, highly seasonal, and cyclical industries.

Oregon.'s economy seems to be in transition. It appears to be moving from a heavy reliance on its historical economic base, i.e., heavy dependence on the forest products industry, to a condition of balance. As the relative importance of food and forest products decline, the high teshnology industries and the metal-related industries increase their shares. In the nonmanufacturing sector, services and trades are experiencing above-average growth. International trade continues to become more important.

Unemployment Characteristics

Several different kinds of unemployment have been distinguished by economists: seasonal, cyclical, frictional, and structural (Schiller, 1983: 115-117). Seasonal unemployment is that which is due to weather and 
harvest activities. Generally particular industries, rather than the entire economy, are affected. Cyclical unemployment is the result of business recessions and depressions when there is an inadequate level of demand for goods and services for labor to be used in production processes.

Frictional unemployment is referred to as normal unemployment (Spencer, 1980: 105). This type of unemployment is usually of short duration. It is experienced by people temporarily unemployed because they are moving between jobs or entering the work force. Structural unemployment is caused by changes in the structure of jobs, business, or the economy. It is the result of a mismatch between the location of skill of the job seeker and the location or requirements of jobs.

Seasonal unemployment plays a major role in Oregon's economic construction. Lumber and wood products, agriculture, trade, canning, fishing, and tourist-related activities typically have strong seasonal components based on weather conditions. In the summer, the state unemployment figures generally reach their annual low point. Cyclical unemployment played a major role in the upsurge of Oregon's unemployment during the recent recession. As the demand for lumber-related products decreased, Oregon's heavy reliance on the lumber industry 
lost approximately 17,000 timber-related jobs during May 1980. The total number of workers employed in the lumber and wood products-related construction industries decreased from 133,800 in 1979 to 85,100 in 1982, a net loss of 48,700 jobs. This accounts for approximately 618 of oregon's total unemployment figure during the period.

A portion of Oregon's unemployment during the study period can be attributed to structural changes in the oregon economy. During the 1970's, growing competition from domestic and foreign competitors has forced several industries, e.g., lumber, wood products, and paper manufacturing, to become more efficient. The application of new technologies has cut unit production costs and demand for labor input.

The recession of 1980-82 has definitely increased structural unemployment in oregon. As a result of the housing slump, many jobs in construction, lumber, wood, and food industries disappeared for good. Many of the unemployed, after several attempts to obtain work in Oregon, dropped out of the labor force; during the recent recession, for example, Oregon's labor force declined by 21,000. Part of this decrease, to be sure, is due to out-migration; however, a portion is almost as certainly due to an increase in discouraged workers who have simply given up job search efforts. 
Frictional unemployment also accounts for part of the unemployment in Oregon. People with skills in professional, technical, and managerial areas tend to change jobs more often than people with other types of skills. Those parts of the state which experience growth in trade and services are the prime breeding grounds for frictional unemployment. During the 1980-82 recession, frictional unemployment was probably down in most industries and occupations since workers knew that the chance of getting a job was slim. They did not quit their current jobs unless they were absolutely certain that they had secured a job elsewhere.

\section{Per Capita Income Variation}

Per capita income varies widely from county to county in Oregon. Unusual or atypical conditions such as a major construction project or an outstanding harvest or a crop failure could cause per capita income to be high or low for a given county in any particular year. In addition, a county with a large institutional population (such as a university population) may have relatively lower per capita income, i.e., income which does not represent the true economic health of the noninstitutional population. In 1972, more than 808 of Oregon's 36 counties had per capita income below the state average. This gap did not decrease during the study period. In 1981, the number of counties with per capita income below the state level stayed 
the same, with per capita income in the Portland metropolitan area (Washington, Clackamas, and Multnomah counties) 328 greater than the balance of the state. This gap leaves considerable room for improvement in the regional distribution of income within Oregon.

\section{OREGON VS. U.S.: A COMPARATIVE PERSPECTIVE}

This section presents aggregate economic data for Oregon and for the U.S., giving a comparison of relative economic performance.

Employment Growth and Stability

The two graphs represented in Figure 5 show the growth of employment in Oregon relative to the U.S. Figure $5 a$ charts the employment indices for both the U.S. and Oregon. This chart sets the 1970 employment at 100 and displays later employment levels relative to this base level. Oregon experienced strong growth from 1976 to 1978 --employment grew by over 7\% per year. The oregon Index rose from 100 in 1972 to its neak of 150 in 1981, an increase of nearly 508. The U.S. index stood at 128 in 1981, an increase of almost $28 \%$. This illustrates the more rapid growth of Oregon employment in comparison with that of the U.S. in general.

Figure $5 \mathrm{~b}$ provides a more convenient summary of economic trends in oregon and in the nation. In this figure, annual changes in employment have simply been 
5a. Employment Index

U.S. versus oregon

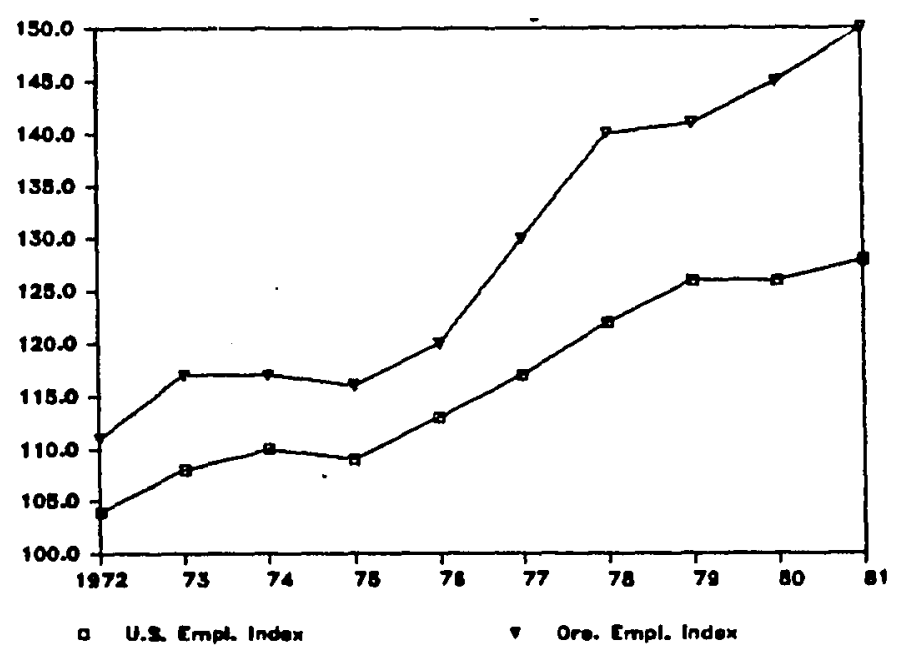

5b. Annual of Change in Employment Index U.S. versus oregon

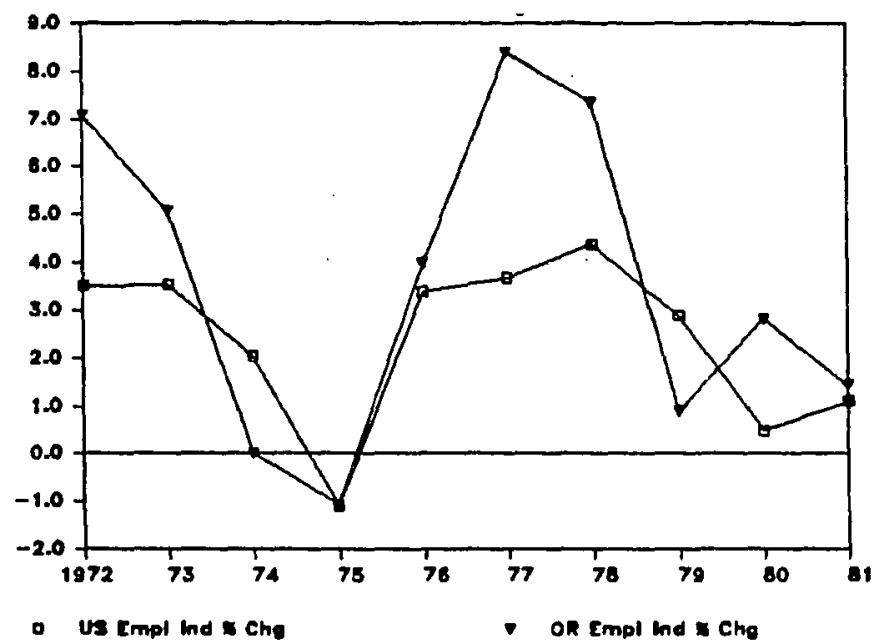

Sources: Employment Division, state of Oregon and Statistical Abstract of the United states

Figure 5. Employment: U.S. and Oregon, 1970-1982. 
transformed into annual percentage change. A pattern of cyclical instability for oregon employment is evident from this figure. It reveals the low points or troughs in the growth rate of oregon employment for the years 1975 and growth rate for economic activity in Oregon. The national low points occur in 1975 and 1980 .

Officially, 1980 is marked as the beginning of the current oregon recession. Although the state's economic performance in 1979 is not a strong one, it has been designated as "another good year" in the Annual Planning Information Calendar for 1981. Following the substantial success of Oregon's economy in 1978, the 1979 performance was expected to continue the trend. Although unemployment rose moderately from 6.08 in 1978 to nearly 6.88 in 1979, nonagricultural wages and salaries averaged $4.1 \%$ higher than in 1978. The annual average employment level exceeded that of 1978 in almost every major category. The only exception was the area of lumber and wood products.

To provide a comparative perspective, two figures have been calculated for oregon and the U.S. The first is the average annual rate of growth of employment over the study period. These averages may be interpreted as estimates of a long-run employment growth trend. As a measure of the longrun employment growth trend, Oregon's average annual 
employment growth rate of $3.59 \%$ is notably higher than the 2.398 rate for the U.S. in general.

The second figure is the standard deviation of the annual rate of growth for oregon and for the U.S. The standard deviation measure has been used to compare variation in growth rates relative to employment growth. The standard deviation of the actual rate of growth for Oregon and for the U.S. are, 3.31 and 1.73 , respectively. Figure 5b shows that oregon's employment growth was both higher and more cyclically volatile than that of the nation in general over the 10-year study period.

\section{Unemployment}

Figure 6 shows the average unemployment rates for both Oregon and the U.S. from 1971 to 1981. Clearly illustrated is the descent from a peak of activity to the recessions at the national and state levels. The Oregon unemployment rates were relatively high during the ten-year period partly due to a significant increase in labor participation (with particularly heavy increases in the female and teenage areas)

During the 1974-75 recession, joblessness rose sharply, both in Oregon and in the U.S. in general. Stated in real terms, the Oregon total unemployment figures increased from 62,000 in 1973 to 110,000 in 1975, an increase of nearly 71\%. For the U.S., total unemployment jumped from 4,400,000 


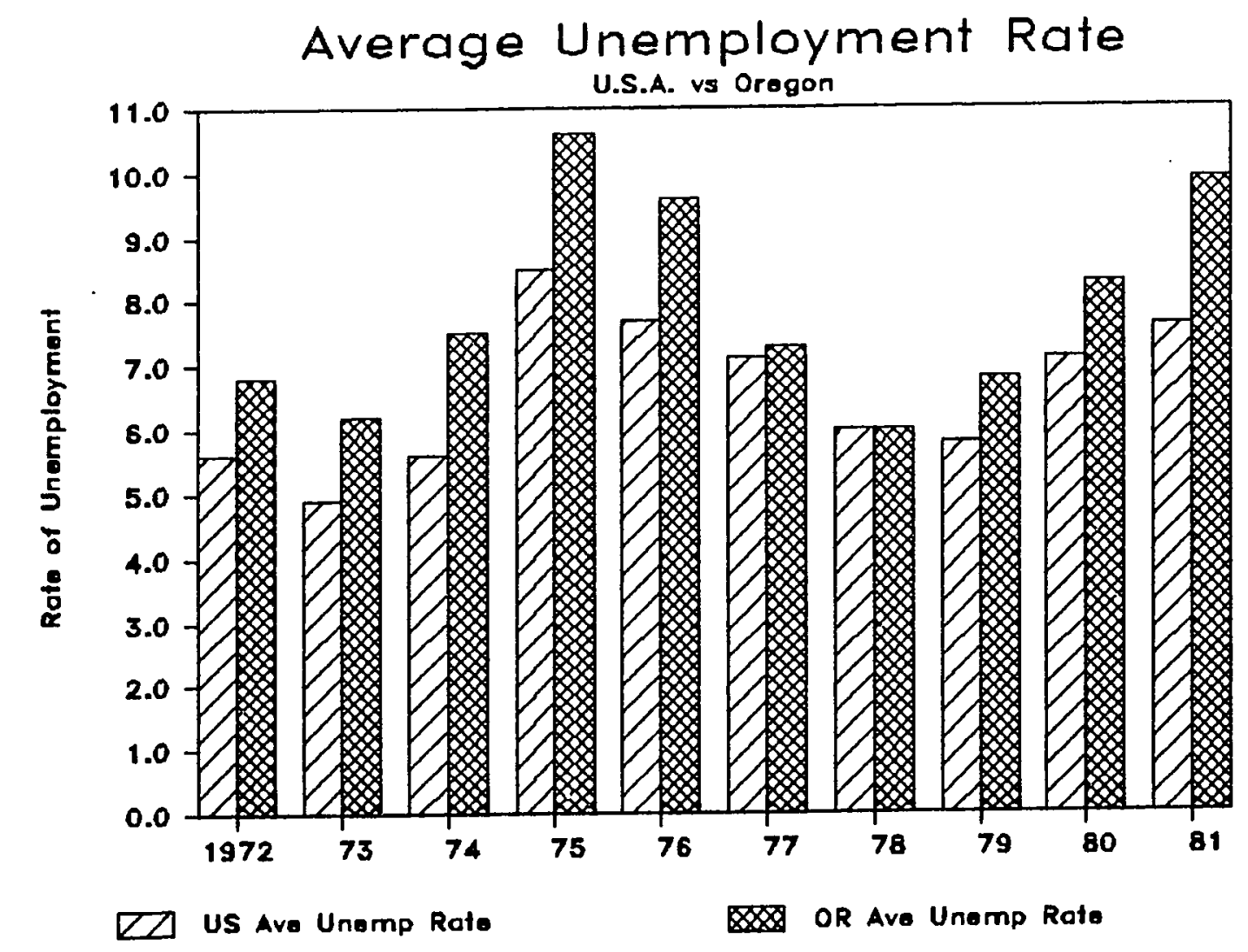

Sources: Oregon Employment Division and Statistical Abstract of the U.S.

Figure 6. Average unemployment rates (in calendar years), Oregon and U.S. 
in 1973 to $7,900,000$ in 1975 , a 748 increase. The effect of an economic downturn of this magnitude takes years to overcome.

Although economic conditions improved substantially throughout the following two years, the oregon unemployment rate did not return to prerecession levels until 1978. This is the only year where the rate of joblessness in Oregon is equal to national unemployment. With 1978 as the exception, from 1971 to 1981, Oregon's rate of unemployment was continuously above that of the U.S.; it averaged 208 higher during this period.

The recent economic slowdown, which began in 1980, has lasted longer and been more severe for Oregon than for the country in general. Throughout this recession, Oregon has consistently ranked among the top 20 states in terms of unemployment rates (Economic Report, 1982, North Coast Area). Statewide unemployment increased from a total of 83,000 in 1979 (6.88 of the labor force) to 152,000 in 1981 (11.5\% of the labor force).

\section{Employment-Population Ratio}

Oregon experienced a substantial population growth of over 208 between 1971 and 1980, with over 778 of the increase due to immigration--or approximately 39,000 new residents every year. Population estimates for 1978 showed approximately 20,820 people more than 1980 estimates. For 
Oregon, the growth in resident employment during the 1972-81 period exceeds the population growth levels for those 16 and over. The employment-population ratio, which is a measure of relative growth of the two categories, rose from 418 in 1972 to 458 in 1981 .

By contrast, the U.S. population increased during the study period by about 19.91 million people, from 109.9 million in 1972 to 229.85 million in 1982. This was a 9.58 increase. For the U.S., the employment-population ratio rose from 398 in 1972 to 448 in 1981. Much of the gain could be attributed to the entry of large numbers of females into the work force, coupled with the movement of the baby boom generation into the work ranks.

As a measure of the long-term growth trend, Oregon's average annual population growth rate of $2.25 \%$ was notably higher than the 1.028 for the U.S. in general. Oregon's rate of population growth also exhibited a pattern of greater instability than that of the U.S during the ten-year study period. This difference in the cyclical instability of population between Oregon and the U.S. is compared by standard deviation measures, .55 and .09, respectively. The low points, or troughs in the rate, occurred during the years 1975 and 1980-81. These were periods of recession for both the state and the nation. 
Growth and Stability: Per Capita Income

Personal income is the income of the residents of an area from all sources. It includes income received from business, government, and households, and it consists of wages, salaries, and other supplementary incomes such as employer pension contributions, rent, dividends, and transfer payments.

Per capita income is simply total personal income divided by total population. Data which measure the per capita income in constant dollars have been calculated by dividing the per capita income in current dollars by the Consumer Price Index (CPI).

Since CPI is not calculated at the state level, the Portland SMSA's CPI has been used for developing the Oregon per capita income in constant dollars. Figure 7 compares the real per capita income of oregon with that of the U.S. in general for the 1972-81 period. The boom times enjoyed by the lumber and wood products industries during the 1976-8 period played an important part in bringing about a strong growth in real per capita income for Oregon. Oregon's real per capita income rose by more than 88 from 1975 to 1978 . Only during the 1980-82 recession did Oregon's real per capita income fall below that of the U.S.

The annual percentage change in real per capita income for the two regions is exhibited in Figure 7b. This figure 
7a. Real Per Capita Income

$$
\text { U.S. versus Oregon }
$$

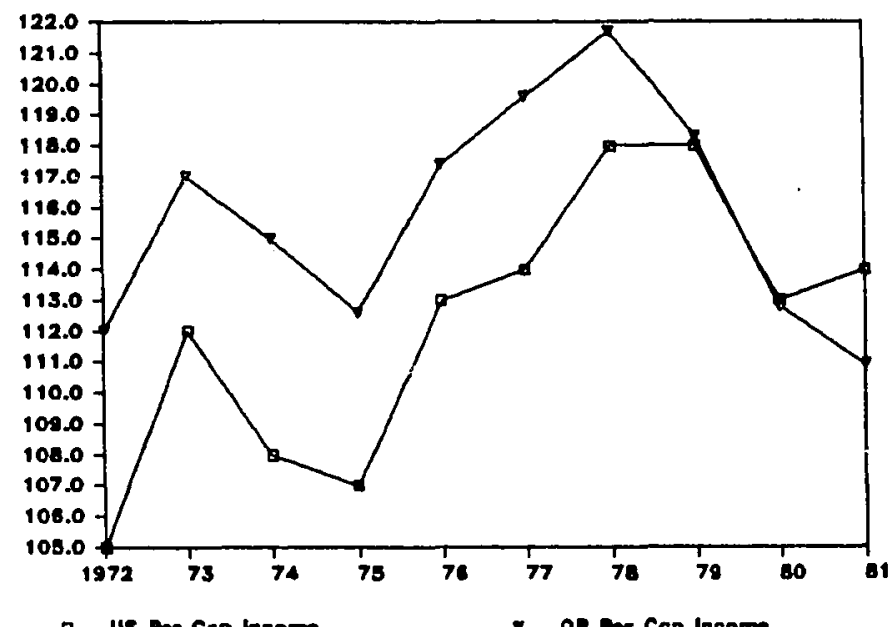

a US Per Cop inoome

$\checkmark$ OR Por COp Ineomo

7b. Annual \& Change in Per Capita Income U.S. versus Oregon

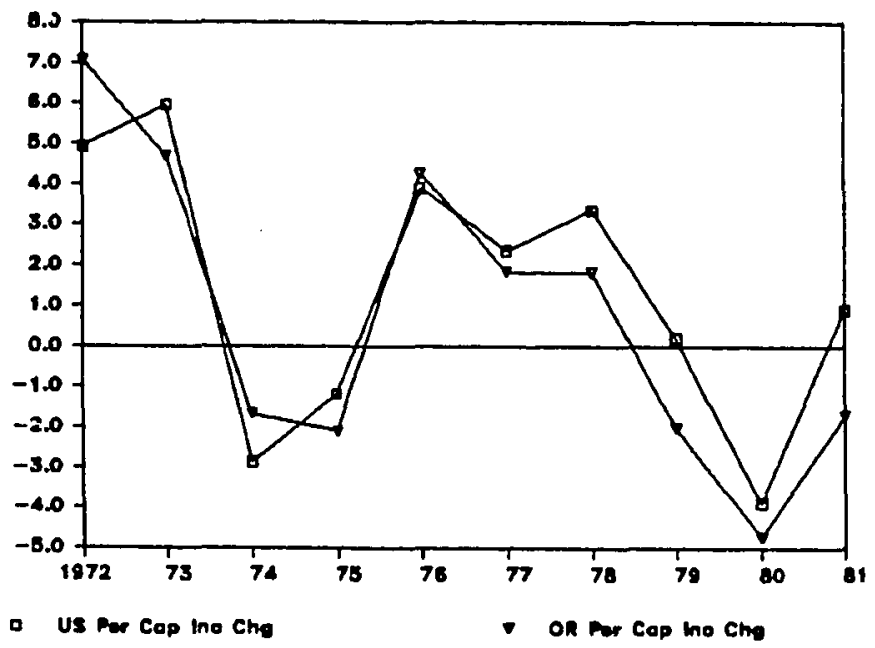

Sources: Oregon Department of Economic Development and statistical Abstract of the United states

Figure 7. Real per capita income: U.S. \& Oregon, 1970-1981 
reveals troughs occurring in the rate of growth during the recessionary years of 1975 and 1980. As a measure of longrun growth trends, Oregon's average annual per capita income growth rate of 758 was lower than the $1.37 \%$ enjoyed by the U.S. in general. As can be seen from Figure 7b, Oregon's rate of real per capita income growth exhibited a pattern of instability which resembles that of the U.S. pattern. The extent of the difference in cyclical instability is captured by the standard deviation measures, 3.76 for oregon, 3.31 for the U.S.

\section{SUMMARY}

In summary, Oregon has recently lived through a devastating recession. Federal fiscal and monetary policies, high and fluctuating interest rates, and inflation took their toll on Oregon's economy in 1980. With the uncertainty and slowdown in the nation's housing industry, Oregon's lumber and wood products industries declined significantly. Several communities lost their major employer almost overnight.

The interest in economic diversification was particularly felt in Oregon during the $1970^{\prime} \mathrm{s}$. The Oregon economy has recently been termed an economy in transition. It has moved from heavy reliance on its resource-based 
forest products industries to a condition of greater balance (i.e., the share of manufacturing employment has decreased in forest products and has increased proportionately in other areas).

A comparison of the performance of the Oregon economy relative to that of the nation, in terms of annual growth of employment and population, provides consistent evidence that during the study period the trend in Oregon's growth was higher. However, the cyclical pattern of oregon's growth was far less stable than that for the nation as a whole. With this portrayal of the oregon economy as a backdrop, Chapter V will present the results of the Oregon study. 


\section{CHAPTER V}

FINDINGS: THE OREGON STUDY

This chapter presents the research findings for the Oregon study. It begins with a study of the economic diversity of employment in the counties of oregon for the 10-year study period, followed by a study of the extent to which diversity indices vary within the state and an assessment of the historical changes in diversification patterns. Finally, economic diversity is studied in relation to unemployment and per capita income in oregon.

\section{VARIATION IN DIVERSITY WITHIN OREGON}

Oregon is far from uniform in terms of the diversity of economic activity within its borders. It varies widely in climate, soils, and vegetation, all of which affect the economic activities from area to area and thus the economic diversity of each region. Figure 8 indicates the diversity indices for employment averaged for the period from 19721981. The indices range from 2.1 for wheeler county to 2.9 for the Portland SMSA.

The highly-diversified regions occupy the Portland SMSA, the mid-Willamette Valley consortium which consists of the Salem SMSA and Yamhill county, their neighboring counties, 


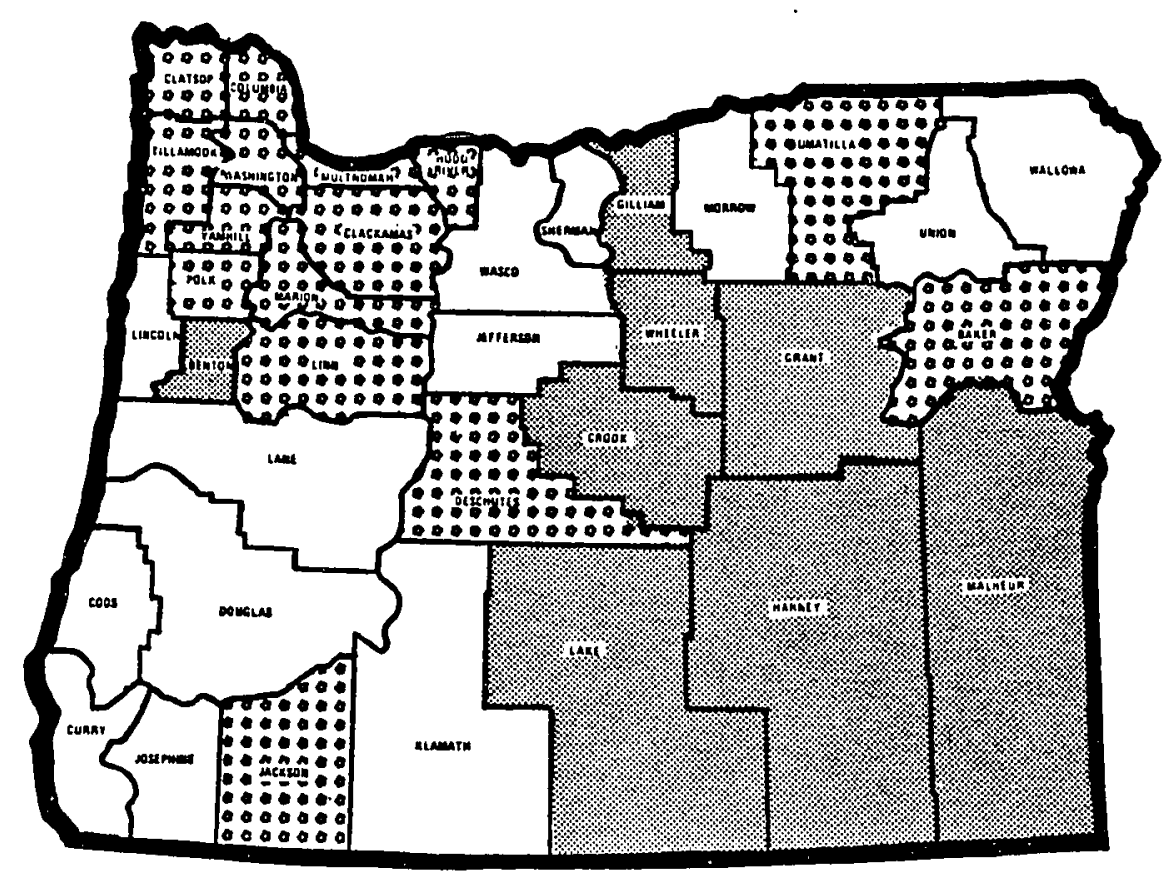

$\begin{array}{crc}\text { GROUP } & & \text { INDEX } \\ \text { I } & & \\ \text { II } & \square & 2.80-2.89 \\ \text { III } & 2.60-2.79 \\ & & 2.15-2.59\end{array}$

Figure 8. Oregon diversification indices. 
Jackson county, and the North Coast area. Oregon's major population and industrial concentrations are found in the Portland and Salem SMSA's, which contain Oregon's eight largest cities. This rapidly growing area is characterized by a diversified economy, a relative lack of dependence on wood products and related industries, and considerable federal, state, and local governmental activities.

The three highly diversified coastal counties (clatsop, Columbia, and Tillamook) lie roughly west to northwest of the Portland SMSA. The economy of many communities is in part dependent upon tourist-related activities. Livestock and dairy products are also important factors in the counties' economies. All three have food products activity. Most of the food industry is centered on seafood processing and canning. In summary, the highly diversified North Coast area is economically dependent on tourism, sport fishing, dairy products, fresh and processed seafood, and forest products (lumber and wood, paper and allied products). Another region of high diversification, the midColumbia area (Hood River, Wasco-Sherman) lies east to northeast of the Portland SMSA. All of the highly diversified counties rank among the top ten counties in per capita income. Their economy primarily relies on the harvesting and processing of fruit and lumber and wood products. Manufacturing has expanded to include not only 
food processing but aluminum reduction, knitted wear, and sporting goods.

Comparatively low diversification indices are to be found in central and eastern oregon. These counties contrast sharply with western oregon due to their higher elevation, greater temperature extremes, and shorter growing seasons. These counties are engaged mainly in the production of grain, potatoes, fruit, and hay crops. With seven of Oregon's national forests located east of the Cascade Mountains, eastern counties remain economically dependent on resource-oriented industries such as lumber and wood products. For example, in 1979 lumber and wood products accounted constituted 38.258 of the total employment in Crook county. In the case of Harney, Grant, and lake counties, the rates were $32.728,25.958$, and 20.688 , respectively.

Outlying areas of moderately high diversification are generally to be found elsewhere in Oregon. Most of the counties which are located in the midwestern and southwestern portion of the state are engaged mainly in agriculture and lumbering industries. This rapidly growing area, home of several universities and colleges, which contains two of Oregon's largest cities, is characterized by a moderately diversified economy, less dependence on wood products, considerable service and trade activities, and 
finally Oregon's largest and most important agricultural producing area.

Figure 9 displays frequency distributions (via a histogram) of the employment diversity indices of 32 counties of Oregon averaged for the period from 1972 through 1981. The scale of the horizontal axis is constructed from the average diversity indices of oregon counties over the ten-year period. County frequencies represent the vertical dimension. The height of each bar represents the class frequency.

During this period, 268 of Oregon's counties averaged diversity indices between 2.73 and 2.79. This interval contains the highest relative frequency, and the intervals tend to contain a smaller fraction of the counties as the the diversity indices get smaller and a larger fraction of the counties as the diversity indices get larger.

There are several explanations to be offered for this distribution of diversification. One important factor, as previously mentioned, is the existence of national forests which have usually resulted in local specialization in the resource-oriented industries of lumber and wood products. Another important factor is the nature of the principal transportation routes.

Portland, the transportation hub of Oregon, provides integrated highway, railroad, and airport facilities which 


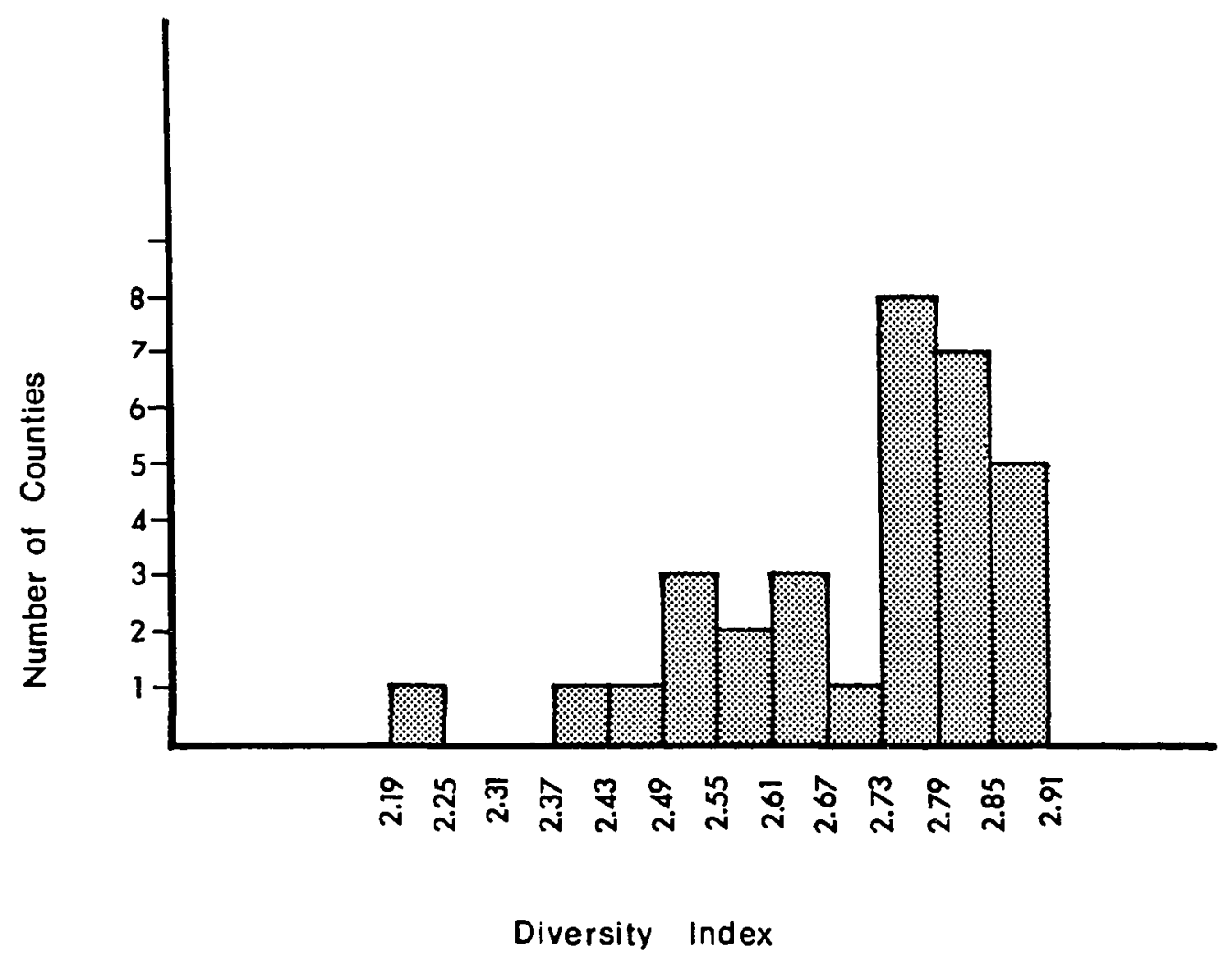

Figure 9. Histogram for diversity indices of oregon counties, averaged for the period 1972-1981. 
are linked to the largest exporting network on the west coast. From Figure 8 , it is clear that a high proportion of the areas having highly diversified local economies are situated on or near the coast, the Columbia River, or Portlana.

The Columbia River is a critical element in the regional economy of many counties in that it provides easy access to ocean transport. Hydroelectric generation provides a stable employment source, and the availability of abundant power is in itself an industrial asset. Over the past decade, many counties have enjoyed population growth and industrial development using the advantage afforded by the presence of the Columbia River and its benefits of water, power, and transportation.

The coastal counties have also exerted a special attraction to a wide range of economic activity, due in large part to their location. Most west coast communities lie within a few hours' driving time from Portland and from other major labor market areas. They are key elements in the development of tourist-related business in Oregon.

THE DIFFICULTY OF ACCURATELY MEASURING DIVERSITY

The range of diversity indices for oregon counties is significantly narrow (the lowest value being 2.19), despite the fact that many counties are known to be extremely 
dependent on the lumber industry (and, judging intuitively, extremely undiversified). Also, the calculated entropies may not reflect "true" diversity because the sectors for which employment data are tabulated are interdependent. The interdependence of the economic sectors used in tabulating employment data is apparent if one calculates the correlations between employments in different sectors. Extremely high positive correlations are observed, as shown in Table I.

Table I was constructed with "raw" employment figures in each sector. What goes into the calculation of diversity, however, is the set of fractional employment numbers. Table II gives the correlation between the set of fractional employment numbers, $P_{i}$ (i.e., the fraction of county employment in the different sectors). While some sectors are weakly correlated, others contain positive or neqative values.

The way in which the employment data is categorized might be the cause of the problem. Although a county may, in reality, be heavily dependent on the lumber and wood products industry, the employment which actually depends on this industry might be counted in other sectors (e.g., paper and allied products, transportation, etc.) rather than in durable goods. It would be most desirable if diversity (entropy) were calculated from sectors which were as nearly 
TABLE I

CORRELATIONS AMONG EMPLOYMENT IN DIFFERENT SECTORS

\begin{tabular}{|c|c|c|c|c|c|c|c|c|}
\hline & Durable & Ndurable & Const & Trans & Trade & Finance & Service & Govern \\
\hline Durable & $\begin{array}{l}1.0000 \\
(0.001)\end{array}$ & $\begin{array}{c}0.9559 \\
(0.001)\end{array}$ & $\begin{array}{c}0.9831 \\
(0.001)\end{array}$ & $\begin{array}{c}0.9832 \\
(0.001)\end{array}$ & $\begin{array}{c}0.9849 \\
(0.001)\end{array}$ & $\begin{array}{c}0.9774 \\
(0.001)\end{array}$ & $\begin{array}{c}0.9833 \\
(0.001)\end{array}$ & $\begin{array}{c}0.9618 \\
(0.001)\end{array}$ \\
\hline Ndurable & $\begin{array}{c}0.9559 \\
(0.001)\end{array}$ & $\begin{array}{l}1.0000 \\
(0.001)\end{array}$ & $\begin{array}{c}0.9795 \\
(0.001)\end{array}$ & $\begin{array}{c}0.9824 \\
(0.001)\end{array}$ & $\begin{array}{c}0.9801 \\
(0.001)\end{array}$ & $\begin{array}{c}0.9799 \\
(0.001)\end{array}$ & $\begin{array}{l}0.9808 \\
(0.001)\end{array}$ & $\begin{array}{c}0.9702 \\
(0.001)\end{array}$ \\
\hline Const & $\begin{array}{c}0.9831 \\
(0.001)\end{array}$ & $\begin{array}{c}0.9795 \\
(0.001)\end{array}$ & $\begin{array}{l}1.0000 \\
(0.001)\end{array}$ & $\begin{array}{c}0.9880 \\
(0.001)\end{array}$ & $\begin{array}{l}0.9939 \\
(0.001)\end{array}$ & $\begin{array}{l}0.9920 \\
(0.001)\end{array}$ & $\begin{array}{c}0.9927 \\
(0.001)\end{array}$ & $\begin{array}{c}0.9782 \\
(0.001)\end{array}$ \\
\hline Trans & $\begin{array}{c}0.9832 \\
(0.001)\end{array}$ & $\begin{array}{c}0.9824 \\
(0.001)\end{array}$ & $\begin{array}{c}0.9880 \\
(0.001)\end{array}$ & $\begin{array}{l}1.0000 \\
(0.001)\end{array}$ & $\begin{array}{c}0.9943 \\
(0.001)\end{array}$ & $\begin{array}{c}0.9924 \\
(0.001)\end{array}$ & $\begin{array}{c}0.9944 \\
(0.001)\end{array}$ & $\begin{array}{c}0.9631 \\
(0.001)\end{array}$ \\
\hline Trade & $\begin{array}{c}0.9849 \\
(0.001)\end{array}$ & $\begin{array}{c}0.9801 \\
(0.001)\end{array}$ & $\begin{array}{c}0.9939 \\
(0.001)\end{array}$ & $\begin{array}{c}0.9943 \\
(0.001)\end{array}$ & $\begin{array}{l}1.0000 \\
(0.001)\end{array}$ & $\begin{array}{c}0.9971 \\
(0.001)\end{array}$ & $\begin{array}{c}0.9996 \\
(0.001)\end{array}$ & $\begin{array}{c}0.9760 \\
(0.001)\end{array}$ \\
\hline Finance & $\begin{array}{c}0.9774 \\
(0.001)\end{array}$ & $\begin{array}{c}0.9799 \\
(0.001)\end{array}$ & $\begin{array}{c}0.9920 \\
(0.001)\end{array}$ & $\begin{array}{c}0.9924 \\
(0.001)\end{array}$ & $\begin{array}{c}0.9971 \\
(0.001)\end{array}$ & $\begin{array}{l}1.0000 \\
(0.001)\end{array}$ & $\begin{array}{c}0.9976 \\
(0.001)\end{array}$ & $\begin{array}{c}0.9671 \\
(0.001)\end{array}$ \\
\hline Service & $\begin{array}{c}0.9833 \\
(0.001)\end{array}$ & $\begin{array}{c}0.9808 \\
(0.001)\end{array}$ & $\begin{array}{c}0.9927 \\
(0.001)\end{array}$ & $\begin{array}{c}0.9944 \\
(0.001)\end{array}$ & $\begin{array}{c}0.9996 \\
(0.001)\end{array}$ & $\begin{array}{c}0.9976 \\
(0.001)\end{array}$ & $\begin{array}{l}1.0000 \\
(0.001)\end{array}$ & $\begin{array}{c}0.9755 \\
(0.001)\end{array}$ \\
\hline Govern & $\begin{array}{c}0.9618 \\
(0.001)\end{array}$ & $\begin{array}{c}0.9702 \\
(0.001)\end{array}$ & $\begin{array}{c}0.9782 \\
(0.001)\end{array}$ & $\begin{array}{l}0.9631 \\
(0.001)\end{array}$ & $\begin{array}{l}0.9760 \\
(0.001)\end{array}$ & $\begin{array}{c}0.9671 \\
(0.001)\end{array}$ & $\begin{array}{c}0.9755 \\
(0.001)\end{array}$ & $\begin{array}{l}1.0000 \\
(0.001)\end{array}$ \\
\hline
\end{tabular}

coefficient/(significance) 
TABLE II

CORRELATIONS AMONG FRACTIONAL EMPLOYMENT IN DIFFERENT SECTORS

\begin{tabular}{|c|c|c|c|c|c|c|c|c|}
\hline & Durable & Ndurable & Const & Trans & Trade & Einance & Service & Govern \\
\hline Durable & $\begin{array}{l}1.0000 \\
(0.001)\end{array}$ & $\begin{array}{c}-0.4360 \\
(0.001)\end{array}$ & $\begin{array}{c}-0.1619 \\
(0.005)\end{array}$ & $\begin{array}{l}-0.2914 \\
(0.001)\end{array}$ & $\begin{array}{l}-0.6607 \\
(0.001)\end{array}$ & $\begin{array}{l}-0.2587 \\
(0.001)\end{array}$ & $\begin{array}{l}-0.5296 \\
(0.001)\end{array}$ & $\begin{array}{l}-0.1559 \\
(0.006)\end{array}$ \\
\hline Ndurable & $\begin{array}{l}-0.4360 \\
(0.001)\end{array}$ & $\begin{array}{l}1.0000 \\
(0.001)\end{array}$ & $\begin{array}{l}0.3108 \\
(0.001)\end{array}$ & $\begin{array}{c}0.0210 \\
(0.369)\end{array}$ & $\begin{array}{c}0.2225 \\
(0.001)\end{array}$ & $\begin{array}{l}-0.0787 \\
(0.105)\end{array}$ & $\begin{array}{l}0.1780 \\
(0.002)\end{array}$ & $\begin{array}{l}-0.4382 \\
(0.001)\end{array}$ \\
\hline Const & $\begin{array}{l}-0.1619 \\
(0.005)\end{array}$ & $\begin{array}{l}0.3108 \\
(0.001)\end{array}$ & $\begin{array}{c}1.0000 \\
(0.001)\end{array}$ & $\begin{array}{c}0.0123 \\
(0.422)\end{array}$ & $\begin{array}{l}-0.1680 \\
(0.004)\end{array}$ & $\begin{array}{l}0.0310 \\
(0.311)\end{array}$ & $\begin{array}{l}-0.1489 \\
(0.009)\end{array}$ & $\begin{array}{l}-0.2795 \\
(0.001)\end{array}$ \\
\hline Trans & $\begin{array}{l}-0.2914 \\
(0.001)\end{array}$ & $\begin{array}{l}0.0210 \\
(0.369)\end{array}$ & $\begin{array}{c}0.0123 \\
(0.422)\end{array}$ & $\begin{array}{c}1.0000 \\
(0.001)\end{array}$ & $\begin{array}{l}0.3749 \\
(0.001)\end{array}$ & $\begin{array}{c}0.0742 \\
(0.118)\end{array}$ & $\begin{array}{c}0.2076 \\
(0.001)\end{array}$ & $\begin{array}{l}-0.2159 \\
(0.001)\end{array}$ \\
\hline Trade & $\begin{array}{l}-0.6607 \\
(0.001)\end{array}$ & $\begin{array}{l}0.2225 \\
(0.001)\end{array}$ & $\begin{array}{l}-0.1680 \\
(0.004)\end{array}$ & $\begin{array}{c}0.3749 \\
(0.001)\end{array}$ & $\begin{array}{l}1.0000 \\
(0.001)\end{array}$ & $\begin{array}{c}0.2366 \\
(0.001)\end{array}$ & $\begin{array}{c}0.5879 \\
(0.001)\end{array}$ & $\begin{array}{l}-0.2352 \\
(0.001)\end{array}$ \\
\hline Finance & $\begin{array}{c}-0.2587 \\
(0.001)\end{array}$ & $\begin{array}{l}-0.0787 \\
(0.105)\end{array}$ & $\begin{array}{l}3.0310 \\
(0.311)\end{array}$ & $\begin{array}{c}0.0742 \\
(0.118)\end{array}$ & $\begin{array}{c}0.2366 \\
(0.001)\end{array}$ & $\begin{array}{l}1.0000 \\
10.001\end{array}$ & $\begin{array}{c}0.2706 \\
(0.001)\end{array}$ & $\begin{array}{l}-0.1464 \\
(0.010)\end{array}$ \\
\hline Service & $\begin{array}{l}-0.5296 \\
(0.001)\end{array}$ & $\begin{array}{l}0.1780 \\
(0.002)\end{array}$ & $\begin{array}{l}-0.1489 \\
(0.009)\end{array}$ & $\begin{array}{c}0.2076 \\
(0.001)\end{array}$ & $\begin{array}{c}0.5879 \\
(0.001)\end{array}$ & $\begin{array}{c}0.2706 \\
(0.001)\end{array}$ & $\begin{array}{l}1.0000 \\
(0.001)\end{array}$ & $\begin{array}{c}-0.3153 \\
(0.001)\end{array}$ \\
\hline Govern & $\begin{array}{l}-0.1559 \\
(0.006)\end{array}$ & $\begin{array}{l}-0.4382 \\
(0.001)\end{array}$ & $\begin{array}{l}-0.2795 \\
(0.001)\end{array}$ & $\begin{array}{l}-0.2159 \\
(0.001)\end{array}$ & $\begin{array}{l}-0.2352 \\
(0.001)\end{array}$ & $\begin{array}{l}-0.1464 \\
(0.010)\end{array}$ & $\begin{array}{l}-0.3153 \\
(0.001)\end{array}$ & $\begin{array}{l}1.0000 \\
(0.001)\end{array}$ \\
\hline
\end{tabular}

coefficient/(significance) 
independent as possible. Though such an assumption might be tenable at the 3- or 4-digit Standard Industrial Classification (SIC) level, it cannot be held at the level used for this research, essentially the 1-digit SIC level. The question thus arises of whether such "orthogonal" sectors can be obtained, either from the official data by some mathematical transformation, or by seeking employment data which are initially less interdependent.

One possible approach to this task, namely factor analysis, has been explored with negative results. Factor analysis necessitates the conversion of fractional employment data into the form of standardized variables, and this form is incompatible with specific a priori constraints on the data, e.g., $\Sigma P=1$. A simpler method, that of aggregating strongly correlated sectors, has also proven to be ineffective.

\section{CHANGES OVER TIME IN DIVERSITY PATTERNS}

An important aspect of the problem of diversity concerns whether there is a tendency toward greater diversity as an area matures. As discussed earlier, oregon has reduced its reliance on traditional resource-oriented industries such as food and forest products. As the traditional bases of timber and agricultural products decline in relative importance, the high technology and 
metal processing sectors increase (see Chapter IV, Figure 4).

While there has been a significant movement away from dependence on the lumber and wood products industry, it has nonetheless continued to dominate the manufacturing sector. Lumber and wood products account for virtually the entire base in many of the state's counties. It was also noted (Chapter IV) that most of the economic transition in Oregon has been geographically concentrated in the metropolitan areas of Portland and Salem. Over $60 \%$ of the nonforest and food products employment is located there, with the balance of the state for the most part still subjected to the unpleasant side effects of slow-growing, highly seasonal, and cyclical industries.

To examine the changes in diversity over time, the diversity indices of employment data were calculated for Oregon for the ten-year study period. The results are shown in Table III. There is some evidence in these results of a slight trend toward greater industry concentration in the overall Oregon economy.

This single-unit total entropy measure does not, however, identify interindustry diversification or concentration patterns and structural changes occurring within the entire economy. The entropy measure can be disaggregated into its between-set and within-set elements 
to express the extent and pattern of dispersal between and within different groups and subsets of industries. the results of this disaggregation analysis are presented in the next section.

TABLE III

EMPLOYMENT DIVERSIFICATION INDICES FOR OREGON, 1972-1981

Year

1972

1973

1974

1975

1976

1977

1978

1979

1980

1981
Diversity Index

2.9327

2.9298

2.9172

2.8940

2.8830

2.8886

2.8844

2.8899

2.8770

2.8619

EXTENT AND PATTERN OF DIVERSIFICATION BETWEEN AND WITHIN INDUSTRIES

Chapter III discussed the decomposition properties of entropy in analyzing the nature and extent of dispersal of economic diversity between and within different groups of counties or subsets of industries. Consider combining the 9 economic sectors of oregon into 2 separate groups or sets: $\mathrm{S}_{\mathrm{g}}(\mathrm{g}=1,2) \cdot \mathrm{S}_{1}$ is defined as manufacturing (durable and 
nondurable goods) and $\mathrm{S}_{2}$ as nonmanufacturing (the remaining seven sectors).

The disaggregation of entropy for the above 2 groups is carried out (using equations 2 through 5 from Chapter III), and the results are presented in Table IV, columns (2) through (7). The aggregated employment diversification indices initially presented in Table III are shown again in column (8). Table IV enables a comparison of manufacturing and nonmanufacturing sets as to the nature of their economic dispersal over time.

The within-set component of the entropy measures for the manufacturing and nonmanufacturing groups produced from applying equation (2) (Chapter III) is presented in columns (2) and (3) respectively. The within-set measure represents the application of the entropy measure to two industry groups treated independently. There is no evidence in column (2) of any trend revealed by the within-set entropy of the manufacturing set. However, columm 3 suggests possible evidence of a trend toward increasing concentration within the nonmanufacturing set.

The weighted within-set entropy measures of the two groups appearing in columns (4) and (5) reflect each group's contribution to the degree of economic diversification within the total economy. In applying equation 4 , the weighted within-set measures for the two groups are summed 
TABLE IV

A DISAGGREGATED ENTROPY MEASURE OF EMPLOYMENT DIVERSITY OREGON, 1972-1981

\begin{tabular}{|c|c|c|c|c|c|c|c|}
\hline Year & $\begin{array}{l}\text { Within-set } \\
\text { Entropy } \\
\text { Mfg } \\
\end{array}$ & $\begin{array}{l}\text { Within-Set } \\
\text { Entropy } \\
\text { Nonmfg } \\
\end{array}$ & $\begin{array}{c}\text { Weighted } \\
\text { within-Set } \\
\text { Entropy } \\
\text { Mfg } \\
\end{array}$ & $\begin{array}{l}\text { Weighted } \\
\text { Within-Set } \\
\text { Entropy } \\
\text { Nonmfg } \\
\end{array}$ & $\begin{array}{c}\text { Total } \\
\text { Weighted } \\
\text { Within-Set } \\
\text { Entropy } \\
\end{array}$ & $\begin{array}{c}\text { Between- } \\
\text { Set } \\
\text { Entropy } \\
\end{array}$ & $\begin{array}{c}\text { Total } \\
\text { Entropy }\end{array}$ \\
\hline (1) & (2) & (3) & (4) & (5) & (6) & (7) & (8) \\
\hline 1972 & .9309 & 2.5257 & .2048 & 1.9700 & 2.1748 & .7579 & 2.9327 \\
\hline 1973 & .8268 & 2.5235 & .2078 & 1.9431 & 2.1508 & .7780 & 2.9289 \\
\hline 1974 & .8268 & 2.5257 & .1949 & 1.9443 & 2.1392 & .7780 & 2.9172 \\
\hline 1975 & .9309 & 2.4654 & .1949 & 1.9483 & 2.1432 & .7508 & 2.8990 \\
\hline 1976 & .8267 & 2.4830 & .1736 & 1.9616 & 2.1352 & .7478 & 2.8830 \\
\hline 1977 & .8268 & 2.5045 & .1685 & 1.9786 & 2.1471 & .7415 & 2.8886 \\
\hline 1978 & .8113 & 2.4874 & .1704 & 1.9651 & 2.1355 & .7489 & 2.8844 \\
\hline 1979 & .8235 & 1.3830 & .1647 & 1.9872 & 2.1519 & .7380 & 2.8899 \\
\hline 1980 & .8468 & 2.4698 & .1694 & 1.9759 & 2.1453 & .7317 & 2.8770 \\
\hline 1981 & .9389 & 2.4346 & .1784 & 1.9720 & 2.1504 & .7115 & 2.8619 \\
\hline
\end{tabular}


to yield the total weighted within-set entropy measure shown in column (6). There is no evidence of any trend revealed by the total weighted within-set entropy measure.

The between-set entropy measure which results from applying equation (3) (Chapter III) is presented in column (7). The between-set measure merely identifies the extent to which Oregon's employment is distributed equally between the manufacturing and nonmanufacturing sets. There is some possible evidence of a trend towards greater between-set concentration over the ten-year period.

In 1972, the percentage employment shares of manufacturing and nonmanufacturing were about $23 \%$ and 778 , respectively. During the rest of the 1970 's, nonmanufacturing percentage shares generally increased to 798, and in 1981 they stood at 818. Because the nonmanufacturing group's percentage share initially was considerably higher than 50 o (comparative norm), the increase in the group's percentage share over the ten-year period accounts for the decrease in between-set entropy, i.e., the greater concentration of the oregon economy in one of the two aggregated sets. By comparison, the within-set entropy shows no clear trend. Thus, a concentration appears to have occurred more between the industry groups than within them.

The total weighted within-set measure is added to the 
between-set measure to yield the total entropy measure as formulated by equation (5). (This is the same as the aggregated entropy measure of industry diversification initially presented in Table III.)

As discussed earlier, there is some possible evidence in column (3) of a trend toward increasing industry concentration within the nonmanufacturing group. The consequence of increasing between-set concentration toward nonmanufacturing and away from manufacturing, then, could be greater concentration and less diversification in the total economy. This finding may lend the perspective to interpreting the structural changes (concentration) occuring within the entire Oregon economy.

The results illustrate the manner in which the entropy measure can be decomposed to allow for identification of some important inter-industry diversification patterns which may not be at all apparent merely from examining the singleunit total entropy measure of diversity.

It should be pointed out that the degree of aggregation used in the computation of wtihin and between entropy influences the results. For example, using two sectors (durable and nondurable goods), there is no evidence of any trend revealed by the within-set entropy of the manufacturing set (see column 2). However, when manufacturing is divided into six sectors as shown in Figure 
4, the within-set manufacturing entropy increases from 2.26 in 1972 to 2.39 in 1981 , indicating a possible trend within the manufacturing set.

FACTORS ASSOCIATED WITH DIVERSITY (HYPOTHESES 1 AND 2)

Unemployment

Unemployment is a factor which is often believed to have a negative association with diversity (National Resource Planning Board, 1937: 62). One of the objectives of this study, as indicated earlier, is to test the hypothesis that there is a statistically significant negative relationship between diversification and unemployment. To assess this association statistically, the diversity indices of the 32 counties of Oregon for the years 1972 to 1981 were correlated with their corresponding unemployment rates (unemployment as a percent of labor force).

Table V shows the calculated Pearson Product Moment Correlation Coefficient (above the Iine) and the level of significance for the one-tailed test (below the line). It is noted that the calculated correlation coefficients for employment diversity measures and unemployment rates are statistically significant for 3 years, where expected negative associations are observed.

The data for the ten-year period were then aggregated. Figure 10 is a bivariate graph of unemployment vs. diversity 
TABLE V

CORRELATION COEFFICIENT OF DIVERSITY WITH UNEMPLOYMENT FOR OREGON COUNTIES, 1972-1981

\begin{tabular}{|c|c|c|c|c|c|c|c|c|c|}
\hline 1972 & 1973 & 1974 & 1975 & 1976 & 1977 & 1978 & 1979 & 1980 & 1981 \\
\hline$-.38^{\star}$ & -.08 & -.09 & -.11 & -.16 & -.11 & $-.31^{\star}$ & $-.42^{*}$ & -.20 & -.10 \\
\hline$(.02)$ & $(.32)$ & $(.31)$ & $(.27)$ & $(.18)$ & $(.18)$ & $(.04)$ & $(.008)$ & $(.14)$ & $(.29)$ \\
\hline
\end{tabular}

* significant correlation at .05 level 


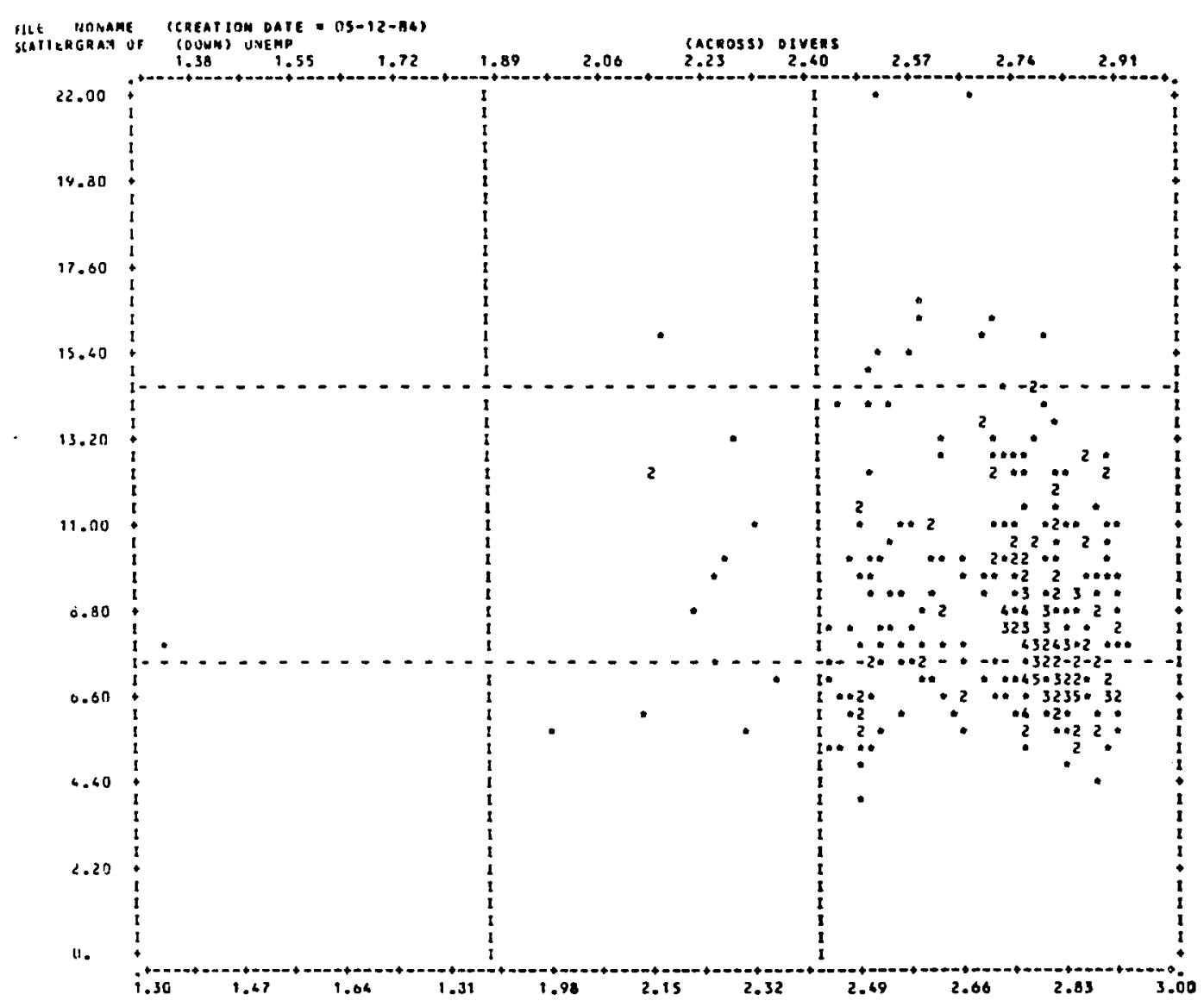

Figure 10. Unemployment vs. diversity, 1972-1981, Oregon. 
for this period. The pattern indicates little association between the variables; even a close visual perusal does not yield evidence of an apparent correlation. Computer analysis of this graph produced a Pearson Product Moment Correlation Coefficient of $-.09(\mathrm{R}=.008)$, indicating a very weak negative correlation between diversity and unemployment. The slope of the regression line was $\mathrm{b}_{\mathrm{m}}=$ -1.30, and the intercept was $b_{I}=12.41$. The empiricallyderived level of significance was calculated to be .05792 . At the .05 level of significance, the null hypothesis (i.e., that there is no correlation between the two variables, diversity and unemployment) cannot be rejected. If, however, type I errors (rejecting a true hypothesis) of more than .057928 are accepted, the null hypothesis could be rejected at a level of significance greater than .05792 . This would allow acceptance of the alternate hypothesis which says that there is a statistically-significant but extremely weak negative correlation between the diversity indices and percent unemployment.

\section{Per Capita Income}

Another hypothesis tested was the existence of a positive correlation between diversity and per capita income for the same 10-year period. To assess this association statistically, the diversity indices of the 32 counties of 
Oregon were correlated with their corresponding per capita income (logarithm of per capita income in constant dollars, i.e., $1967=100$ ). In Table VI, the calculated correlation coefficient (above the line) and the level of significance for the one-tailed test (below the line) are shown.

It is evident from this table that there are positive correlations between employment diversities and logarithms of real per capita income for the four years where correlations are statistically significant.

The data for the ten-year period were then aggregated. Figure 11 is a bivariate graph of the effects of per capita income vs. diversity for the above study period. The pattern indicates little association between the variables. Computer analysis of this graph produced a correlation 2 coefficient of $+.18(r=.03)$, indicating a weak degree of positive correlation between diversity and per capita income. The slope of the regression 1 ine was $b_{0}=.13$, and the intercept was $b_{1}=7.80$. The calculated level of significance was .0007 , which is less than the .05 established criterion; thus, the null hypothesis may be rejected. There is, then, a statistically significant, but very weak degree of positive correlation between diversity indices and real per capita income. Despite the apparent random pattern of this graph, the null hypothesis could also have been rejected with a more stringent level of 
TABLE VI

CORRELATION COEFFICIENTS OF DIVERSITY WITH LOGARITHMS OF REAL PER CAPITA INCOME FOR THE COUNTIES OF OREGON,

$$
1972-1981
$$

\begin{tabular}{|c|c|c|c|c|c|c|c|c|c|}
\hline 1972 & 1973 & 1974 & 1975 & 1976 & 1977 & 1978 & 1979 & 1980 & 1981 \\
\hline .29 & .002 & .09 & .16 & $.34^{\star}$ & $.56^{*}$ & $.43^{\star}$ & $.48^{*}$ & .11 & .26 \\
\hline$(.06)$ & $(.50)$ & $(.32)$ & $(.19)$ & $(.03)$ & $(.0005)$ & $(.007)$ & $(.003)$ & $(.28)$ & $(.07)$ \\
\hline
\end{tabular}

* significant correlation at .05 level 


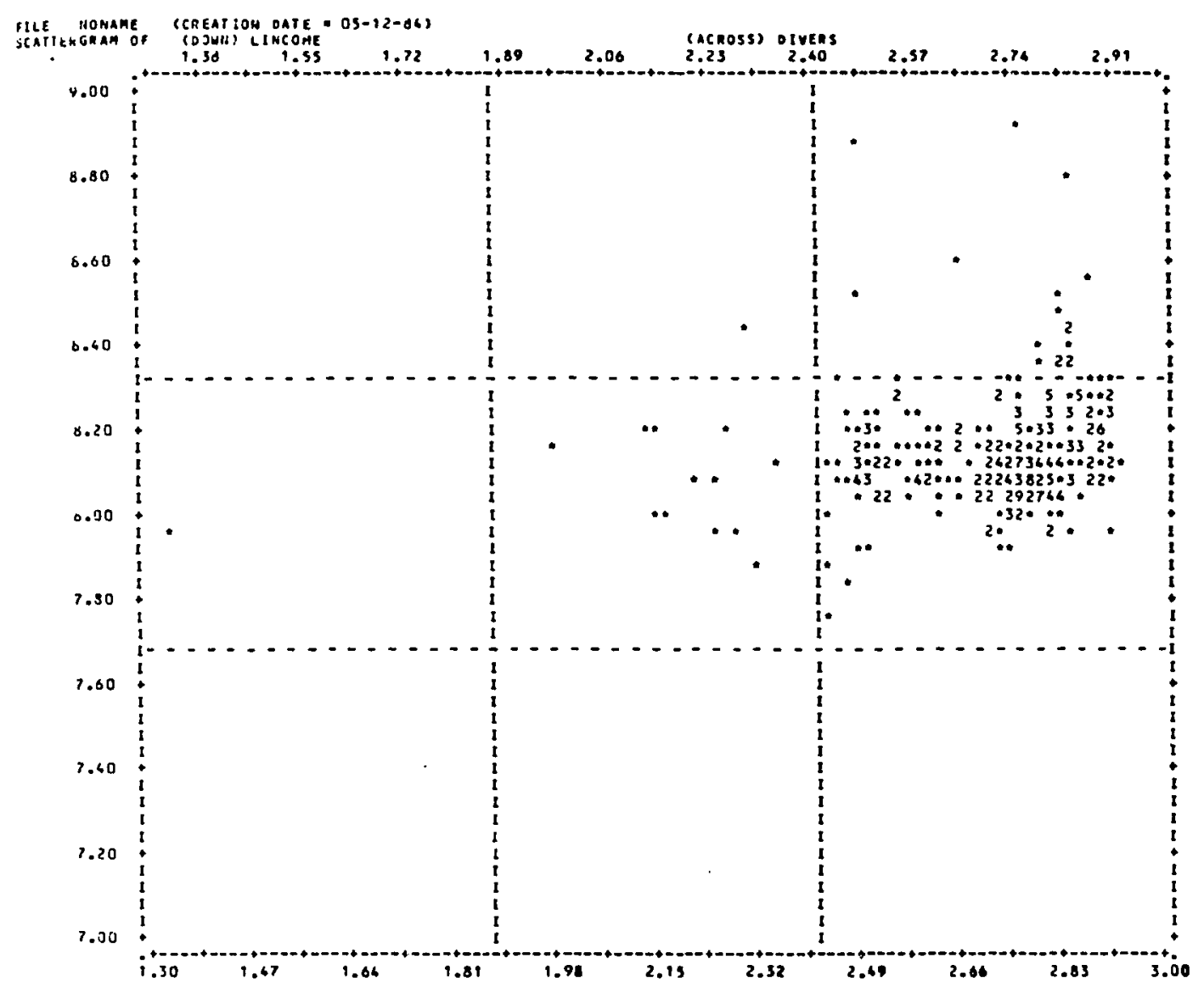

Figure 11. Per capita income vs. diversity, 1972-1981, oregon. 
significance such as .01 .

THE EFFECT OF RECESSION ON THE STRENGTH OF RELATIONS

As a supplementary test of the relationship between diversity indices and unemployment, the period of study was divided into recession and nonrecession years. During this period, Oregon experienced recessions in 1974-1975 and again in 1980-1981. (Chapter IV gives a detailed review of Oregon's economy during the study period.) The Pearson Product Moment Correlation Coefficient was calculated for the recession period and for the remaining years. The results were then correlated with unemployment and real per capita income for the above two periods.

\section{The Recession Years}

Unemployment. Many of Oregon's counties were severely affected by the recession and its aftermath. Figure 12

presents a bivariate graph of unemployment vs. diversity for the 4-year recessionary period. The pattern suggests little association between the variables. A computer analysis of the graph produced a correlation coefficient of $\left(r=-.06, r^{2}=.004\right)$, i.e., a very weak negative correlation between diversity and unemployment. However, the calculated level of significance was .25 (which is greater than the established criterion of .05); thus, the null hypothesis that there is no correlation between the two 


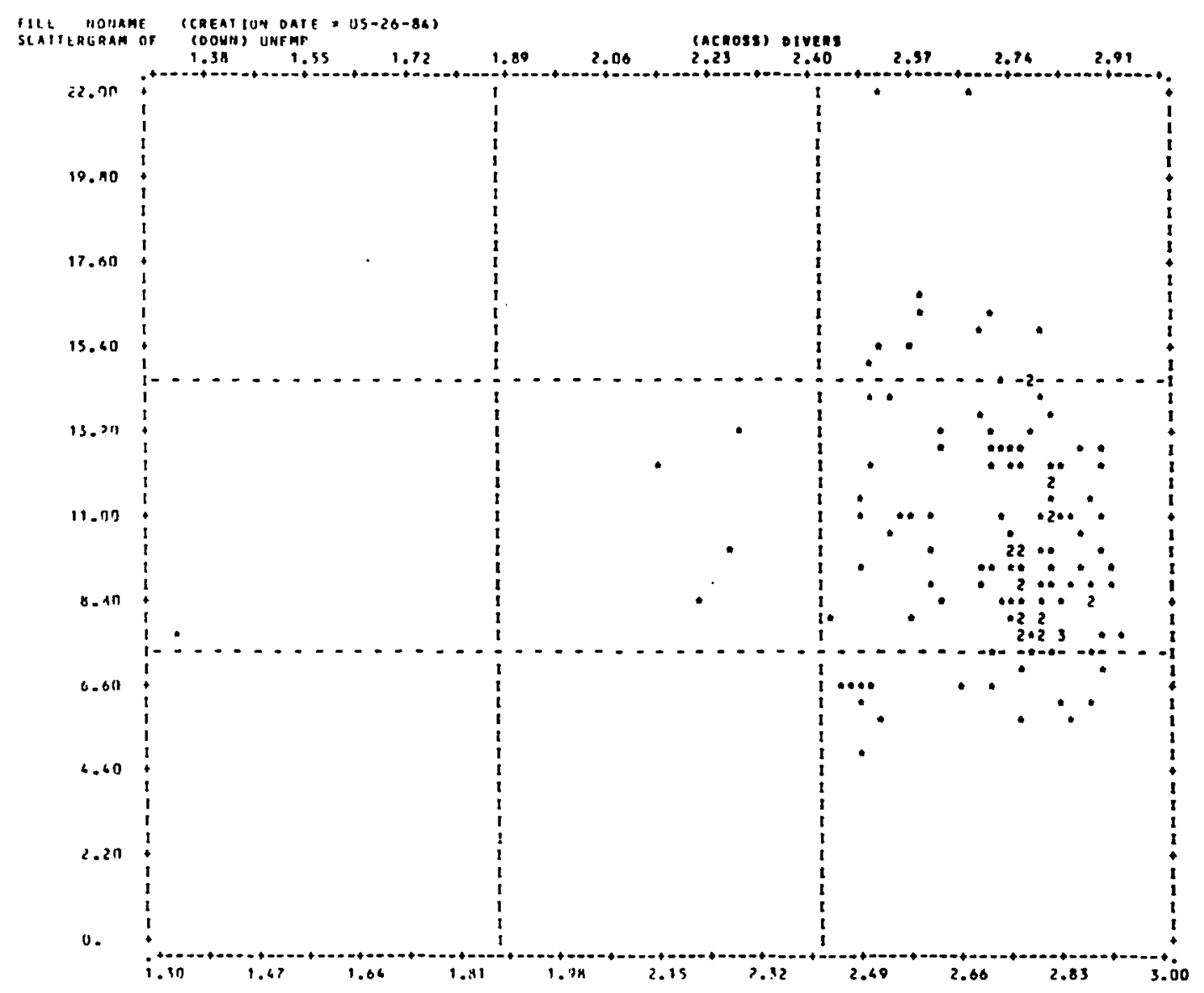

Figure 12. Unemployment vs. diversity, recessionary years, Oregon. 
variables cannot be rejected.

Per Capita Income. Figure 13 presents a bivariate graph of the logarithm of real per capita income vs. diversity for the 4-year recessionary period. The resultant curve appears to suggest visually a positive correlation between the two variables. The correlation coefficient found for this bivariate relationship was $(r=.10, r$ $=.01)$, indicating a very weak positive correlation between diversity and per capita income. The empirically-derived level of significance was calculated to be .13 , which is higher than the .05 level of significance. Thus, the null hypothesis again cannot be rejected.

\section{The Nonrecession Years}

Unemployment. Figure 14 presents a bivariate graph of unemployment vs. diversity. The pattern indicates little association between the variables. The calculated correlation coefficient found for this bivariate relationship was -.12 , which demonstrates a higher degree of correlation than was found for the recession years. The empirically-derived level of significance was calculated to be .043 , which is less than the .05 established criterion, thus allowing the null hypothesis to be rejected.

Per Capita Income. Figure 15 presents a bivariate graph of the logarithm of real per capita income vs. 


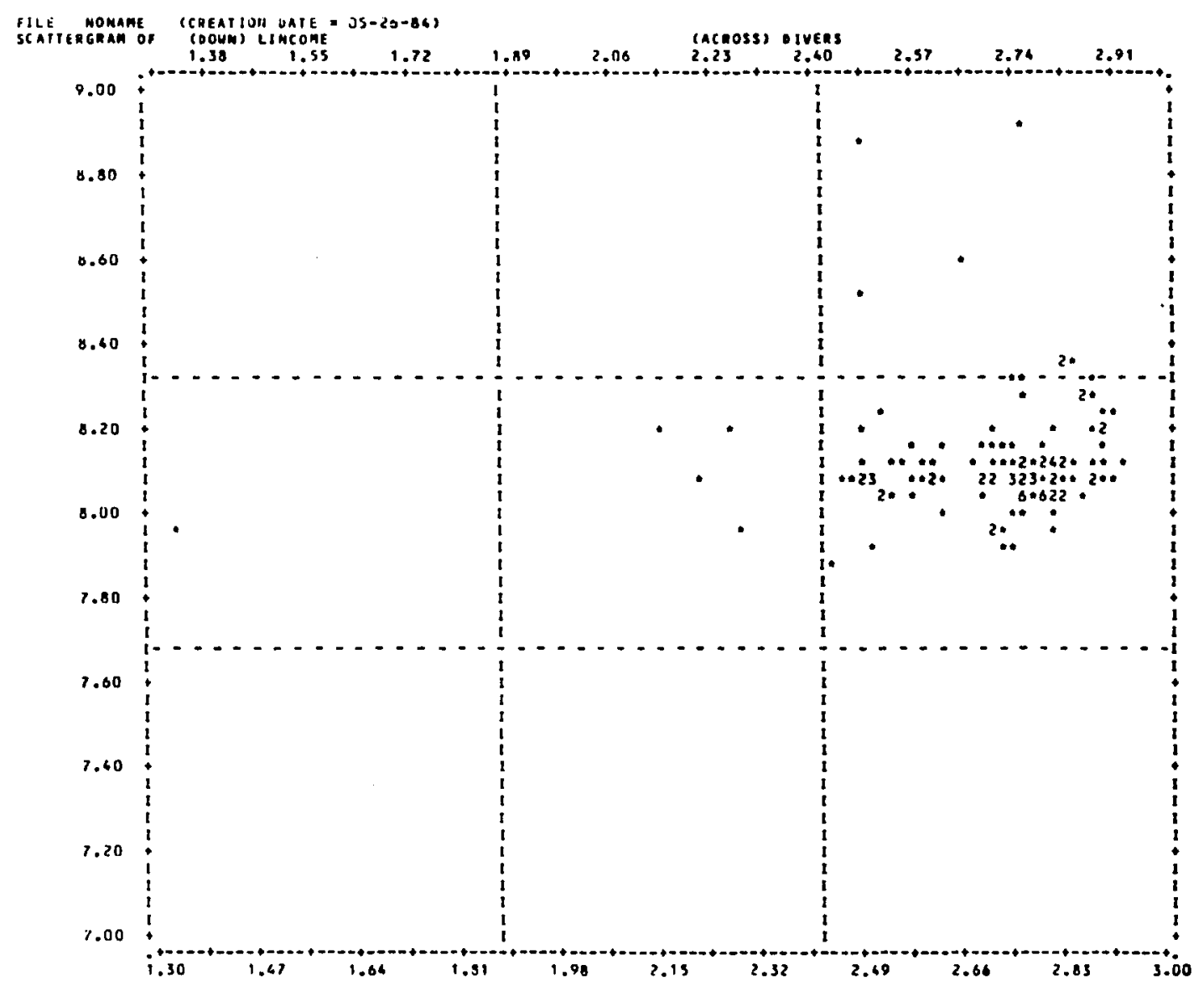

Figure 13. Per capita income vs. diversity, recessionary years, Oregon. 


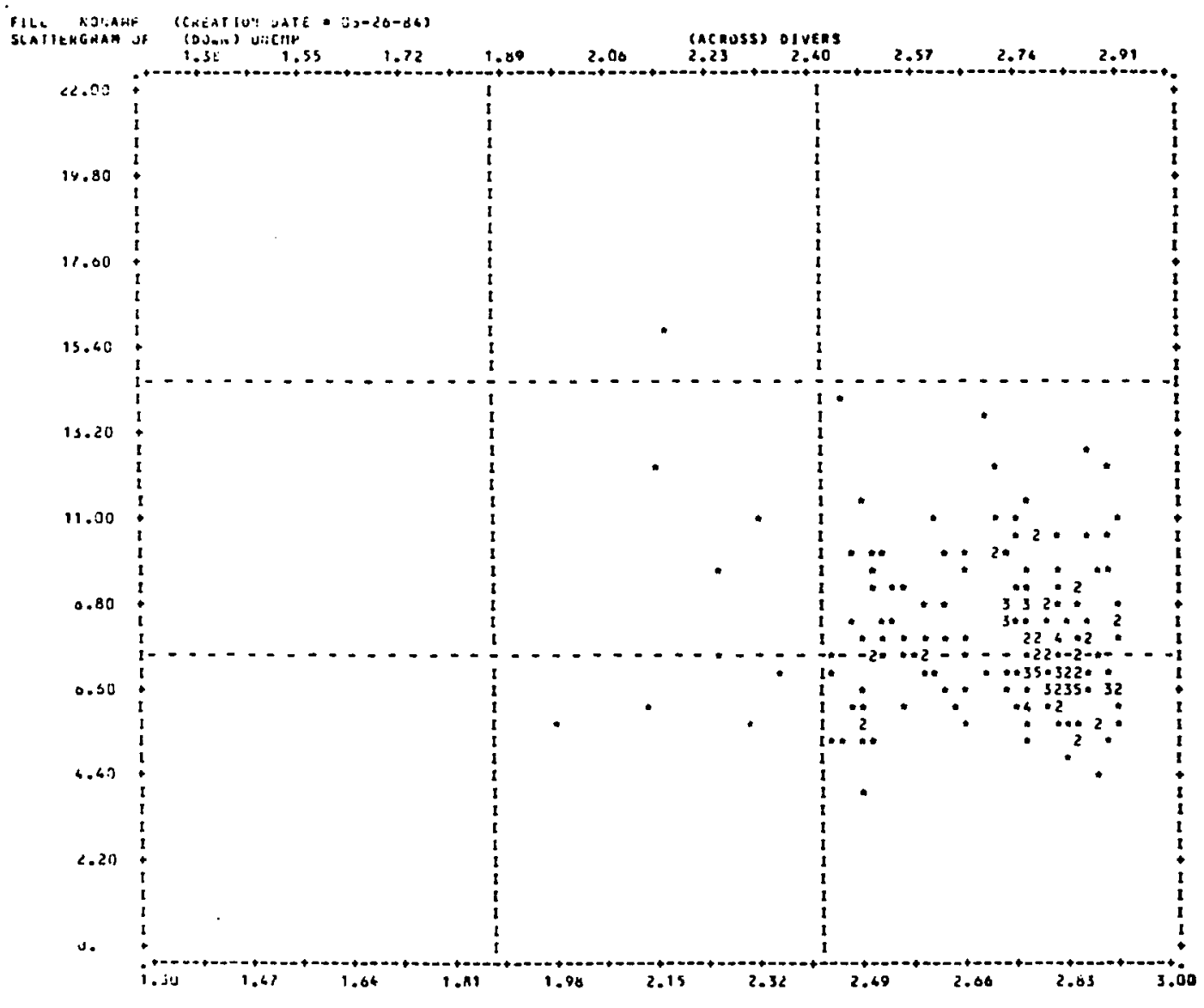

Figure 14. Unemployment vs. diversity, nonrecessionary years, Oregon. 


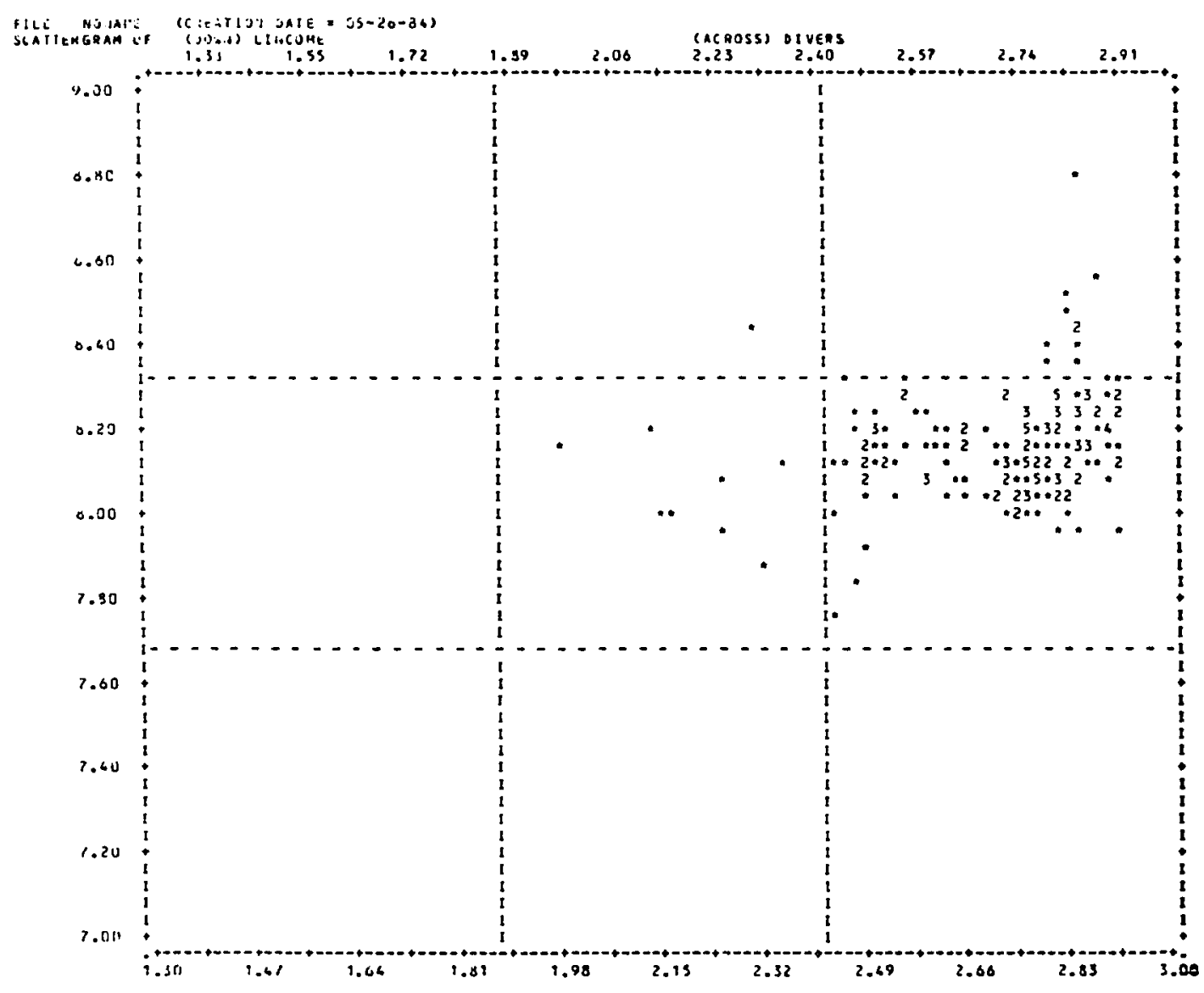

Figure 15. Per capita income vs. diversity, nonrecessionary years, Oregon. 
diversity. The resultant curve appears to suggest visually a positive correlation between the two variables. Computer analysis of this graph produced a correlation coefficient of .25, which again demonstrates a higher degree of correlation than was found for the recession years.

The calculated level of significance for the above correlation coefficient was .0003 . On this basis, the null hypothesis can be rejected. It also could have been rejected even if a more stringent measure, such as .01 , had been used.

Summary Tests of Hypotheses 1 and 2

A summary of statistical tests for the two hypotheses are presented in Table VII. This format should facilitate a comparison of the results and highlights the relative values found for the two hypotheses for different periods. In each category, four values are being reported: correlation coefficient, slope and intercept of the regression line, and the percent of change in unemployment or per capita income which would in particular be associated with a change in diversity from the calculated minimum average diversity (i.e., 2.1 for wheeler county) to maximum diversity. This may be calculated by:

$\&$ change $-\frac{m\left(D_{\max }-2.1\right)}{I}=\frac{m(3.2-2.1)}{I}=\frac{1.1 \mathrm{~m}}{I}$ 
TABLE VII

SUMMARY OF HYPOTHESES 1 AND 2: LEVEL STUDIES FOR RECESSION NONRECESSION, AND TOTAL STUDY PERIOD

\begin{tabular}{|c|c|c|c|}
\hline & & Unemployment & $\begin{array}{l}\text { Per Capita } \\
\text { Income }\end{array}$ \\
\hline $\begin{array}{l}\text { Recession years } \\
1974 / 75,1980 / 81\end{array}$ & $\begin{array}{l}\text { Correlation Coefficient } \\
\text { Slope } \\
\text { Intercept } \\
\text { \& Change }\end{array}$ & $\begin{array}{c}-.06(.24833) \\
\star \star \\
\star \star \\
\star \star\end{array}$ & $\begin{array}{c}.10(.13372) \\
\star \star \\
\star \star \\
\star \star\end{array}$ \\
\hline $\begin{array}{l}\text { Nonrecession years } \\
1972 / 73,1976 / 79\end{array}$ & $\begin{array}{l}\text { Correlation Coefficient } \\
\text { Slope } \\
\text { Intercept } \\
8 \text { Change }\end{array}$ & $\begin{array}{l}-.12(.04275)^{\star} \\
-1.35066 \\
11.52416 \\
12.89\end{array}$ & $\begin{array}{l}.25(.00030) \\
.17650 \\
7.67890 \\
2.53\end{array}$ \\
\hline $\begin{array}{l}\text { Total Study Period } \\
1972-1981\end{array}$ & $\begin{array}{l}\text { Correlation Coefficient } \\
\text { Slope } \\
\text { Intercept } \\
\& \text { Change }\end{array}$ & $\begin{array}{c}-.09(.05792) \\
\star \star \\
\star \star \\
\star \star\end{array}$ & $\begin{array}{l}.18(.00068)^{\star} \\
.13118 \\
7.78749 \\
1.85\end{array}$ \\
\hline
\end{tabular}

^ Significant at .05 level

** No information on regression lines are reported for nonsignificant correlations 
where $m$ and $I$ are slope and intercept, respectively, of the regression line. For the nonrecession years, for example, the slope and intercept of the regression equation which estimates the relationship between diversity and unemployment are $\mathrm{m}=-1.35066$ and $\mathrm{I}=11.52416$, respectively. The percent of change in unemployment associated with a change in diversity given by this equation is -.3725 , which indicates that, if the diversity index had changed from minimum diversity (in which the economic activity of a region is concentrated in only one sectorl to maximum diversity (in which all sectors contribute equally to the region's employment), the regression line would yield an associated 37.58 decrease in total regional unemployment The information contained in Table VI suggests a major difference in the strength of relationship between the pair of variables during the different periods. The following summarizes the results: (1) The direction of the correlations for each of the two hypotheses for three periods does agree with the hypothesized direction of correlation; i.e., diversity is negatively correlated with unemployment and positively correlated with income. (2) For the ten-year study period, the null hypothesis could be rejected if a type I error of slightly more than .05792 were risked. (3) The statistical test did not allow the two null hypotheses to be rejected at the .05 level of significance 
for the recession years. (4) The correlation coefficient for diversity and unemployment and/or between diversity and per capita income, when measured for the nonrecession years, was higher and more statistically significant than when measured for the other two periods. (5) As discussed in Chapter IV, the recession of the 1970's has definitely increased structural unemployment in oregon since many jobs in the construction, lumber and wood, and food industries disappeared permanently as a result of that recession. If structural unemployment accounts for a major portion of Oregon's unemployment figures in periods of generally good economic conditions, then diversification correlates more strongly with variation in this type of employment. Diversity accounts for more of the variation in the level of per capita income than in the level of unemployment (correlation coefficients are higher). (7) But to the degree that diversity is associated with unemployment and per capita income, differences in diversity are associated with greater differences in unemployment li.e., percent of changes are higher).

The calculations contained in Table VII suggest that there is a statistically significant but extremely weak relationship between the level of economic diversity and the rate of unemployment and per capita income. This finding is intriguing since it appears to contradict conventional 
assumptions about the relationship between diversity and economic performance. As discussed earlier, the range of diversity for oregon counties is narrow. The calculated entropy values may not accurately reflect real economic diversity, which may explain the very weak correlations found between the level of diversity and the rate of unemployment and per capita income.

Another explanation for the weak results might be the nature of the economy during the 1970's. The 1970's witnessed a turnaround in the previously sluggish performance of the Oregon economy. Housing prices were rising rapidly, and the real cost of home ownership was decreasing nationwide. The resulting activity in housing construction led to an increase in the work force in Oregon. Also, the dramatic decline in the value of the dollar made agricultural commodities favorable for export to foreign countries. These two factors benefitted states such as Oregon, which are dependent on lumber and agriculture. This may account for the weak relationships which have been found. The only other empirical analysis available to date which tests indices of industrial diversification of Oregon counties against unemployment rates is that of ElHimus (1982). Using a new measure of diversification, LID, he calculated a correlation coefficient of $-.528\left(r^{2}=.279\right)$ between diversity indices of 36 counties of oregon and their 
corresponding unemployment rates for 1980. For the same year, this study found the correlation coefficient of -.205 2 $(r=.042)$ between the above two variables. However, the correlation coefficient was statistically insignificant at the .05 level. El-Himus was not as successful in his longitudinal study which measured strength of the relationship between diversity and unemployment rates of Morrow and Harney counties for a six-year period from 1975 to 1980. The relationships proved to be statistically insignificant at the .05 level. His conclusion appears to support that of this study with respect to negative but weak correlations between economic diversification an unemployment rates, as discussed in Chapter II.

\section{DIVERSITY, GROWTH AND CYCLICAL INSTABILITY}

It was noted earlier (Chapter I) that diversification is perceived as a strategy for enabling an economy to be less vulnerable to cyclical instability. Specifically, the stabilization of employment and income through compensation of seasonal and cyclical fluctuations has been suggested as an economic advantage of diversification (Hoover, 1948: 285) .

One of the objectives of this study, as indicated earlier, is to test several hypotheses regarding the relationship between diversity and indicators of economic 
growth and stability. In this section, research findings of these analyses will be discussed.

Levels and Rate of Growth (Hypotheses 1-4)

As a supplementary test of the relationship between diversification and unemployment and real per capita income (Hypotheses 1 and 2), the mean of diversity indices over the ten-year study period of each of the 32 counties were correlated with the corresponding ten-year means of unemployment and real per capita income for these counties. The resulting correlation coefficient, derived levels of significance, slopes and intercepts of the regression lines, and the calculated percent changes are shown in Table VIII. Columns (1) and (2) are closely related to the results presented in Table VII and bear on Hypotheses 1 and 2; columns (3) and (4) present the findings for Hypotheses 3 and 4 .

The relationship between mean diversity and mean unemployment proved to be statistically insignificant at the .05 level. However, there was a significant but weak degree of positive correlation between mean diversity and mean per capita income for the period of study. The results support the previously-stated findings regarding the strength of relationship between diversity and level of employment and per capita income.

This support is, of course, expected. The earlier 
TABLE VIII

CORRELATION RESULTS OF DIVERSITY AND LEVEL AND RATE OF GROWTH FOR OREGON COUNTIES, 1972-1981

Correlation with Levels

(1)

$\begin{array}{cc}\begin{array}{c}\text { Mean } \\ \text { Unemployment }\end{array} & \begin{array}{c}\text { Mean Per } \\ \text { Capita Income }\end{array} \\ -.16071(.1979) & .23311(.04976)^{*} \\ * & .38514 \\ \star * & -.42628 \\ \star \star & * \quad * \quad *\end{array}$

$\begin{array}{cc}\text { Correlation with Rates of Growth } \\ \begin{array}{c}\text { (3) } \\ \begin{array}{c}\text { Slope of } \\ \text { Unemployment Trend }\end{array}\end{array} \\ \begin{array}{c}\text { Slope of Per } \\ \text { Capita Trend }\end{array} \\ -.25959(.04962)^{*} & .36261(.0269)^{*} \\ -.12722 & 4.74151 \\ 2.74463 & 2.68926 \\ 5.10 & 193.94\end{array}$

* Significant at .05 level

** No information on regression lines is reported for nonsignificant correlations

*** change is only calculated for cases where intercept is greater than zero 
calculation was based on actual diversity indices and unemployment and per capita income figures for each county and every year. In the second case, average diversity indices were correlated with average unemployment and per capita income. Variables in both cases are level-type variables; one is actual level, and the other is average level over time.

Regarding growth rates, two hypotheses were tested: (1) the expectation of a negative correlation between diversity and the rate of growth of unemployment, and (2) the anticipation of a positive correlation between diversity and rate of growth of per capita income. Using the leastsquares method, trend lines (i.e., estimated unemployment or per capita income expressed as a function of time) were derived for each of the 32 counties of oregon over the 10year study period. The slopes of these trend lines were then correlated with the mean indices of diversity for the counties. These results are also shown in Table VIII. The calculated correlation coefficients indicate a significant but weak degree of negative correlation between mean diversities of the counties and slopes of their unemployment trend lines and a significant, moderate degree of positive correlation between mean diversity and slopes of per capita income trend lines. The results support the hypotheses that diversity is associated with lower rates of 
growth of unemployment and higher rates of growth of real per capita income for the counties of oregon during the 10year period.

It is also noted that the calculated percent of change for per capita income is higher than the percent of change for unemployment. This means that to the degree that diversity is associated with growth in unemployment and per capita income levels, the differences in diversity are associated with greater differences in the growth rate of per capita income than of unemployment.

Cyclical Fluctuations (Hypotheses 5-8)

Fluctuations in the general level of economic activity over periods of several months to several years may be described as medium-term instability or cyclical instability. The term "cyclical" instability has also been used by Thompson (1956) to refer to "a more or less regular oscillation of business activity about a growth trend . . " (Thompson, 1956: 160).

One of the objectives of this study, as indicated earlier, is to test the hypotheses (5 and 6 ) that there is a negative correlation between diversity and cyclical fluctuation of the unemployment level and between diversity and cyclical fluctuation of the level of per capita income. To assess this relationship empirically over the years 1972 to 1981 , the mean of diversity indices of the 
32 counties of oregon were correlated with the corresponding standard deviations of unemployment and real per capita income of these counties.

The results are shown in Table IX. The calculated level of significance for the two correlation coefficients (columns 1 and 2 ) was below the .05 established criterion, thus allowing the null hypothesis to be rejected. These empirical results favor the initial assumption that diversity stabilizes levels of employment and income through compensation of cyclical fluctuations. It is also noted that to the degree that diversity is associated with stability of unemployment levels and per capita income levels, differences in diversity are associated with greater differences in the stability of per capita income than in unemployment (i.e., percent of changes are higher).

In connection with this analysis, two additional hypotheses $(7$ and 8$)$ were tested statistically: the existence of negative correlations between diversity and instability of (yearly) changes in unemployment and real per capita income (columns (3) and (4)). To assess these relationships empirically, mean diversity indices and standard deviations of annual changes of unemployment and real per capita income were calculated for the period of study. These results are also shown in Table IX. In this context, the standard deviation statistic serves as a direct 
TABLE IX

CORRELATION RESULTS OF DIVERSITY AND CYCLICAL INSTABILITY OF LEVELS AND GROWTH RATES FOR THE COUN?IIES OF OREGON, 1972-1981

\begin{tabular}{|c|c|c|c|c|}
\hline & (1) & (2) & (3) & (4) \\
\hline & $\begin{array}{c}\text { SD } \\
\text { \& Unemployment } \\
\end{array}$ & $\begin{array}{c}\text { SD } \\
\text { Per Capita Income }\end{array}$ & $\begin{array}{c}\text { SD of } \Delta \\
\text { Unemployment }\end{array}$ & $\begin{aligned} & \text { SD of } \Delta \\
& \text { Per Capita Income }\end{aligned}$ \\
\hline $\begin{array}{l}\text { Correlation } \\
\text { Coefficient }\end{array}$ & $-.2781(.04787)^{\star}$ & $-.30075(.04012)^{\star}$ & $-.26076(.04987)^{\star}$ & $-.34894(.02515) *$ \\
\hline slope & -.04173 & -.92668 & -.05032 & -.76729 \\
\hline Intercept & 2.79646 & 2.78558 & 2.81173 & 2.77162 \\
\hline 8 Change & 1.64 & 36.59 & 1.97 & 30.45 \\
\hline
\end{tabular}

significant correlation at .05 level 
index of cyclical economic instability in that it measures the degree of cyclical fluctuations in economic activity around a long-run secular growth trend. Here again, the associations are negatively correlated and statistically significant. This would again suggest that the diversified areas were more stable (in terms of yearly changes of employment and per capita incomel than the specialized ones during the period of study.

SUMMARY

The diversity indices of Oregon counties were calculated for the study period, and the extent to which diversity indices vary within the state was examined. Decomposition of entropy into its within-set and between-set aspects permitted the analysis of the nature and extent of dispersal of economic activity between and within different groups of industries. Economic diversity was then studied in relation to unemployment and per capita income, and the effect of the recession on the strength of relations was analyzed. It was concluded that the strength of the relations between variables for nonrecessionary years was stronger and more statistically significant than when measured for the recessionary periods.

Finally, economic diversity was studied in relation to growth and cyclical instability of unemployment and per 
capita income. The results suggest that the diversified areas were more stable (in terms of unemployment and per capita income) than the specialized ones. The results also support the notion that diversification brings about lower rates of growth of unemployment and higher rates of growth of real per capita income for the study areas during the period from 1972-1981. Table X summarizes the results of the hypothesis tests for the state of Oregon. Chapter VI, following, presents the results of the U.S. study 
TABLE X

SUMMARY OF MAIN RESULTS FOR OREGON

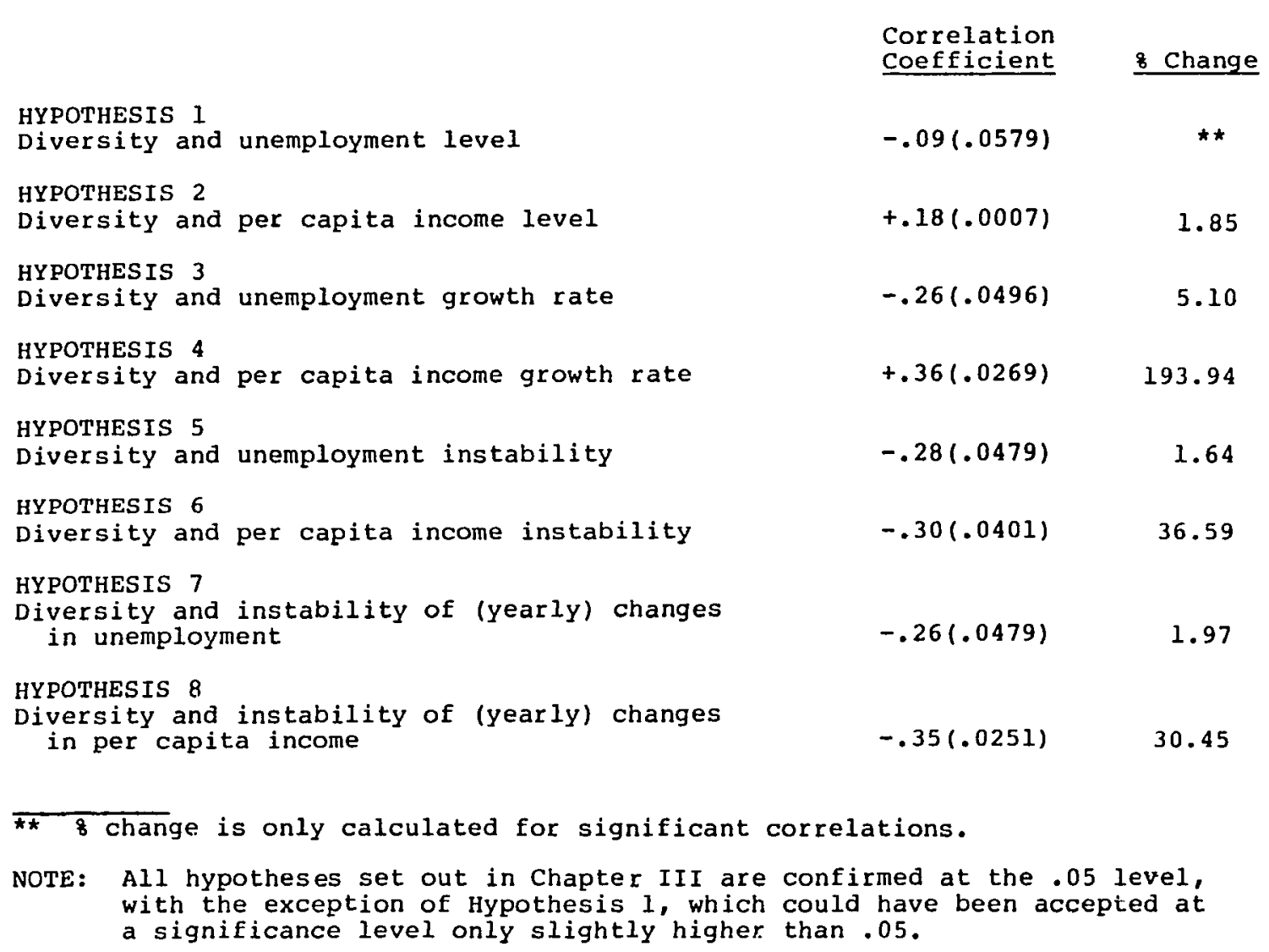


CHAPTER VI

FINDINGS: THE U.S. STUDY

This chapter presents the research findings conducted for the U.S. phase of the study. Using the entropy method previously described, employment diversity indices were computed for the 50 states and the District of Columbia from 1972 to 1981 .

Table VIII, presented in the Appendix, indicates the calculated diversity indices of each state for the 10-year study period. These indices were averaged, and the results were analyzed and divided into four classes: high diversity, moderate diversity, low diversity, and specialized. The data were then mapped to see whether significant regional variations in diversification were observable. The results are shown in Figure 16, following. of the 51 study areas, roughly half showed high to moderate diversification over the 10-year interval. It is evident from the map that none of the broad regions of the country may be classified as either highly diversified or highly specialized; however, there are patterns which may be identified. With the exception of Arkansas, the west south central region can be considered a region of high diversity; the middle Atlantic clearly is a region of moderate 


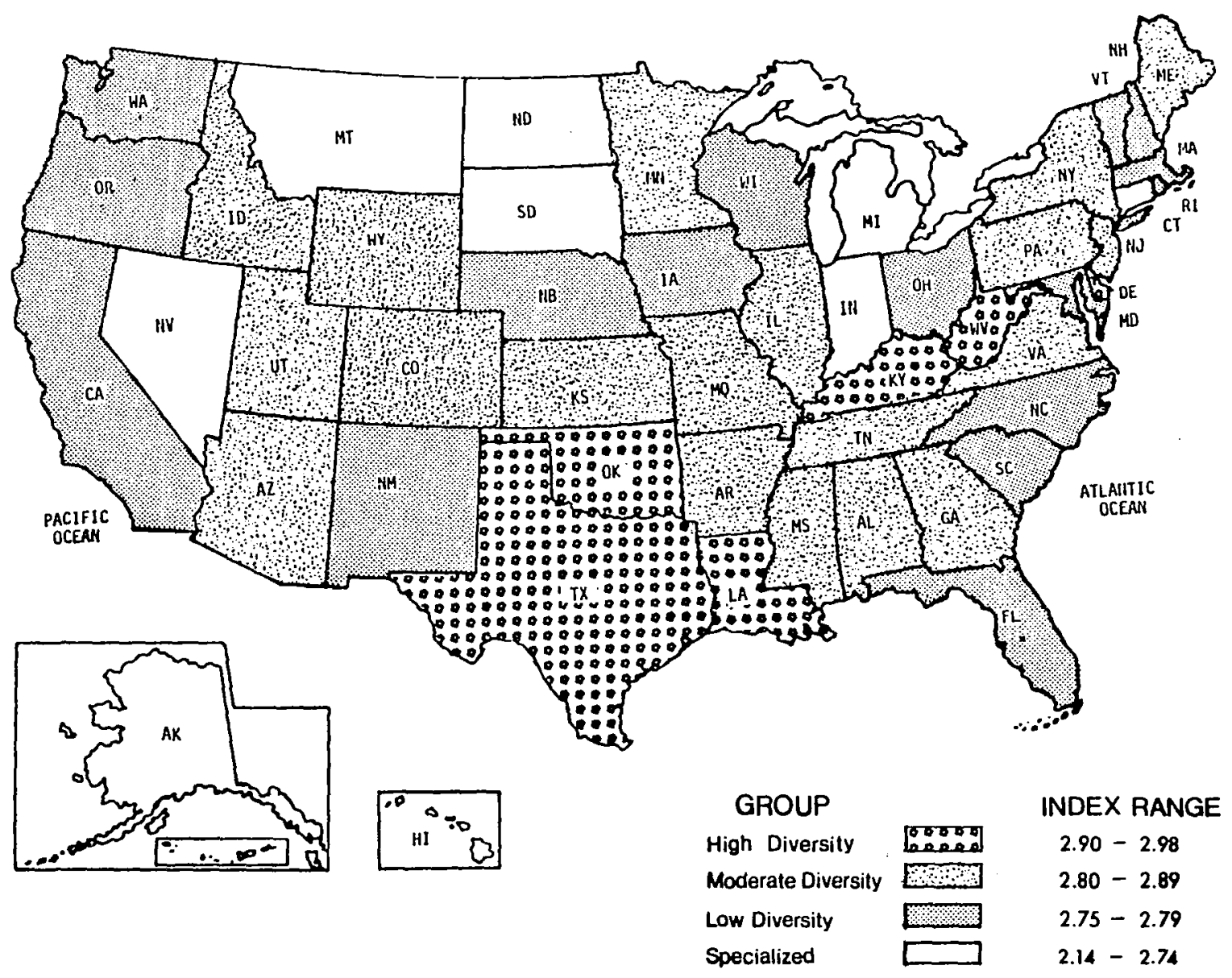

Figure 16. Average diversification indices, 1972-1981. 
diversity. Other highly diversified areas are scattered in the south and the northeast.

Several broad areas of specialization are apparent, the most important being (1) the steel production area of Indiana and the auto producing portion of Michigan in the eastern north central region; (2) North and South Dakota in the western north central region; (3) Montana and Nevada in the Mountain region; (4) Alaska and Hawaii in the Pacific region. While the Mountain region is dominated by moderately diversified states, the Pacific and New England areas appear to be dominated by states having low diversity. Thus, the south alone is mainly an area of high to moderate diversity while the west, central and eastern United States areas have moderate to low diversity.

FACTORS ASSOCIATED WITH DIVERSITY (HYPOTHESES 1 \& 2 )

Unemployment

Table XI presents a summary of the results of correlation runs between diversity indices of the 51 study areas and their corresponding unemployment rates for the correlation between the variables. While all of the correlation coefficients are negative as expected, none of the coefficients is significant at the .05 level, the minimum level of significance established for this study. Figure 17 contains a bivariate graph of the effects of 


\section{TABLE XI}

THE CORRELATION COEFFICIENTS OF DIVERSITY WITH UNEMPLOYMENT: THE UNITED STATES, 1972-1981

$\begin{array}{llllllllll}1972 & 1973 & 1974 & 1975 & 1976 & 1977 & 1978 & 1979 & 1980 & 1981 \\ -.12 & -.22 & -.11 & -.0009 & -.20 & -.22 & -.14 & -.11 & -.07 & -.06 \\ (.21) & (.06) & (.21) & (.50) & (.08) & (.06) & (.16) & (.22) & (.32) & (.34)^{*}\end{array}$

* No correlations are significant at the .05 level. 


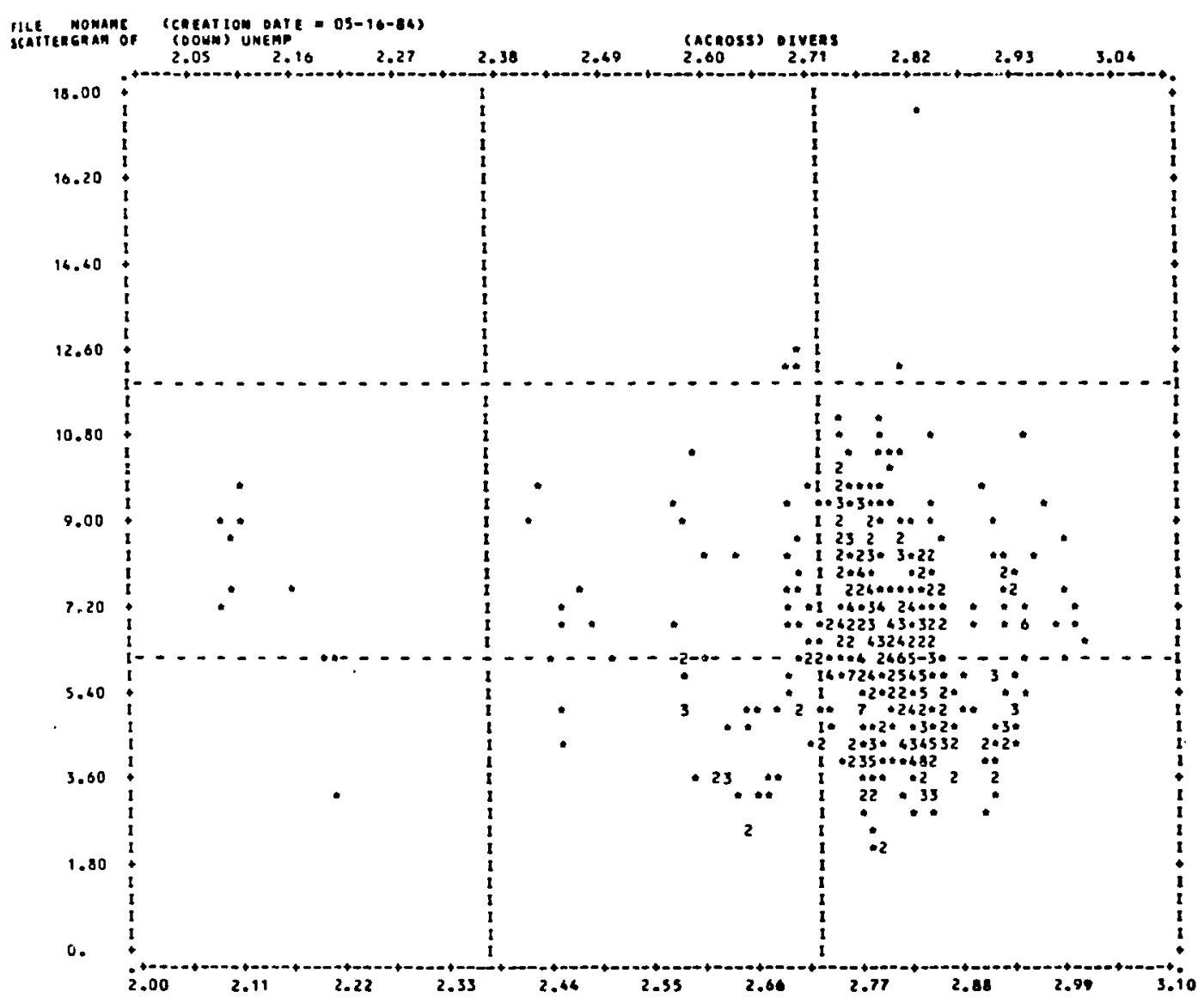

Figure 17. Unemployment vs. diversity, 1972-1981, U.S. 
unemployment vs. diversity aggregated for all states over the 10-year period. The pattern indicates little association between the variables. Computer analyses of this graph produced a Pearson Product Moment Correlation of $-.11(r=.01)$, indicating an extremely weak negative correlation. The calculated level of significance was .007 , which is less than the minimum established standard of .05; thus, the null hypothesis (which hypothesizes that there is no correlation between diversity and unemployment) may be rejected. The converse hypothesis, then, has statistical merit: where data is aggregated over the 10-year period, there is a statistically significant but extremely weak negative correlation between the two variables. Despite the apparent random pattern of the graph in Figure 17, the null hypothesis might also have been rejected with an even more stringent level of significance, such as .01.

The only study cited in the literature which comes close to an investigation of the relationship between economic diversity and level of employment was conducted by Conkling (1963). In his cross-sectional study of 52 employment exchange areas of South Wales, Great Britain, he 2 obtained an $r$ of only .026 ( $r$ carried a negative sign) between 1959 unemployment rates of the 52 areas and their ogive-based diversity indices. He concluded that "there is virtually no statistical relationship between the two . . ." 
(Conkling, 1963: 270).

Per Capita Income

In Table XII, the calculated correlation coefficient and the level of significance of correlation run between diversity indices and a logarithm of real per capita income of the 51 study areas are shown. It is evident from this table that the calculazea correlation coefficients for employment diversity measures and real per capita income are statistically significant for all the years, but the coefficients are negative, contrary to expectation.

Figure 18 presents a bivariate graph of the effects of real per capita income vs. diversity for the 10-year study period. The pattern of points is suggestive of a negative correlation between the two variables. This is confirmed by the Pearson Product Moment Correlation Coefficient of -.44 2 $(r=.19)$, as computed by the statistical software routine. The empirical level of significance for this correlation coefficient was approximately 0.00001 . On this basis, the null hypothesis (i.e., that there is no correlation between the variables, diversity and real per capita income) for the 51 study areas during the 10-year study period may be rejected.

Conversely, the alternate hypothesis can be accepted; i.e., there is a statistically significant degree of negative correlation between diversity indices and real per 


\section{TABLE XII}

THE CORRELATION COEFFICIENTS OF DIVERSITY WITH LOGARITHM OF PER CAPITA INCOME: THE UNITED STATES, 1972-1981

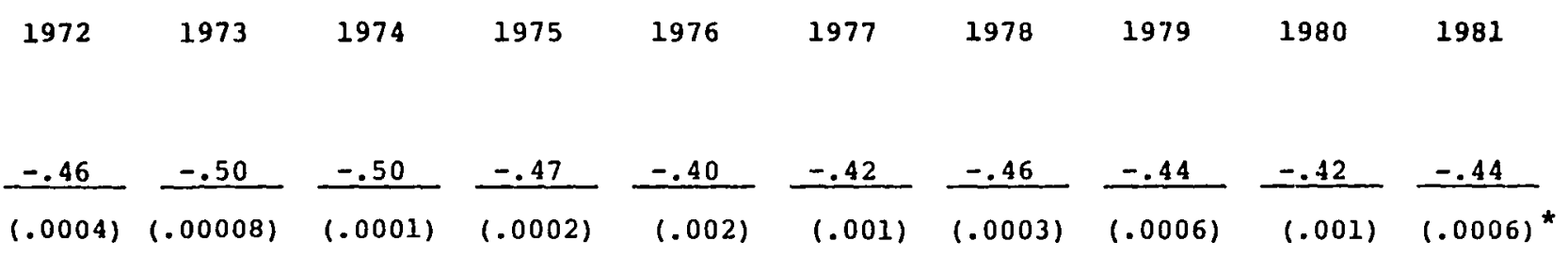

* Correlations are significant at the .05 level. 


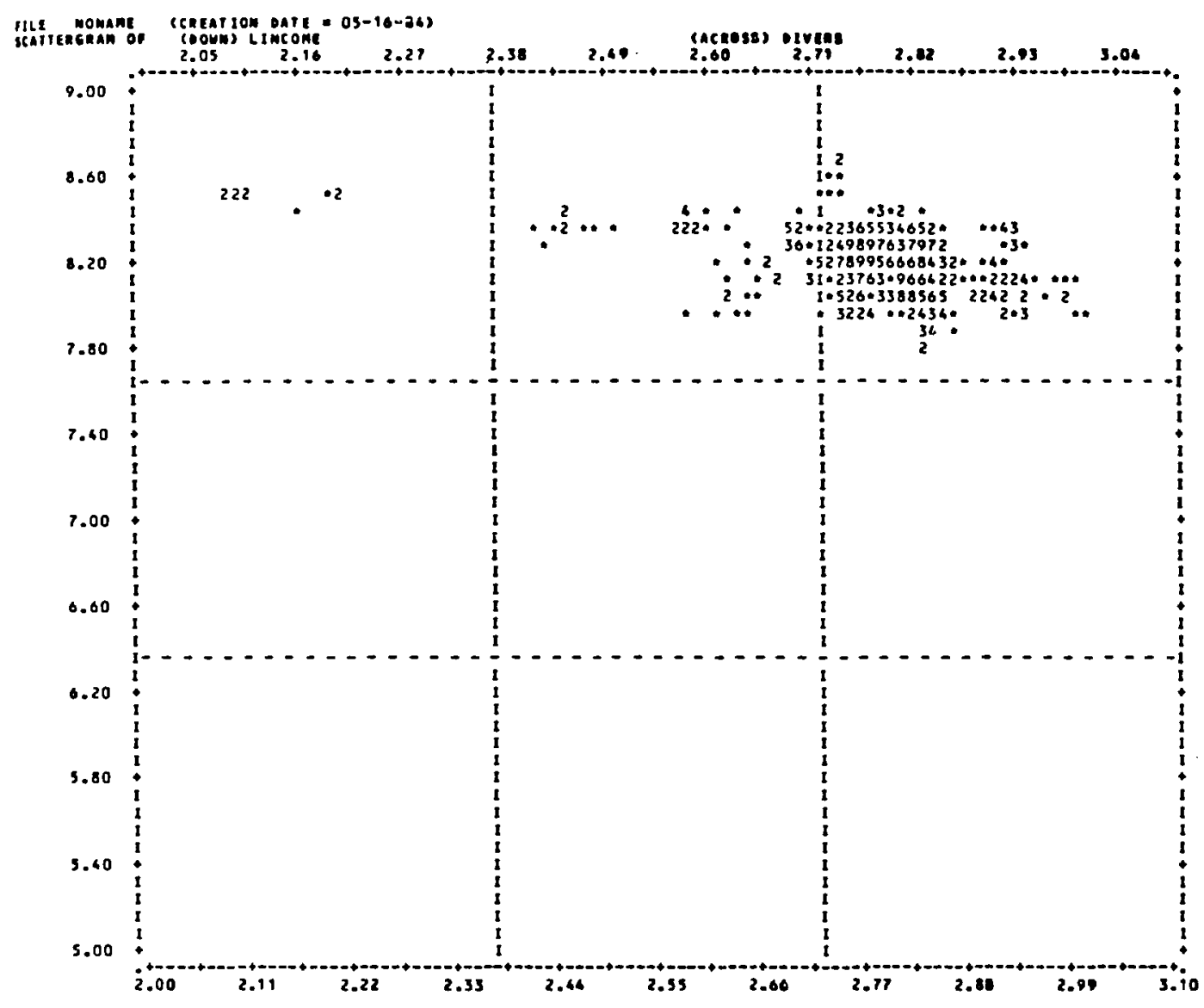

Figure 18. Per capita income vs. diversity, 1972-1981, U.S. 
capita income for this data. As before, the null hypothesis could have been rejected even if a more stringent level of significance, e.g., 0.01, had been applied.

Table XII and Figure 18 both confirm the existence of a significant negative correlation between diversity and real per capita income. However, the correlation sign is contrary to the stated hypothesis. The negative correlation implies that the lower diversity is associated with higher levels of per capita income; i.e., that specialized regions tend to have higher levels of per capita income than diversified ones. These results also contradict the Oregon findings, in which a positive correlation was found between diversity and the level of per capita income.

One possible explanation for this difference might be the effect of difference in size of geographic aggregation (i.e., counties vs. states). Secondly, these results might be explained as an effect of sector aggregation (i.e., using 1-digit SIC). The third and most interesting explanation might be the nature of regional industrial composition. As discussed in Chapter II, empirical studies of income differentials using states as the regional basis proved the existence of a strong relationship between income levels and the industrial mix of a region. Evidence exists of a negative relationship between income levels and percentage of employment in agriculture and resource-processing 
industries (Kuznets, 1958; Perloff et al, 1960). Conversely, evidence can be cited which shows a positive relationship between income levels and fabricating and service industry employment (Perloff et al, 1960).

That evidence is reinforced by the findings of this research. Four of the five states with the lowest mean diversity (over the 10-year study period) shared at least two distinguishing characteristics: (1) a high percentage of their working populaces were generally employed in service and fabricating industries (such as machinery and equipment, and miscellaneous manufacturing), and (2) a low percentage of their working populaces (over the ten-year study period) were generally employed in the agriculture and resourceoriented industries of lumber and wood. The exception is Washington, D.C., with about 468 of its employment in the governmental sector. Table XIII summarizes these findings.

One conclusion which might be reached from this comparison is that, while wide variations were found in the states' economic structures, the least diversified states were highly specialized in high income-generating sectors. This might explain the negative correlation found between the diversity indices of the various states and their per capita incomes.

On the other hand, four of the five least diversified Oregon counties derived from ranking by mean diversity over 
the 10-year study period are highly specialized in agriculture and the resource-processing industries of lumber and wood. An exception is Benton County in which approximately 468 of its populace is employed in the TABLE XIII

RELATIVE IMPORTANCE OF VARIOUS EMPLOYMENT CATEGORIES IN THE FIVE STATES WITH THE LOWEST MEAN DIVERSITY

Ranks

Avg

States Diversity

D.C.

NV

CT

MI

IN
Proportion of Employment

Lumber

Agri \& Wood Service Industries

$$
.01
$$

0.0

.26

.02

.01

.01

.48

.03

.01

.01

.19

.31

.02

.01

.18

.25

.03

.01

.15

.23

Source: U.S. Dept. of Labor, Bureau of Labor Statistics, Employment \& Earnings, States and Areas, Bulletins 1370-13 and $1370-16$.

governmental sector, i.e., state and local education (including university education). Moreover, low percentages of the working populaces in these counties were employed in service and fabricating industries. Table XIV summarizes these findings. 
It is noted that the least diversified counties were highly specialized in the low income-generating sectors. This might explain the positive correlation found between the diversity indices of the oregon counties and their per capita income levels.

\section{TABLE XIV}

RELATIVE IMPORTANCE OF VARIOUS EMPLOYMENT CATEGORIES IN THE FIVE OREGON COUNTIES WITH THE LOWEST MEAN DIVERSITY

\begin{tabular}{|c|c|c|c|c|c|}
\hline \multicolumn{2}{|c|}{ Ranks } & \multicolumn{4}{|c|}{ Proportion of Employment } \\
\hline Counties & $\begin{array}{c}\text { Avg } \\
\text { Diversity }\end{array}$ & Agri & $\begin{array}{l}\text { Lumber } \\
\& \text { Wood } \\
\end{array}$ & Service & $\begin{array}{l}\text { Fabricating } \\
\text { Industries }\end{array}$ \\
\hline Wheeler & (32) & .28 & .35 & .02 & 0.0 \\
\hline Gilliam & (31) & .34 & 0.0 & .12 & 0.0 \\
\hline Benton & $(30)$ & .05 & .14 & .12 & 0.0 \\
\hline Crook & (29) & .09 & .41 & .10 & .01 \\
\hline Lake & $(28)$ & .22 & .19 & .06 & .01 \\
\hline $\begin{array}{l}\text { Sources: } \\
\text { Resident } \\
1981, \text { and } \\
1980,198\end{array}$ & $\begin{array}{l}\text { State of Or } \\
\text { Labor Force } \\
\text { Annual Plar } \\
1,1982 \text {. }\end{array}$ & $\begin{array}{l}\text { gon, E } \\
\text { Jnempl } \\
\text { ing In }\end{array}$ & $\begin{array}{l}\text { oloymen } \\
\text { yment a } \\
\text { ormatio }\end{array}$ & $\begin{array}{l}\text { Division } \\
\text { Employm } \\
\text { Calenda }\end{array}$ & $\begin{array}{l}\text { Oregon } \\
\text { nt, 1972- } \\
\text { Years 1979, }\end{array}$ \\
\hline
\end{tabular}

$$
\text { DIVERSITY, GROWTH, AND CYCLICAL INSTABILITY }
$$

Diversity and Growth (Hypotheses 3 and 4)

The results reported in Tables XI and XII were 
supported by correlations of mean diversities and mean unemployment or per capita income. Correlating the mean diversity indices of 51 study areas and corresponding means of unemployment for the 10-year period produced a correlation coefficient of $(r=-.12, r-.02)$. The relationship proved to be statistically insignificant at the .05 level; however, a moderate but negative correlation was found between mean diversity and mean per capita income for the period of study (r $=-.47, r-.22)$. The empirically-derived level of significance was calculated to be .0002 , which is lower than the .05 established level of significance. This indicates that the proportion of the variation in the observed mean per capita income which is explained by the mean diversity indices is approximately 228.

\section{Cyclical Fluctuations (Hypotheses 5-8)}

The central question which this section seeks to answer is: To what extent have the fluctuations in the economic activity of the study areas been related to the relative diversity of their respective industrial structures?

To answer this question, the mean diversity indices of the 51 study areas for the 10-year study period were correlated with their corresponding standard deviations in the areas of unemployment and per capita income. The results are presented in Table XV. 
The relationships proved to be statistically insignificant; no significant evidence was found to support the hypothesis that the diversified areas were more stable than the specialized ones.

TABLE XV

CORRELATION RESULTS OF DIVERSITY AND CYCLICAL INSTABILITY, U.S. STUDIES*

\begin{tabular}{|c|c|c|c|c|}
\hline $\begin{array}{c}\text { Mean } \\
\text { Dvrsty }\end{array}$ & $\begin{array}{c}\text { SD } \\
\text { onempl } \\
\end{array}$ & $\begin{array}{r}\mathrm{SD} \\
\mathrm{PCI} \\
\end{array}$ & $\begin{array}{l}\text { SD of } \triangle \\
\text { Unemp } 1\end{array}$ & $\begin{array}{c}\mathrm{SD} \text { of } \\
\underline{\mathrm{PCI}}\end{array}$ \\
\hline $\begin{array}{l}1972- \\
1981\end{array}$ & $\frac{-.12}{(.21)}$ & $\frac{.13}{(.18)}$ & $\frac{-.03}{(.41)}$ & $\frac{-.14}{(.17)}$ \\
\hline
\end{tabular}

* no information on regression lines is reported for nonsignificant correlations

The mean diversity indices were then correlated with the standard deviations of annual changes in unemployment and per capita income, and the resulting coefficients are also contained in Table XV. The resulting coefficients of correlation between the variables were again found to be statistically insignificant at the .05 level. None of these relationships was statistically significant at even the .15 level.

Neither diversification nor specialization per se can 
be said to necessarily lead to either growth or stability. What is crucial in determining growth and stability patterns is the industrial mix of a region and the patterns of growth and stability of the individual industries that make up the area's economy. This context refers to the reduction of fluctuations over time in the levels of regional income, unemployment, or other measures.

The findings of this study confirm the results of previous studies regarding the relationship between diversity and fluctuation in economic activity. For example, Rodgers (1957) correlated the ogive-based diversity indices of twelve highly varied industrial areas of the United States with their standard deviations of employment over a twenty-five year period; his findings proved to be statistically insignificant. Correlations of the 1940 overall percentage change in employment of the 76 industrial areas of the U.S. for the 28-year period with their diversity indices proved also to be insignificant. Rodgers concluded that no strict assumptions can be made regarding a clear relationship between diversification and economic stability as measured solely by the composition spread of industry in a given area.

\section{SUMMARY}

The research findings for the U.S. study began with a 
study of the economic diversity of employment in the 50 states and the District of Columbia for the 10-year study period. It was noted that th South is an area of overall high to moderate diversity, while the eastern, central, and western regions of the U.S. appear to have been characterized by moderate and low diversity during the period of study. Economic diversity was then studied in relation to unemployment and per capita income. The results revealed diversity to be negatively but very weakly correlated with unemployment. However, unexpectedly, a negative correlation was found between diversity and per capita income. This implied that during the period of study, specialized regions enjoyed a higher level of per capitai income than diversified ones. Finally, economic diversity was studied in relation to growth and cyclical instability of both unemployment and per capita income. No evidence was found for any relation between diversity and either growth rates or stability.

Chapter VII, following, presents conclusions and limitations of the study and discusses some suggested avenues for further research. 


\author{
CHAPTER VII \\ CONCLUSIONS, IMPLICATIONS, \& SUGGESTED DIRECTIONS \\ FOR FUTURE RESEARCH
}

CONCLUSIONS

Goals

The objective of this study was to gain a greater understanding of the nature and significance of economic diversity and to test the generally-held assumptions regarding its value.

A review of the literature indicated a debate among regional economists about whether economic diversity creates economic stability. Diversity is said by some authors to enhance economic well-being as measured by such indicators as per capita income and percent unemployment and/or economic stability as measured by fluctuations in such indicators (Nourse, Richardson, Hoover and Fisher). The argument is a crucial one, because governmental planners at almost every level have attempted to promote economic diversity on the assumption that a wide spectrum of economic activity is desirable. The policy measures adopted to pursue this goal have ranged from simple provision of information on locational characteristics of an area to outright tax exemptions for newly locating industries. 
The interest in economic diversity has been particularly felt in oregon. Many Oregon counties rely heavily on the timber industry. A depressed housing market caused by high interest rates drastically reduced the demand for Oregon forest products during the recent depression. This, in turn, caused high unemployment rates in many of Oregon's counties which are dependent on the wood products industry. At the same time, less dependent counties continued to grow.

Many state programs in Oregon have attempted to promote economic diversity. Community leaders, including Governor Atiyeh, have repeatedly stressed the importance of economic diversity for Oregon. Much of the discussion aimed at improving the economy has been based on the assumption that growth and stability in the state's economy require diversification.

But what is diversification? Do the diversity measures have any explanatory or predictive value in relation to levels and growth rates of per capita income and unemployment? What part might diversity have in smoothing out cyclical fluctuations? It was to answer these questions that the theoretical and empirical work of this study was directed.

Past studies in this area were accomplished by utilizing four measures of industrial diversification: 
the national average measure, the ogive measure, the portfolio theoretic measure, and the information theoretic entropy measure. The second measure implied that some national average of industries was conceptually equivalent to full diversification. The first and fourth implied that equal proportions of employment in all sectors is a desirable norm for diversification. The third implied that diversification should be viewed as a process of investing real regional resources in economic activities. Diversification in this context is specified as the process of choosing such industrial assets in a manner which minimizes the variance associated with a given level of returns. This approach claims that regions with small portfolio variances are more stable.

For this study, entropy was selected as the measure of diversity. This technique was useful, not only in providing an overall index of diversity over time, but also, through its decomposition properties, in analyzing the nature of such a dispersal. The decomposition properties have permitted the analysis of economic concentration and structural changes, both within and between groups of sectors, which appeared to offer some useful extension of regional analysis.

The empirical analysis of employment diversity in Oregon and the U.S. offered an opportunity to test a number 
of hypotheses with respect to relationships between diversity and economic performance (measured by percent unemployment and per capita income). Although the main focus of the study was the oregon economy, the U.S. study was conducted to provide a comparative norm.

\section{Findings}

In the Oregon study, the diversity indices (based upon employment data) were calculated for 32 counties, and the variation in diversity within the state was studied. It was noted that most of the diversification in Oregon has been geographically concentrated in the metropolitan areas of Portland and Salem (Figure 8).

Next, the economic sectors were divided into two groups, manufacturing and nonmanufacturing, and entropy was disaggregated into within-set and between-set quantities. The results indicated some possible evidence of a trend toward increasing economic concentration within the nonmanufacturing set. Within the manufacturing set, no trend was apparent. The between-set entropy indicated a possible trend toward greater concentration (Table IV). In the U.S. study, the diversity indices were calculated for the fifty states and the District of Columbia from 1972 to 1981. The indices were averaged and grouped into four classes based on the level of diversity of the 51 areas. Roughly half showed high to moderate 
diversification, and none were distinguished as either highly diversified or specialized (Figure 16).

The economic diversity of employment of the Oregon counties was studied in relation to unemployment and per capita income over the ten-year study period. A significant but very weak positive correlation was found between diversity and real per capita income, and a very weak but insignificant negative correlation was found between diversity and unemployment. The signs of the correlations were in accord with hypothesized expectations (Table VII).

Then, the period of study was divided into recession and nonrecession years, and the same correlation was performed for these groupings. The relations between the variables for nonrecession years were stronger and more statistically significant than for the recession years (Table VII). If unemployment rates may be said to be measures of structural unemployment in periods of generally good economic conditions, then it may also be said that diversification correlates more strongly with variation in this type of unemployment.

The economic diversity of employment in the 51 study areas was examined in relation to unemployment and per capita income over the ten-year study period. A fairly significant, but very weak, negative correlation was found 
between diversity and unemployment. The sign of the correlarion was again as expected (Figure 17). However, unexpectedly, a negative correlation was found between diversity and per capita income (Figure 18).

According to these results, for both Oregon and the U.S., diversification is associated with lower levels of unemployment. Yet, the effect is very meager. But the lack of a strong correlation between the two may simply be an artifact of the classification system used in collecting employment statistics. In the U.S. study, a moderate degree of negative correlation was found between the variables, which indicates that during the period of study, contrary to the hypothesized relation, the specialized regions enjoyed a higher level of real per capita income than the diversified ones.

To explore this unexpected finding, a review of the literature indicated the empirical existence of a strong relationship between income levels and industrial mixes of the regions. Of particular note was the existence of a positive correlation between income levels and the proportion of employment in fabrication industries and services and a negative correlation between income levels and the proportion of employment in agriculture and resource-oriented industries. The differences between the oregon and U.S. studies are explained by the above 
correlation results. Four of the five states (U.S. study) with the lowest diversity tended to have notably larger proportions of their employment in fabrication and service. By contrast, the low diversity counties in oregon are not specialized in these high income sectors, but rather in the low income sectors of agriculture and lumber. Low diversity for Oregon is associated with low income, but this is not a general result.

In connection with this analysis, slopes of trend lines of unemployment and per capita income of the 32 counties for the ten-year study period were correlated with corresponding diversity indices. The calculated correlations indicated a weak negative correlation between mean diversity and slopes of unemployment trend $I$ ines and a moderate but positive correlation between mean diversity and slopes of per capita income (Table VIII). These empirical results support the assumptions that high diversity is associated with higher rates of growth of real per capita income and with lower rates of growth of unemployment. For the U.S. study, these relationships proved to be statistically insignificant.

A series of correlation runs produced additional information regarding the relationship between diversity and indicators of economic stability for oregon counties. It was found that during the period of study, there was a significant negative correlation between diversity and 
cyclical fluctuation of both unemployment and real per capita income (Table IX). This supports the assumption that diversified economies are more stable (in terms of employment and income) than specialized economies. For the U.S. study, correlations of mean diversity indices of the 51 study areas for the ten-year study period and their corresponding indices of cyclical fluctuations in employment and per capita income were found to be statistically insignificant (Table XV). The diversified areas were no more stable than the specialized ones.

Although the hypotinesized patterns of relationship between diversity and various economic indicators seem to hold, if weakly, in the Oregon study, still, comparison with the U.S. study suggests that no blanket assumptions should be made regarding a strict relationship between economic diversity, unemployment, and per capita income-based measures of economic performance. Diversification or specialization per se is not necessarily associated with either growth or stability of a region's economy.

\section{IMPLICATIONS}

The above findings have implications which are potentially important to regional policy. They imply that what is needed for an effective industrial planning policy is an overall evaluation of the economic structure of an 
area. In such an evaluation, measurement of the diversity indices of the industrial complex is not enough; additionally, there must be an analysis of the character of the individual industries with respect to the size of the firms, their growth rates and degrees of instability, the types of labor they employ, and the interrelationships among them.

Developmental planning agencies of local governments should not assume that diversification automatically means higher income and employment levels and/or less vulnerability to outside forces, and hence a more stable economy. What is crucial is the industrial mix of a region, i.e., the growth and stability properties of the individual industries that make up the area's economy. The process of economic diversification thus becomes a considerably more complex matter than simply finding new industries which are merely different from the existing ones. Specialization is not of itself unhealthy; however, if an area is highly specialized, it is important whether the specialized sector is growing or declining, whether it is high- or low-income generating, and whether it is stable or unstable.

A prime use for the results of this study is in future decisionmaking efforts. In addition to the results establishing relations between diversity and economic 
performance, the decomposition of entropy into its betweenset and within-set aspects is useful for identification of some important interregional diversification patterns which may not be at all apparent merely from a visual examination of the single unit total entropy measure of diversity.

\section{SUGGESTED DIRECTIONS FOR FUTURE RESEARCH}

Further investigation of some aspects of this project is desirable. This study, for example, has been restricted to a very high degree of aggregation in industries categories. Use of less aggregated data (e.g., 2-, 3- or 4-digit SIC level) which redistributes employment into more nearly independent sectors might obtain more accurate measures of diversity. Correlations of diversity values with economic performance indicators could then be reassessed.

Another area for further work might be in the inclusion of a calculation of income-based diversity and a measurement of strength of relationship between this measure and unemployment and income. As discussed earlier, the present study was limited to utilization of the entropy measure for employment diversity.

This project has been limited to the study of counties and states as the unit of study. The domain of investigation could be applied to multi-state regions as the 
unit of study. Alsc; an analysis might be made of the relationship between seasonal (as opposed to cyclical) employment fluctuations by industrial area and the comparable indices of diversification.

Finally, it would have been particularly interesting to be able to compare the entropy measure with other measures of diversity discussed briefly in this paper. It is hoped that future work in this area will include this interesting and potentially very valuable dimension. 
REFERENCES

Atiyeh, Vic. "Governor Atiyeh's Proposed Changes in Corporate Taxation," Speech to the World Affairs Council's International Business Roundtable Meeting at the Hilton Hotel in Portland, Oregon, June 20, 1984 .

Bahl, Roy W., Robert Firestine, and Donald Phares. "Industrial Diversity in Urban Areas: Alternative Measures and Intermetropolitan Comparisons." Economic Geography, 47, July 1971, 414-425.

Barth, James, John Kraft, and Philip Wiest. "Portfolio Approach to Industrial Diversification," Journal of Regional Science, 15(1), 1975, 9-15.

Bernhardt, I and $K$ D Mackenzie. "Measuring Seller Unconcentration, Segmentation and Product Differentiation," Western Economic Journal, 6, 1968, 395-403.

Borts, George H. "Regional Cycles of Manufacturing Employment in the U.S., 1914-53," National Bureau of Economic Research, Occasional Paper No. 75, 1961.

Borts, George $\mathrm{H}$ and Jerome L. Stein. Economic Growth in a Free Market, New York: Columbia University Press, 1964.

Brennan, Tom. "Portland Suffers Least in Recession," The Oregonian, June 22, 1980.

Chapman, G. P. "The Application of Information Theory to the Analysis of Population Distribution in Space," Economic Geography, 46, 1970, 317-331.

Clark, J. M. Strategic Factors in Business Cycles, New York: Harper \& Row, 1934.

Conkling, Edgar C. "South Wales: A Case Study in Industrial Diversification," Economic Geography, 39(3), July 1963, 258-272. 
Conroy, Michael E. "The Optimal Diversification of Regional Industrial Structures," Paper presented at the 1972 Annual Meeting of the Econometric Society, Toronto, Canada, December 28, 1972a.

- "Optimal Regional Industrial Diversification, a Portfolio-Analytic Approach," Unpublished PhD

dissertation, The University of Illinois at UrbanaChampaign, 1972 b.

"Alternative Strategies for

Regional Industrial Diversification," Journal of Regional Science, 14(1), April 1974, 35-51.

- The Challenge of Urban Economic Development, New York: Lexington Books, 1975a.

- Regional Economic Diversification, New York:

Praeger Publishers, Inc, 1975b.

"The Concept and Measurement of Regional

Industrial Diversification," Southern Economic Journal, January $1975 \mathrm{C}, 492-505$.

Duncan, Otis Dudley and Albert Reiss. Social Characteristics of Urban and Rural Communities, 1950, New York: John Wiley and Sons, Inc, 1956.

El-Haimus, Adil H. "The Effect of Economic Diversification on Regional Development," PhD Dissertation, School of Urban Studies and Planning, Portland State University, winter 1982 .

Florence, Sargent. Industrial Location and National Resources, Washington, DC: National Resources Planning Board, 1943.

Garrison, Charles. "Industrial Growth in the Tennessee Valley Region, 1959 to 1968," American Agricultural Economics, $56(1)$, February 1974, 50-60.

Gratton, Chris. "Industrial Diversification in New Towns," Urban Studies, 6(2), July 1979, 155-163.

Hackbart, M. M. and D. A. Anderson. "On Measuring Economic Diversification," Land Economics, L1(4), November 1975, 374-378. 
Herniter, Jerome D. "An Entropy Model of Brand Purchase Behavior," Technical Report, Cambridge, Massachusetts: Marketing Science Institute, December 1972.

- "An Entropy Model of Brand Purchase Behavior," Journal of Marketing Research, x, November 1973, 36175 .

Hodges, J. L. and G. L. Lehman. Basic Concepts of Probability and Statistics, San Francisco: Holden-Day, 1970.

Hoover, Edgar. The Location of Economic Activity, New York: MCGraw-Hi11, 1948 .

Hoover, Edgar and Joseph L. Fisher. "Research in Regional Economic Growth," Problems in the Study of Economic Growth, New York, 1949 .

Horowitz, Ann and Ira Horowitz. "The Real and IIlusory Virtue of Entropy-Based Measures for Business and Economic Analysis," Decision Science, 7, 1976, 121-135.

, "Entropy, Markov Processes and Competition in the Brewing Industry," Journal of Industrial Economics, 16 , 1968 , 196-211.

Horowitz, Ira. "Employment Concentration in the Common Market: An Entropy Approach," Journal of the Royal Statistical Society, 133 (Part 3), 1970, 463-479.

- "Number-Equivalent in U.S. Manufacturing Industries: 1954, 1958, 1963," Southern Economic Journal, 37, April 1971, 396-408.

Horowitz, Ira and Ann R. Horowtiz. "Structural Changes in the Brewing Industry," Applied Economics, 2, May 1970, $1-13$.

Kuznets, Simon. "Quantitative Aspects of the Economic Growth of Nations, Part III: Industrial Distribution of Income and Labor Force by States, United States, 1919-1921 to 1955," Economic Development and Cultural Change, 6(4), 1958 .

Jacquemin, Alexis P. and Charles H. Berry. "Entropy Measure of Diversity and Corporate Growth," The Journal of Industrial Economics, XXVII(4), June 1979, 359-368. 
Lev, B. "The Aggregation Problem in Financial Statements: An Information Approach," Journal of Accounting Research, 16, Autumn 1968, 247-261.

- "The Informational Approach to Aggregation in Financial Statements: Extensions," Journal of Accounting Research, 8, Spring 1970, 78-94.

MCClave, J. T. and F. H. Dietrich II. Statistics, San Francisco: Dellen Publishing Company, 1979.

MacLaughlin, Glenn. "Industrial Diversification in American Cities," Quarterly Journal of Economics, 45, November $1930,131-149$.

- Growth of American Manufacturing Areas, Pittsburgh: Bureau of Business Research, University of Pittsburgh, 1938.

Markowitz, Harry M. Portfolio Selection, Efficient Diversification of Investments, Chicago: Cowles Foundation for Economic Analysis, 1959.

- "Portfolio Selection," The Journal of Finance, July 1952, 77-91.

Matilla, John M. and Wilbur R. Thompson. "Toward an Econometric Model of Urban Economic Development," in Issues in Urban Economics, Harvey S. Perloff and Lowdon Wingo, Jr., editors, Baltimore: The Johns Hopkins Press, 1968, 63-78.

Medvedkov, Y. "Entropy: An assessment of Potentialities in Geography," Economic Geography, 46 (2 Supplement, June) $1970,306-316$.

- "The Concept of Entropy in Settlement Pattern Analysis," Papers, Regional Science Association 18, $1967,165-168$.

National Resource Planning Board. "Our Cities," Washington, D. C., 1937.

Nourse, Hugh. Regional Economics, New York: McGraw-Hill, 1968 .

Parr, John B. "Specialization, Diversification, and Regional Development," Professional Geography, XVII(6), $1965,21-25$. 
Paulson, Albert S. and Charles B. Garrison. "An Entropy Measure of the Geographic Concentration of Economic Activity," Economic Geography, 49(4), 1973, 319-324.

Perloff, Harvey Z, Edgar S. Dunn Jr., Eric E. Lampard, and Richard F. Muth. Regions, Resources, and Economic Growth, Lincoln: The University of Nebraska Press, 1960 .

Philippatos, George $C$ and Charles $J$ wilson. "Entropy, Market Risk, and the Selection of Efficient Portfolios," Applied Economics, (4), 1972, 209-220.
- "Entropy, Market Risk, and the Selection of Efficient Portfolios: Reply," Applied Economics, 6 , $1974,77-81$.

- "Information Theory and Risk in Capital Markets," Omega, 2, 1974, 523-532.

Richardson, H. W. Regional Economics, New York: Praeger, 1969 .

Rodgers, Allen. "Some Aspects of Industrial Diversification in the United States," Economic Geography, January $1957,16-30$.

Schiller, R. Bradley. The Economy Today, 2nd edition, New York: Random House, 1983 .

Semple, R. K. and H. L. Gauthier. "Spatial-Temporal Trends in Income Inequalities in Brazil," Geograph. Anal., 4, 1972 , 169-180.

Semple, R. K. and R. G. Golledge. "An Analysis of Entropy Changes in a Settlement Pattern Over Time," Economic Geography, 46, April 1970, 157-160.
- "Recent Trends in the Spatial Concentration of Corporate Headquarters," Economic Geography, 49, 1973, 309-318.

Shannon, C. E. and W. Weaver. The Mathematical Theory of Communication, Urbana: The University of Illinois Press, 1949.

Sharpe, W. F. Portfolio Theory and Capital Market, New York: McGraw-Hill, 1970 . 
Shear, James A. "A General Measure of Diversity," Professional Geographer, XVII(2), March 1965, 14-17.

Spencer, H. Milton. Contemporary Economics, 4th edition, New York: Worth Publishers, Inc, 1980.

State of Oregon, Department of Economic Development. "A Statistical Profile," Salem, 1982.

$\overline{1983 .}$

- "Oregon County Economic Indicators," Salem, 1981,

1976-1984," Salem, February 1984.

State of Oregon, Department of Human Resources, Employment Division. "North Coast Area," Economic Report, 1982.

- "Oregon Resident Labor Force, Unemployment and Employment," Salem, 1972-1981. May 1983.

"State of Oregon Agricultural Report," Salem,

- "Annual Planning Information," Salem, Calendar Years $1980,1981,1982$.

State of Oregon, Executive Department. "Oregon Economic and Revenue Forecast," 15(4), Salem, December 1982.

Steigenga, W. "A Comparative Analysis and Classification of Netherlands Towns." Tisdschrift Voor Economische en Sociale Geographie, June-July 1955, 105-108.

Thiel, H. Economics and Information Theory, Amsterdam, Holland: North Holland Publishing Company, 1967.

- "On the Use of Information Theory Concepts in the Analysis of Financial statements." Management Science, 15, May $1969,459-480$.

- Statistical Decomposition Analysis, New York:

American Elsevier Publishing Company, Inc., 1972.

Thompson, Wilbur. A Preface to Urban Economics.

Baltimore: Johns Hopkins University Press, 1956.

Tobin, J. "Liquidity Preference as Behavior Towards Risk," Review of Economic Studies, 25, 1958, 65-85. 
Tress, R. C. "Unemployment and the Diversification of Industry," The Manchester School, September 1938, 1417 .

U.S. Department of Commerce, Bureau of the Census. Statistical Abstract of the United States, Washington, D.C., 1972-1984.

U.S. Department of Commerce, Bureau of Economic Analysis. Survey of Current Business, Washington, D.C.: USGPO, 1972-1981.

U.S. Department of Labor, Bureau of Labor Statistics. Employment and Earnings, States and Areas, 1939-1978, Bulletin 1370-13, Washington, D.C.: USGPO, 1979 .

${ }_{\text {and }}$ Areas, 1977-81, Bulletin 1370-16, Washington, D.C.: USGPO, 1982 .

- Handbook of Labor Statistics, Bulletin 2070, Washington, D.C., USGPO, December 1980 .

- Geographic Profile of Employment and

Unemployment, 1979, Report No. 619, Washington, D.C.: USGPO, December 1980. 
APPENDIX A

OREGON: DATA AND RESULTS 
TABLE XVI

OREGON : TOTAL EMPLOYMENT

1972

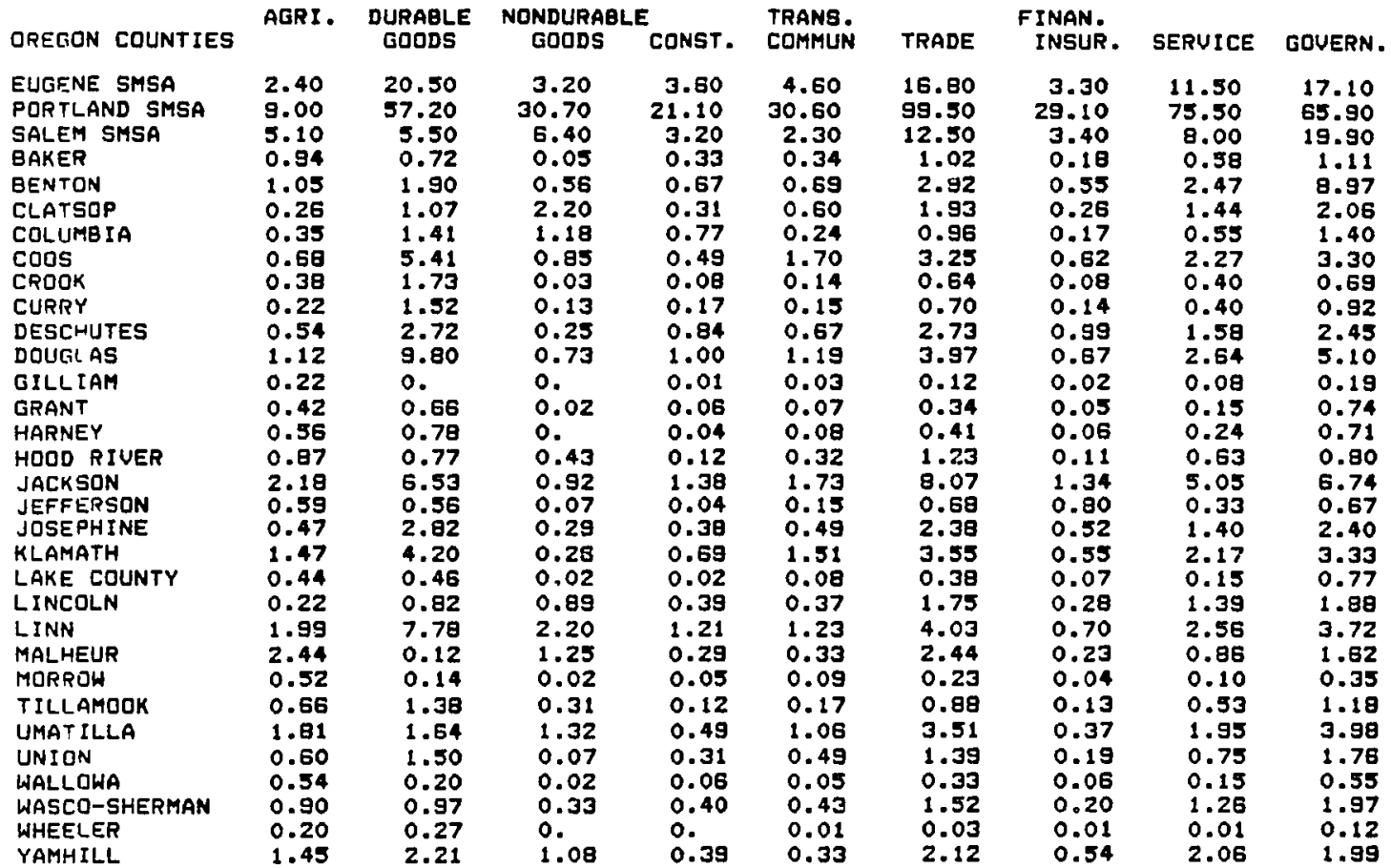

* Sources: State of Oregon, "Oregon Resident Labor Force, Unemployment and Employment," 1972-1981, and

State of Oregon, "State of Oregon Agricultural Report," May 1983. 
TABLE XVI (continued)

OREGON: TOTAL EMPLOYMENT

1973

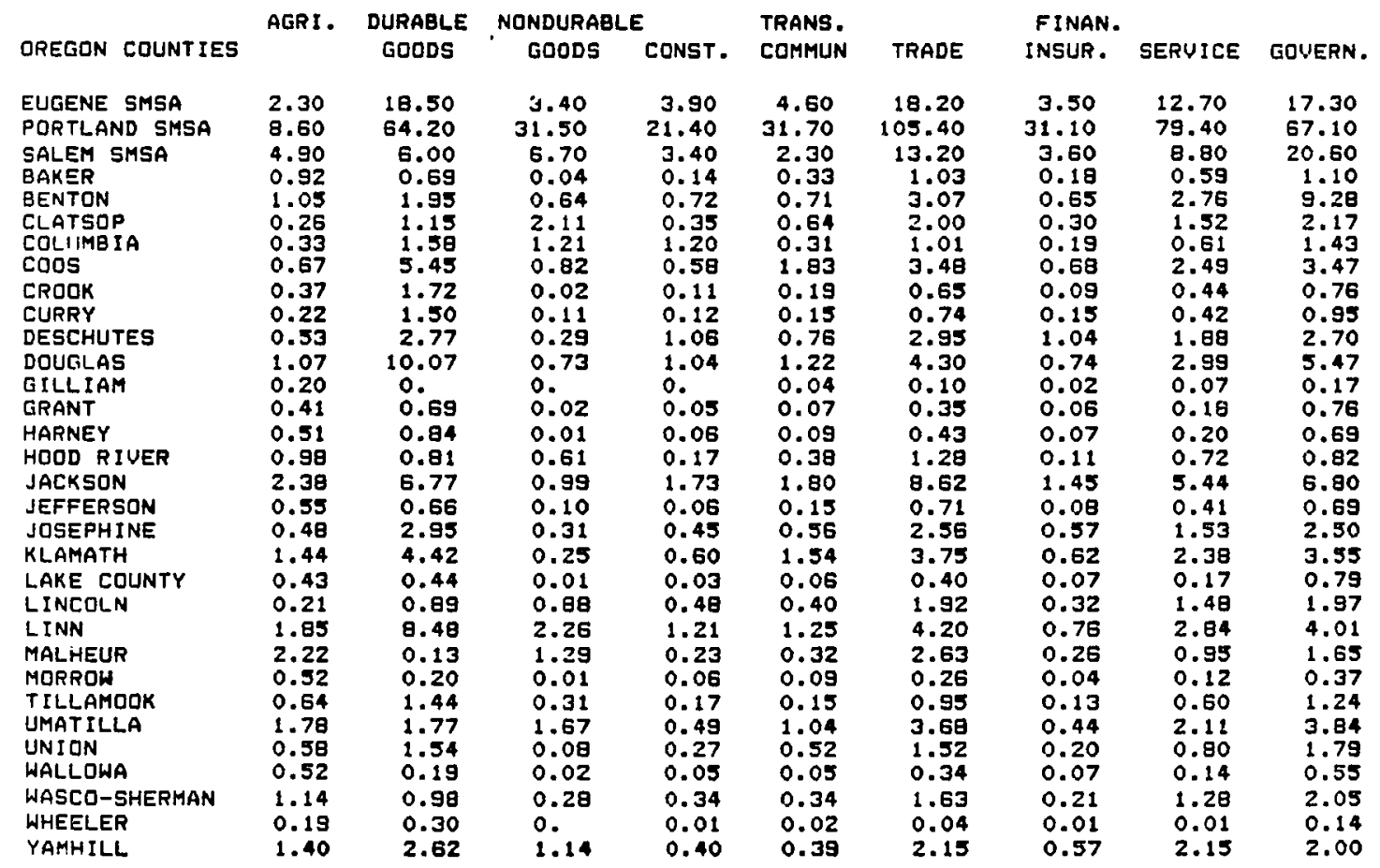


TABLE XVI (continued)

OREGON: TOTAL EMPLOYMENT

1974

\begin{tabular}{|c|c|c|c|c|c|c|c|c|c|}
\hline OREGON COUNTIES & AGR I. & $\begin{array}{c}\text { DURABLE } \\
\text { GOODS }\end{array}$ & $\begin{array}{l}\text { NONDURABLE } \\
\text { GOODS }\end{array}$ & EONST. & $\begin{array}{l}\text { TRANS. } \\
\text { COMMUN }\end{array}$ & TRADE & $\begin{array}{l}\text { FINAN. } \\
\text { INSUR. }\end{array}$ & SERUICE & GOUERN. \\
\hline EUGENE SMSA & 2.40 & 17.60 & 3.30 & 3.90 & 4.80 & 18.80 & 3.50 & 13.60 & 18.00 \\
\hline PORTLAND SMSA & 8.20 & 67.10 & 31.50 & 21.30 & 31.80 & 109.20 & 31.70 & 83.20 & 70.50 \\
\hline SALEM SMSA & 4.60 & 5.90 & 6.60 & 3.50 & 2.40 & 13.30 & 3.70 & 9.40 & 22.10 \\
\hline $\begin{array}{l}\text { BAKER } \\
\text { BENTON }\end{array}$ & $\begin{array}{l}0.90 \\
1.02\end{array}$ & $\begin{array}{l}0.80 \\
1.89\end{array}$ & $\begin{array}{l}0.04 \\
0.72\end{array}$ & $\begin{array}{l}0.09 \\
0.76\end{array}$ & $\begin{array}{l}0.32 \\
0.72\end{array}$ & $\begin{array}{l}1.02 \\
3.10\end{array}$ & $\begin{array}{l}0.19 \\
0.58\end{array}$ & $\begin{array}{l}0.63 \\
3.04\end{array}$ & $\begin{array}{l}1.13 \\
9.46\end{array}$ \\
\hline $\begin{array}{l}\text { CLATSOP } \\
\text { COLUMBIA }\end{array}$ & 0.26 & $\begin{array}{l}1.16 \\
1.55\end{array}$ & $\begin{array}{l}2.30 \\
1.14\end{array}$ & $\begin{array}{l}0.29 \\
1.69\end{array}$ & $\begin{array}{l}0.65 \\
0.33\end{array}$ & $\begin{array}{l}2.0 j \\
1.04\end{array}$ & $\begin{array}{l}0.30 \\
0.19\end{array}$ & $\begin{array}{l}1.56 \\
0.65\end{array}$ & $\begin{array}{l}2.21 \\
1.53\end{array}$ \\
\hline $\cos$ & 0.65 & 5.41 & 0.76 & 0.54 & 1.76 & 3.43 & 0.69 & 2.32 & 3.87 \\
\hline $\begin{array}{l}\text { CROC } \\
\text { CURK }\end{array}$ & 0.37 & 1.47 & 0.02 & 0.10 & 0.20 & 0.66 & 0.09 & 0.46 & $\begin{array}{l}0.79 \\
1.04\end{array}$ \\
\hline $\begin{array}{l}\text { CURRY } \\
\text { DESCHUTES }\end{array}$ & $\begin{array}{l}0.21 \\
0.51\end{array}$ & $\begin{array}{l}1.37 \\
2.65\end{array}$ & $\begin{array}{l}0.18 \\
0.31\end{array}$ & $\begin{array}{l}0.09 \\
0.05\end{array}$ & $\begin{array}{l}0.13 \\
0.85\end{array}$ & $\begin{array}{l}0.71 \\
3.13\end{array}$ & $\begin{array}{l}0.16 \\
1.06\end{array}$ & $\begin{array}{l}0.43 \\
2.03\end{array}$ & $\begin{array}{l}1.04 \\
2.94\end{array}$ \\
\hline DOUGLAS & 1.02 & 10.00 & $0.7 \theta$ & 0.99 & 1.28 & 4.42 & 0.76 & 3.12 & 5.68 \\
\hline GILLIAM & 0.19 & 0. & 0.01 & 0.02 & 0.04 & 0.10 & 0.02 & 0.08 & 0.18 \\
\hline $\begin{array}{l}\text { GRANT } \\
\text { HARNEY }\end{array}$ & 0.40 & $\begin{array}{l}0.64 \\
0.84\end{array}$ & $\begin{array}{l}0.03 \\
0.01\end{array}$ & $\begin{array}{l}0.04 \\
0.08\end{array}$ & $\begin{array}{l}0.08 \\
0.08\end{array}$ & $\begin{array}{l}0.34 \\
0.43\end{array}$ & $\begin{array}{l}0.07 \\
0.08\end{array}$ & $\begin{array}{l}0.20 \\
0.21\end{array}$ & $\begin{array}{l}0.79 \\
0.73\end{array}$ \\
\hline HOOD RIUER & 0.92 & 0.85 & 0.66 & 0.21 & 0.34 & 1.39 & 0.11 & 0.79 & 0.85 \\
\hline $\begin{array}{l}\text { JACKSON } \\
\text { JEFFERSON }\end{array}$ & 2.21 & $\begin{array}{l}5.06 \\
0.61\end{array}$ & 1.08 & $\begin{array}{l}1.92 \\
0.08\end{array}$ & $\begin{array}{l}1.80 \\
0.16\end{array}$ & 8.79 & & 5.66 & $\begin{array}{l}7.20 \\
0.76\end{array}$ \\
\hline JOSEPHINE & $\begin{array}{l}0.54 \\
0.47\end{array}$ & $\begin{array}{l}0.61 \\
2.70\end{array}$ & $\begin{array}{l}0.13 \\
0.35\end{array}$ & $\begin{array}{l}0.08 \\
0.39\end{array}$ & $\begin{array}{l}0.16 \\
0.55\end{array}$ & $\begin{array}{l}0.74 \\
2.57\end{array}$ & $\begin{array}{l}0.08 \\
0.59\end{array}$ & $\begin{array}{l}0.41 \\
1.57\end{array}$ & $\begin{array}{l}0.75 \\
2.80\end{array}$ \\
\hline MLAMATH & 1.40 & 4.35 & 0.26 & 0.55 & 1.54 & 3.77 & 0.60 & 2.50 & 3.57 \\
\hline LAKE COUNTY & 0.42 & 0.43 & 0.01 & 0.02 & 0.08 & & 0.07 & & 0.80 \\
\hline LINCOLN & 0.20 & 0.94 & 0.89 & 0.34 & 0.39 & 1.89 & 0.34 & 1.50 & 2.10 \\
\hline $\begin{array}{l}\text { LINN } \\
\text { MALHEUR }\end{array}$ & $\begin{array}{l}1.71 \\
2.26\end{array}$ & $\begin{array}{l}8.78 \\
0.13\end{array}$ & $\begin{array}{l}2.27 \\
1.46\end{array}$ & $\begin{array}{l}1.24 \\
0.28\end{array}$ & $\begin{array}{l}1.21 \\
0.38\end{array}$ & $\begin{array}{l}4.21 \\
2.53\end{array}$ & $\begin{array}{l}0.81 \\
0.33\end{array}$ & $\begin{array}{l}3.01 \\
1.05\end{array}$ & $\begin{array}{l}4.32 \\
1.69\end{array}$ \\
\hline MORROW & 0.00 & 0.22 & 0.06 & 0.19 & 0.09 & 0.36 & 0.04 & 0.11 & 0.38 \\
\hline TILLAMOOK & 0.63 & 0.63 & 1.15 & 0.33 & 0.15 & 0.16 & 0.94 & 0.15 & $\begin{array}{l}0.73 \\
3.80\end{array}$ \\
\hline UMATILLA & 1.77 & 1.70 & 1.86 & & 1.06 & & & & 3.80 \\
\hline UN!ON & 0.56 & 1.50 & 0.09 & 0.23 & 0.55 & 1.51 & 0.23 & 0.85 & 1.81 \\
\hline WALLOWA & 0.52 & 0.23 & 0.01 & 0.07 & 0.05 & 0.36 & 0.08 & 0.13 & 0.56 \\
\hline WASCD-SHERMAN & 0.59 & 1.01 & 0.27 & 0.26 & 0.34 & 1.62 & 0.21 & 1.31 & 2.11 \\
\hline WHEELER & 0.17 & 0.28 & 0. & 0.01 & 0.03 & 0.05 & 0.01 & 0.01 & 0.15 \\
\hline YAMHILL & 1.35 & 2.67 & 1.03 & 0.42 & 0.38 & 2.17 & 0.60 & 2.24 & 2.13 \\
\hline
\end{tabular}


TABLE XVI (continued)

OREGON: TOTAL EMPLOYMENT

1975

\begin{tabular}{|c|c|c|c|c|c|c|c|c|c|}
\hline QREGON COUNTIES & AGR I. & $\begin{array}{l}\text { DURABLE } \\
\text { GOODS }\end{array}$ & $\begin{array}{l}\text { NONDURABLE } \\
\text { GOODS }\end{array}$ & $E$ CONST. & $\begin{array}{l}\text { TRANS. } \\
\text { COMMUN }\end{array}$ & TRADE & $\begin{array}{l}\text { FINAN. } \\
\text { INSUR. }\end{array}$ & SERUICE & GOUERN. \\
\hline $\begin{array}{l}\text { EUGENE SMSA } \\
\text { PORTLAND SMSA }\end{array}$ & $\begin{array}{l}2.20 \\
8.00\end{array}$ & $\begin{array}{l}15.40 \\
60.40\end{array}$ & $\begin{array}{r}2.90 \\
29.90\end{array}$ & $\begin{array}{r}3.50 \\
19.30\end{array}$ & $\begin{array}{r}4.30 \\
30.50\end{array}$ & $\begin{array}{r}20.00 \\
111.50\end{array}$ & $\begin{array}{r}3.70 \\
32.10\end{array}$ & $\begin{array}{l}13.90 \\
85.20\end{array}$ & $\begin{array}{l}19.40 \\
72.70\end{array}$ \\
\hline SALEM SMSA & 4.50 & 5.60 & 5.30 & 3.40 & 2.40 & 13.70 & 3.80 & 10.70 & 23.40 \\
\hline $\begin{array}{l}\text { BAKER } \\
\text { BENTON }\end{array}$ & $\begin{array}{l}0.87 \\
0.98\end{array}$ & $\begin{array}{l}0.58 \\
1.81\end{array}$ & $\begin{array}{l}0.06 \\
0.61\end{array}$ & $\begin{array}{l}0.16 \\
0.65\end{array}$ & $\begin{array}{l}0.31 \\
0.71\end{array}$ & $\begin{array}{l}1.02 \\
3.12\end{array}$ & 0.19 & 0.66 & $\begin{array}{l}1.12 \\
9.87\end{array}$ \\
\hline CLATSOP & $\begin{array}{l}0.98 \\
0.24\end{array}$ & 1.04 & 2.00 & 0.31 & 0.65 & 2.04 & $\begin{array}{l}0.58 \\
0.32\end{array}$ & $\begin{array}{l}3.21 \\
1.58\end{array}$ & $\begin{array}{l}9.87 \\
2.25\end{array}$ \\
\hline COLUMBIA & 0.31 & 1.45 & 0.98 & 1.98 & 0.35 & 1.07 & 0.21 & 0.69 & 1.64 \\
\hline $\begin{array}{l}\text { COOS } \\
\text { CROOK }\end{array}$ & $\begin{array}{l}0.54 \\
0.35\end{array}$ & $\begin{array}{l}4.44 \\
1.37\end{array}$ & $\begin{array}{l}0.67 \\
0.03\end{array}$ & $\begin{array}{l}0.57 \\
0.08\end{array}$ & $\begin{array}{l}1.54 \\
0.19\end{array}$ & $\begin{array}{l}3.35 \\
0.65\end{array}$ & $\begin{array}{l}0.68 \\
0.09\end{array}$ & $\begin{array}{l}2.36 \\
0.50\end{array}$ & $\begin{array}{l}4.32 \\
0.85\end{array}$ \\
\hline CURRY & 0.20 & 1.07 & 0.16 & 0.13 & 0.13 & 0.73 & 0.15 & 0.45 & 1.10 \\
\hline DESCHUTES & 0.50 & 2.65 & 0.31 & 0.68 & 0.85 & 3.2 & 1.15 & z. & 3.18 \\
\hline $\begin{array}{l}\text { DOUGLAS } \\
\text { GILLIAM }\end{array}$ & $\begin{array}{l}1.01 \\
0.19\end{array}$ & $\begin{array}{l}9.07 \\
0 .\end{array}$ & $\begin{array}{l}0.72 \\
0.01\end{array}$ & $\begin{array}{l}1.08 \\
0.03\end{array}$ & $\begin{array}{l}1.23 \\
0.04\end{array}$ & $\begin{array}{l}4.00 \\
0.13\end{array}$ & $\begin{array}{l}0.77 \\
0.02\end{array}$ & $\begin{array}{l}3.29 \\
0.09\end{array}$ & $\begin{array}{l}6.18 \\
0.18\end{array}$ \\
\hline GRANT & 0.38 & 0.56 & 0.03 & 0.03 & 0.08 & 0.35 & 0.06 & 0.20 & 0.82 \\
\hline HARNEY & 0.46 & 0.84 & 0.01 & 0.05 & 0.08 & 0.43 & 0.08 & 0.20 & 0.75 \\
\hline HOOD RIVER & 0.88 & 0.85 & 0.55 & 0.21 & 0.32 & 1.54 & 0.13 & 0.79 & 0.90 \\
\hline JACKSON & 2.12 & 5.46 & 1.07 & 1.69 & 1.72 & 9.01 & 1.53 & 5.96 & 7.72 \\
\hline JEFFERSON & 0.51 & 0.61 & 0.12 & 0.07 & 0.14 & 0.76 & 0.08 & 0.45 & 0.81 \\
\hline JOSEPHINE & 0.46 & 2.64 & 0.29 & 0.40 & 0.54 & 2.72 & 0.62 & 1.66 & 3.08 \\
\hline KLAMATH & 1.36 & 4.17 & 0.24 & 0.53 & 1.41 & 3.94 & 0.64 & 2.57 & 3.83 \\
\hline $\begin{array}{l}\text { LAKE COUNTY } \\
\text { LINEDLN }\end{array}$ & $\begin{array}{l}0.41 \\
0.19\end{array}$ & $\begin{array}{l}0.37 \\
0.87\end{array}$ & $\begin{array}{l}0.01 \\
0.90\end{array}$ & $\begin{array}{l}0.05 \\
0.28\end{array}$ & $\begin{array}{l}0.06 \\
0.36\end{array}$ & $\begin{array}{l}0.35 \\
2.08\end{array}$ & $\begin{array}{l}0.07 \\
0.32\end{array}$ & $\begin{array}{l}0.17 \\
1.55\end{array}$ & $\begin{array}{l}0.86 \\
2.17\end{array}$ \\
\hline LINN & 1.67 & 9.24 & 2.14 & 1.11 & 1.17 & 4.59 & 0.05 & 3.13 & 4.65 \\
\hline MALHEUR & 2.40 & 0.14 & 1.59 & 0.27 & 0.73 & 2.66 & 0.31 & 1.12 & 1.70 \\
\hline MORROW & 0.85 & 0.38 & 0.21 & 0.13 & 0.10 & 0.43 & 0.05 & 0.13 & 0.40 \\
\hline TILLAMOOK & 0.60 & 0.79 & 0.33 & 0.11 & 0.14 & 1.04 & 0.14 & 0.73 & 1.42 \\
\hline UMATILLA & 1.86 & 1.63 & 1.09 & 0.39 & 1.03 & 3.83 & 0.46 & 2.50 & 3.89 \\
\hline UNION & 0.55 & 1.38 & 0.07 & 0.17 & 0.55 & 1.55 & 0.24 & 0.98 & 1.89 \\
\hline WALLOWA & 0.53 & 0.28 & 0.01 & 0.07 & 0.08 & 0.37 & 0.09 & 0.15 & 0.59 \\
\hline WASCO-SHERMAN & 0.67 & 0.94 & 0.23 & 0.24 & 0.37 & 1.78 & 0.20 & 1.38 & 2.11 \\
\hline WHEELER & 0.17 & 0.23 & 0. & 0.01 & 0.03 & 0.05 & 0.01 & 0.01 & 0.15 \\
\hline YAMHILL & 1.34 & 2.57 & 0.96 & 0.43 & 0.35 & 2.37 & 0.83 & 2.36 & 2.15 \\
\hline
\end{tabular}


TABLE XVI (continued)

OREGON: TOTAL EMPLOYMENT

1976

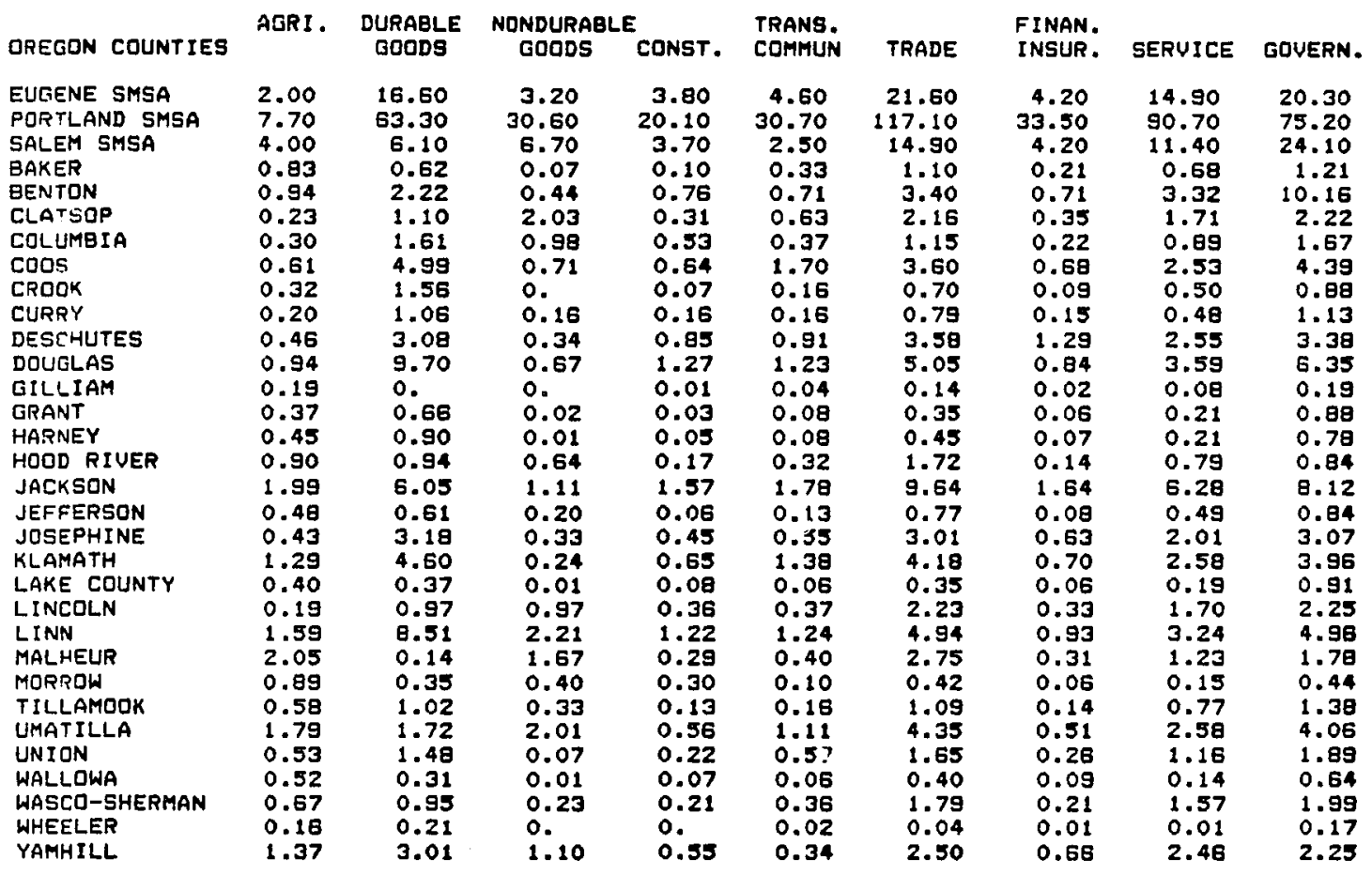


TABLE XVII (continued)

OREGON: TOTAL EMPLOYMENT

1977

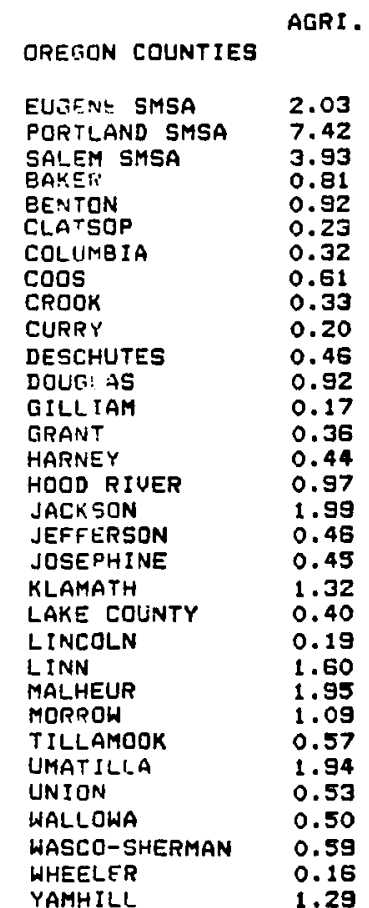

DURABLE NONDURABLE

TRANS. FINAN.

GOODS GOODS

CONST.

COMMUN TRADE

INSUR.

SERUICE

GOUERN.

17.20
67.70

3.50
31.20

31.20

4.90
22.70

6.70

7.20

22.70

4.80

23.30
124.10

4.60
37.20

16.90

96. 20

20.80

0.60
3.14

0.07
0.47

0.13

3.00

16.50

4.70

12.60

0.73

3.72

0.77

2.44

0.80

0.41

0.22

1.66

5.36

1.70

2.28
1.03

0.37

0.62

0.43
1.76

0.78
0.04

0.04

0.72

$0.08 \quad 0.14$

0.170 .18

3.41

9.86

0.

0.40

0.68

1.31

0.19

1.21

4.00
0.75

0.73

0.73
0.09

0.84

4.11

1.28

0.01

$0.73 \quad 0.03$

$0.65 \quad 0.01$

$0.98 \quad 0.62$

$6.64 \quad 1.15$

0.03

0.04

0.08

5.37

0.14

0.35

$0.08 \quad 0.08 \quad 0.49$

0.34

1.71

1.85

10.60

0.05

0.13

0.85

$3.39 \quad 0.35$

$4.89 \quad 0.25$

$0.40 \quad 0.01$

$1.05 \quad 1.07$

8.72

0.12

0.38

2.35

2.35
1.65

0.44

0.36

1.78

1.57

2.38

0.08

$0.29 \quad 0.02$

0.98

0.20

0.2

0 .

$\begin{array}{ll}0.67 & 1.46 \\ 0.06 & 0.06\end{array}$

0.06

4.35

0.36

0.44

0.40

1.31

0.35

0.42

2.60

5.47

2.80

0.45

$0.16 \quad 0.17$

$0.73 \quad 1.22$

1. 23

4.49

1.76

0.06

0.60

0.37

0.01

3.39

0.02
0.37

1.84

0.04

2.83

0.17

1.58

0.90

0.02

0.06

0.15

1.76

0.09

0.70

0.80

0.05

0.37

1.08

0.33
0.07

0.17

0.56

0.26

0.10

0.22

0.01

3.65

1.78
1.02

1.02
2.56

0.55

1.28

3.90

$\begin{array}{ll}3.90 & 6.62 \\ 0.07 & 0.16\end{array}$

$0.24 \quad 0.94$

$0.23 \quad 0.80$

$0.85 \quad 0.93$

$6.69 \quad 8.53$

$0.58 \quad 0.87$

$2.42 \quad 3.09$

$2.70 \quad 4.10$

$0.20 \quad 0.93$

$1.97 \quad 2.20$

$3.43 \quad 5.14$

$1.28 \quad 1.85$

$0.16 \quad 0.47$

$0.84 \quad 1.43$

$2.72 \quad 4.35$

$1.31 \quad 1.93$

0.160 .60

$\begin{array}{ll}1.54 & 1.99\end{array}$

2.692 .25 
TABLE XVI (continued).

OREGON: TOTAL EMPLOYMENT

1978

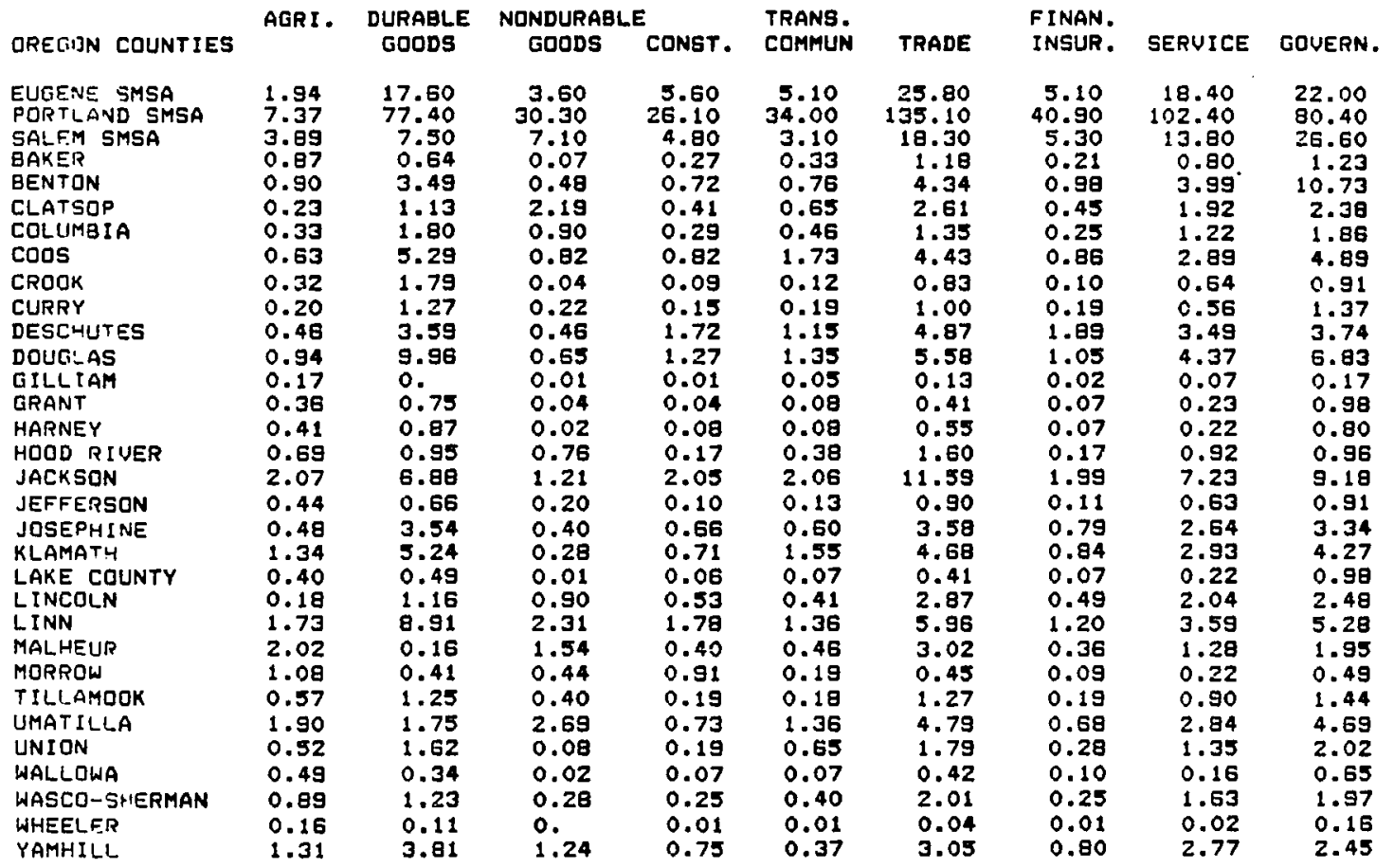


TABLE XVI (continued)

OREGON: TOTAL EMPLOYMENT

1979

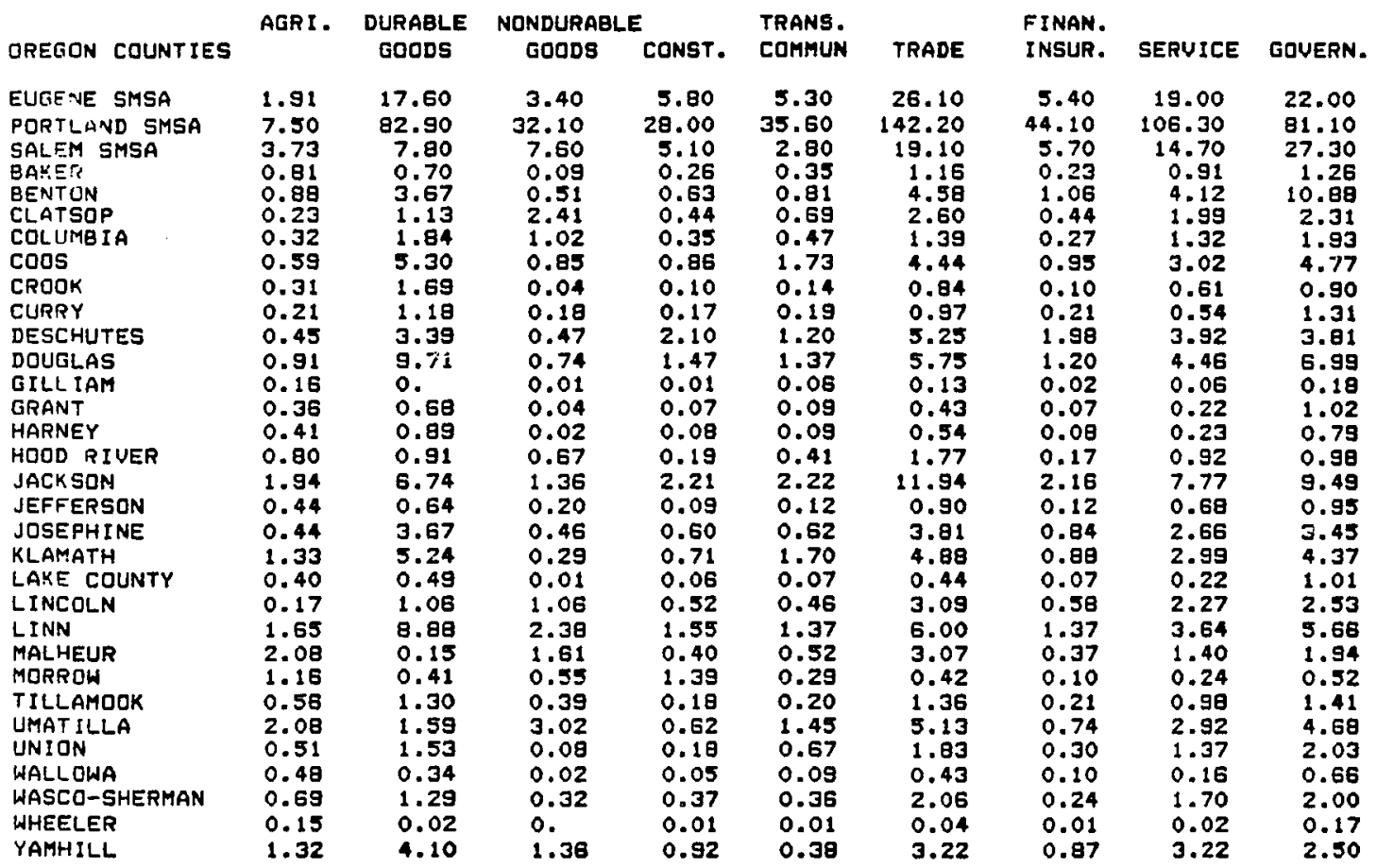


TABLE XVI (continued)

OREGON: TOTAL EMPLOYMENT

1980

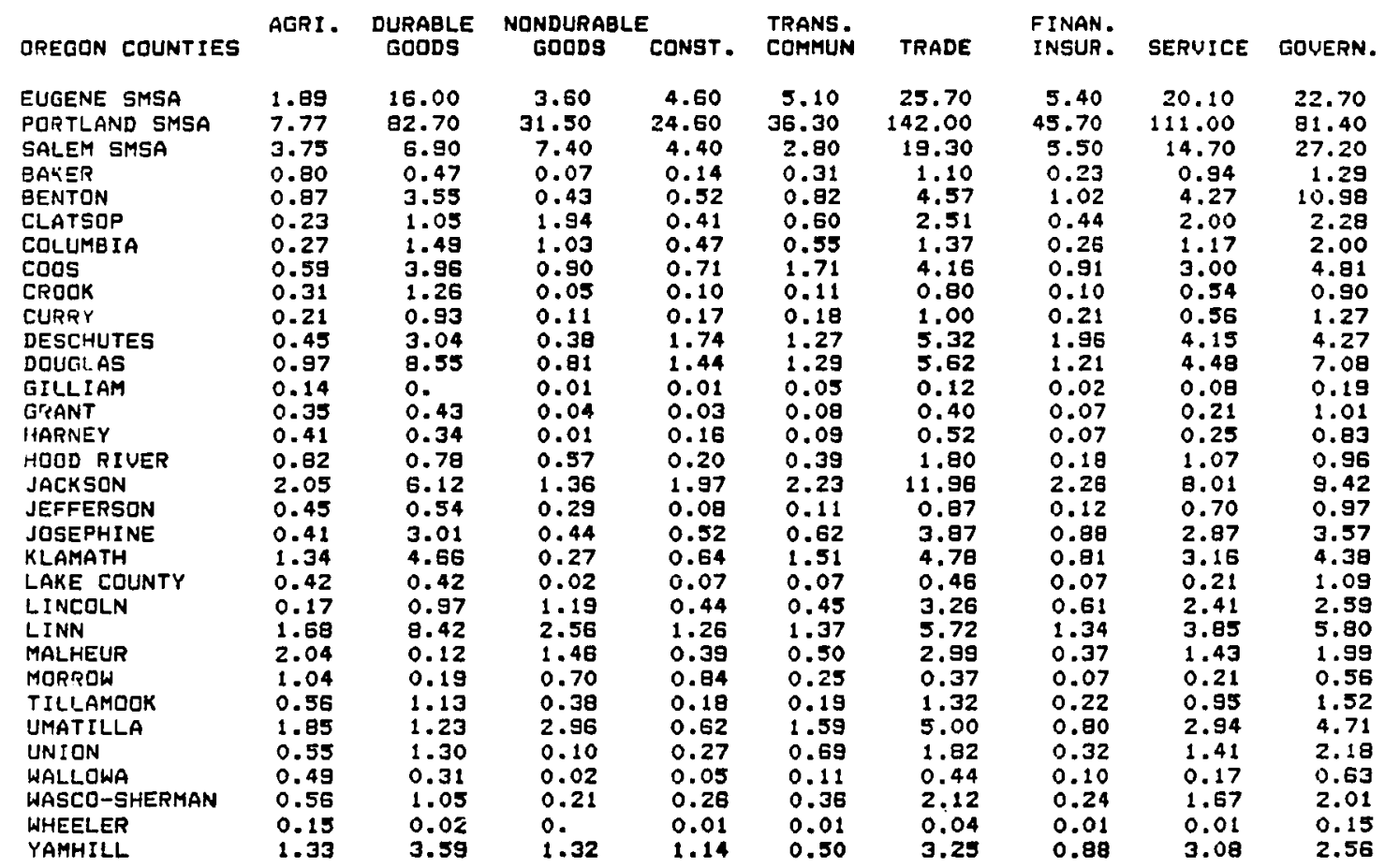


TABLE XVI (continued)

OREGON: TOTAL EMPLOYMENT

1981

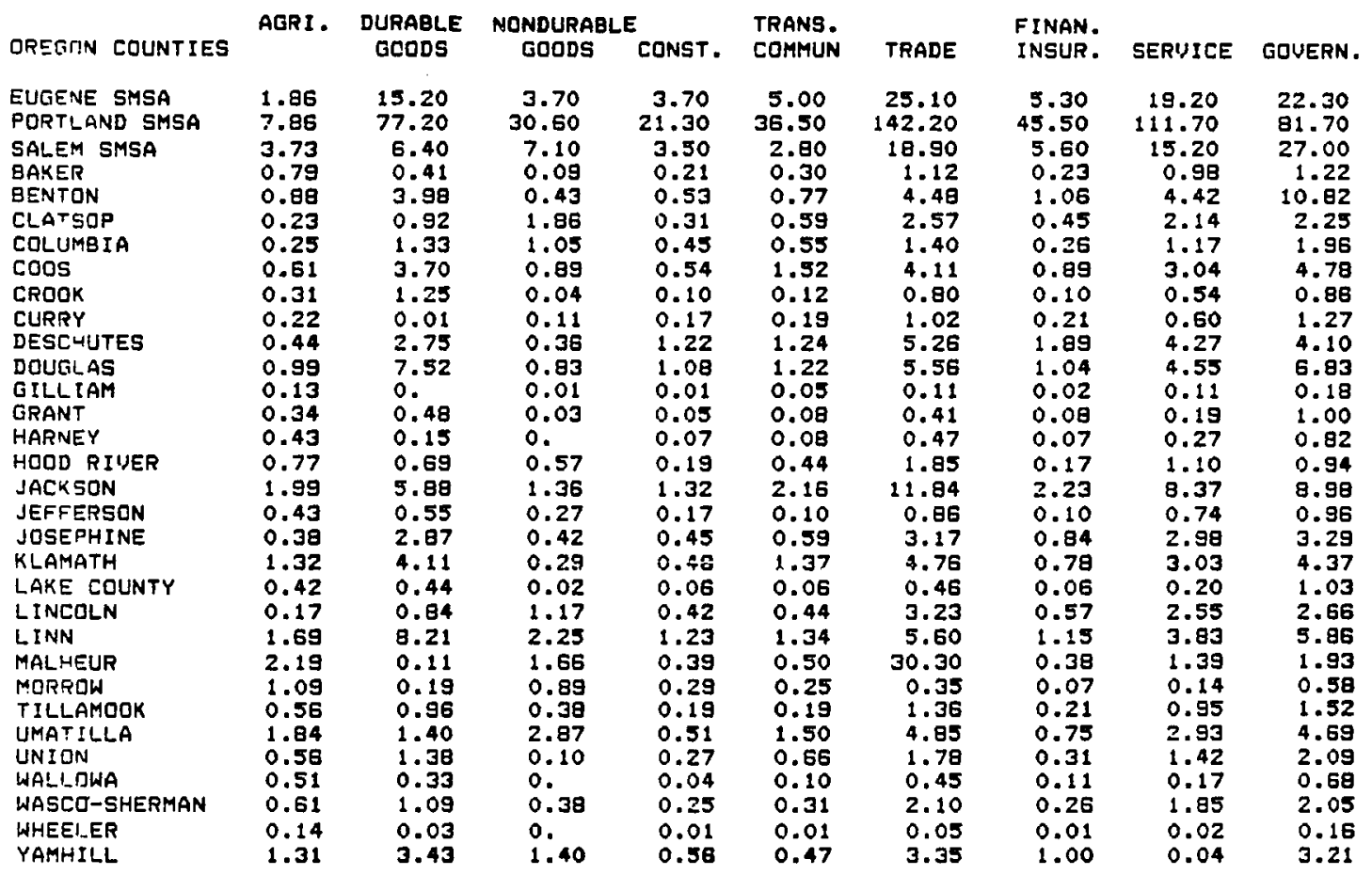


TABLE XVII

OREGON UNEMPLOYMENT RATES * BY COUNTY, 1972-1981

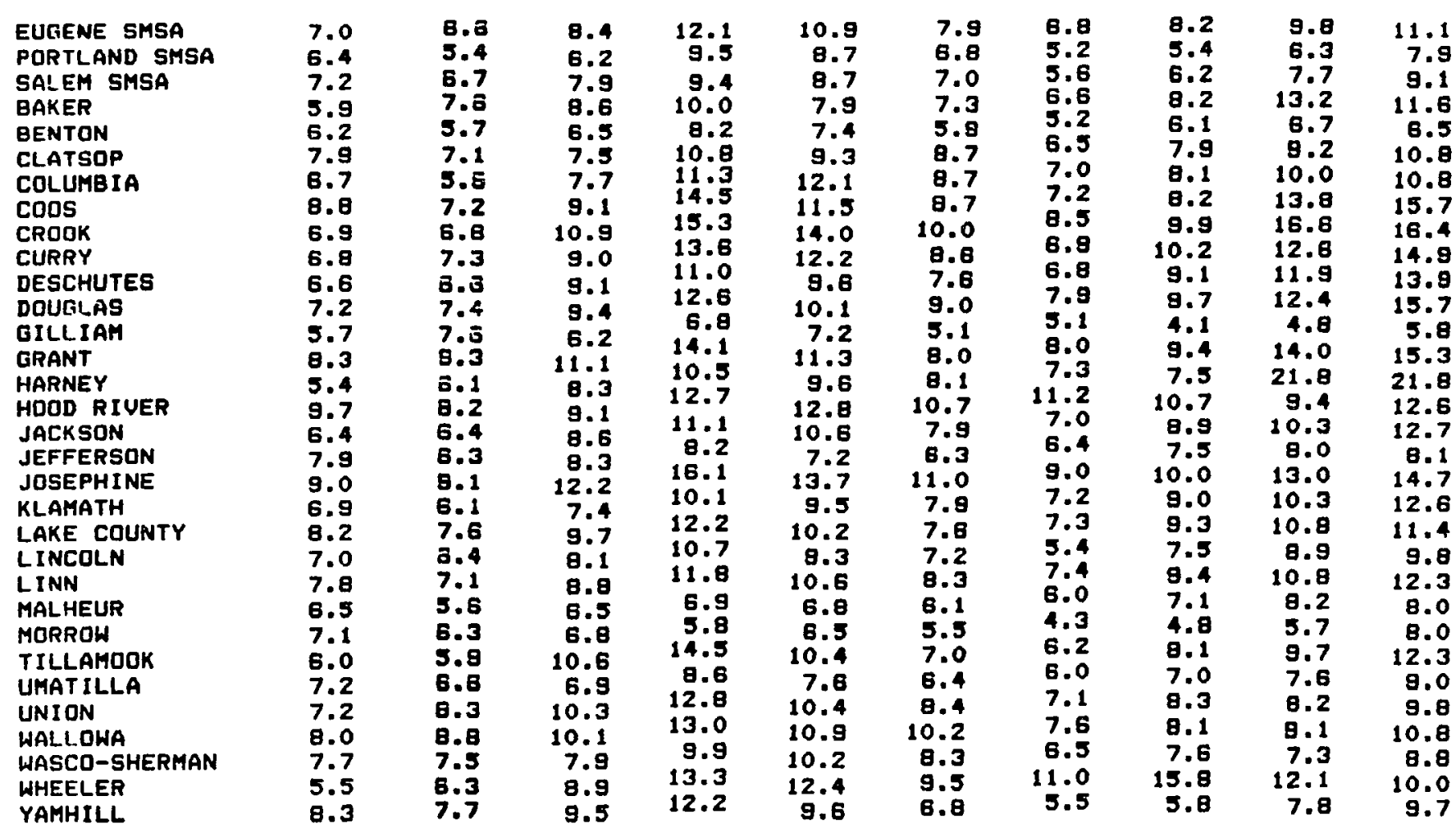

- Unemployment as percent of labor force.

Source: State of Oregon, Department of Economic Development 
TABLE XVIII

OREGON PER CAPITA INCOME BY COUNTY AND PLACE OF RESIDENCE,

(in dollars)

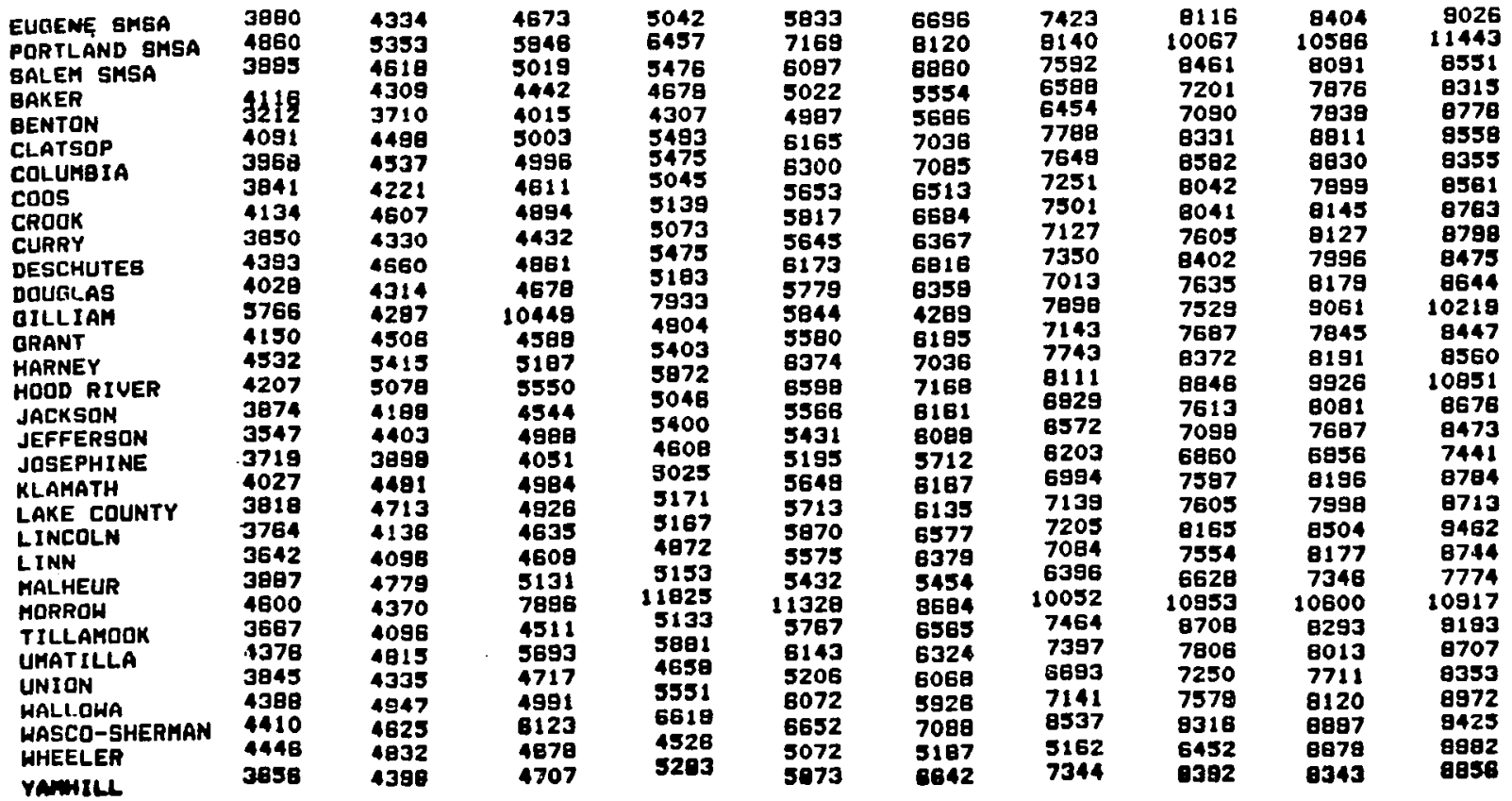

Source: State of Oregon, Department of Economic Development, "Oregon County Economic Indicators," 1981, 1983 
TABLE XIX

OREGON INDICES OF DIVERSITY

County

\begin{tabular}{l} 
EUGENE SMSA \\
PORTLAND SMSA \\
SALEM SMSA \\
BAKER \\
BENTON \\
CLATSOP \\
COLUMBIA \\
COOS \\
CROOK \\
CURRY \\
DESCHUTES \\
DOUGLAS \\
GILLIAM \\
GRANT \\
HARNEY \\
HDOD RIUER \\
JACKSON \\
JEFFERSON \\
JOSEPHINE \\
KLAMATH \\
LAKE CDUNTY \\
LINCDLN \\
LINH \\
MALHEUR \\
MORROW \\
TILLAMOOK \\
UMATILLA \\
UNION \\
WALLOWA \\
WASCD-SHERMAN \\
WHEELER \\
YAMHILL \\
\hline
\end{tabular}

1972

2.77095291 2.90673557 2.85031646 2.85379684 2.47273493 2.81079060 2.90168691 2.76827160 2.44482660 2.62375429 2.85250089 2.59153110 2.29605106 2.53228104 2.51258543 2.89202003 2.80866620 2.81664079 2.73001590 2.80830914 2.53468481 2. 02977271 2. 03977520 2.66270727 2.61320919 2.76336485 2.86654955 2. 75339210 2.58983827 2. 86589047 1.99244533 2.92246819
1973

2.78954357

2.89625987

2.84978390

2.78385910

2.49474573

2.83232677

2.91262347

2.78148627

2. 49849823

2.59657085

2.86819941

2.59501295

2.26028734

2.53671268

2.55509850

2.92065853

2.82889950

2. 76548398

2.74805579

2.78797510

2.51596063

2. 83589715

2.81535652

2.66371566

2.63591215

2.76556078

2.89185071

2.74307638

2.58595058

2. 01780276

2.12519848

2.91873389

\section{4}

2.78983322

2. 88196644

2. 82723442

2.75601777

2.50173542

2.80876651

2.89670452

2.76042888

2.56509998

2.61770156

2.85022244

2.60189736

2. 48455384

2.57011148

2.57131171

2.91日34894

2.83649379

2.79195163

2.74520355

2.78212360

2.48347902

2.80289784

2.80215034

2.71305135

2.65732005

2.85790339

2.89295164

2.75178662

2.60050038

2.77041179

2.21931481

2.90885565
1975

2.75355870

2.85628736

2.79742187

2. 80812696

2.44503564

2.81850526

2.87820059

2.77418247

2.57713631

2.69754016

2.82244408

2.63036448

2. 49716783

2.54949012

2.53309014

2. 89489982

2.80996162

2.76309377

2.71749428

2.76807648

2.51119417

2. 75140983

2.80785108

2.75553218

2.75375706

2.77153945

2. 97493973

2.72340104

2.63049340

2. 73966274

2.27929291

2.89866248 
TABLE XIX (continued)

OREGON INDICES OF DIVERSITY

County

\begin{tabular}{l} 
EUGENE SMSA \\
PORTLAND SMSA \\
SALEM SMSA \\
BAKER \\
BENTON \\
CLATSOP \\
COLUMBIA \\
CODS \\
CROOK \\
CURRY \\
DESCHUTES \\
DOUGLAS \\
GILLIAM \\
GRANT \\
HARNEY \\
HOOD RIVER \\
JACKSON \\
JEFFERSON \\
JOSEPHINE \\
KLAMATH \\
LAKE COUNTY \\
LINCOLN \\
LINN \\
MALHEUR \\
MORROW \\
TILLAMOOK \\
UMATILLA \\
UNION \\
WALLOWA \\
WASCD SHERMAN \\
WHEELER \\
YAMHILL \\
\hline
\end{tabular}

1976

2.75234994 2.85037330 2.79834649 2. 78135604 2.44203854 2.81589451 2.89969382 2.76410395 2.46021429 2.71462733 2.81806326 2.61985600 2.35378748 2.49837264 2. 50783628 2.865639日1

2.78691417

2.78289822

2.70153090

2.75912270

2.52114463

2.76014033

2.80919209

2.72580004

2.84677154

2. 78379190

2. 88452497

2.73770016

2.51149049

2.73579931

2.15217155

2.89649788
1977

2. 76877192 2.85086548 2.80787721 2.79900435 2.49408144 2.80505261 2. 90960807

2.75719234 2.48129529 2.72857359 2.84816024 2. 62855420 2.43127349 2.49171659 2.55567637 2.86587320 2.77953818

2.76104295

2.71576834

2.76250964

2. 4986:592

2.76490453

2.82996291

2. 73922113

2.83062515

2. 79537019

2.90902907

2.72912139

2.65632370

2.73369725

2.24572161

2.88997179
1978

2.76312864 2.84354161

2.81311134

2.83801761

2.49119294

2.81818125

2.85272819

2.77715233

2.47262645

2.68966842

2.85289511

2.63415986

2.44833505

2.51731381

2.55633834

2.90769410

2. 78243792

2.79410815

2.72958234

2.75945979

2.51454997

2.75638416

2. 84735513

2.75484887

2.87414595

2.81442371

2.90662456

2.72169447

2.65622652

2.78784084

2.31479070

2.88296619
1979

2.76480478 2.84673861 2.80666807 2.85742295 2. 49314702 2.82037425 2.86479965 2.789717 2.50770301 2.71585107 2.85286680 2.56811311 2. 48229709 2.55500296 2.57968733 2.89687702

2.79067269

2.78147605

2.71720496

2.76431394 2.50503278 2.75404671 2.8432959E 2. 76205656 2.82779285 2.81360430 2.89364615 2.72398487

2.65959567 2.79019958 2.16835248 2.88485751 
TABLE XIX (continued)

OREGON INDICES OF DIVERSITY

County

EUGENE SMSA
PORTLAND SMSA
SALEM SMSA
BAKER
GENTON
CLATSOP
COLUMBIA
CDOS
CROOK
CURRY
DESCHUTES
DOUGLAS
GILLIAM
GRANT
HARNEY
HOOD RIUER
JACKSON
JEFFERSON
JOSEPHINE
KLAMATH
LAKE COUNTY
LINCOLN
LINN
MALHEUR
MORROW
TILLAMOOK
UMATILLA
UNION
WALLOWA
WASCO-SHERMAN
WHEELER
YAMHILL
YIMA

1980

2.74476281

2.83746257

2. 78287858

2. 77568364

2. 46234825

2.82099825

2.89849451

2.81670323

2.58974469

2.71061283

2.82069689

2. 70385572

2. 49221593

2.51107258

2. 56884392

2.88349918

2.78846210

2.75743257

2.71181843

2.75865012

2.49814329

2. 72567782

2.84977329

2.75242555

2.83914971

2.81397489

2. 88496533

2. 76353148

2.68619639

2.71132457

2.14176014

2.93786842
1981

2.73569840

2.82475817

2.76170490

2. 30939456

2.4763379 !

2.78909039

2.89917311

2.79713586

2.59199038

2.51416832

2.78783429

2.70014268

2.52052368

2.52831876

2.51822519

2.87103102

2.75746557

2.82236803

2.72154850

2.74517462

2.48709282

2. 59702688

2.93388495

1. 33171183

2.75013511

2.81617586

‥87923992

2.76872632

2.60547161

2.74327186

2.27120668

2.70876613 
APPENDIX B

U.S.: DATA AND RESULTS 
TABLE XX

U.S.: TOTAL EMPLOYMENT

1972

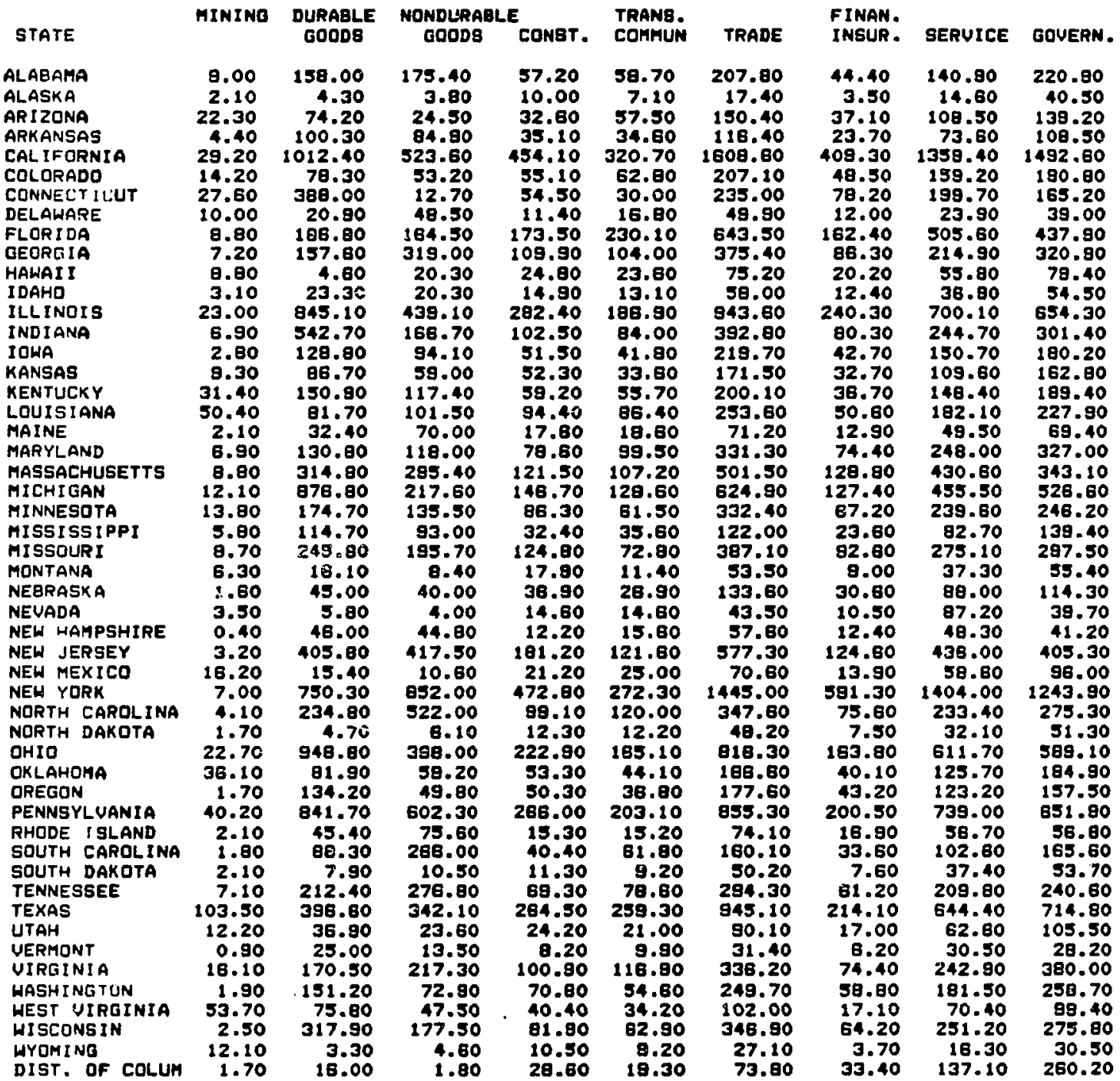

- Sources: U. S. Department of Labor, Bureau of Labor

. S. Department lo went and Earnings states and Areas, 1939-1978, Bul1etin $1370-13,1979$, and

U. S. Department of Labor, Supplement to Employment and Earnings, States and Areas, 1977-81, Bulletin 1370-16, 1982 . 
TABLE XX (continued)

U.S.: TOTAL EMPLOYMENT

1973

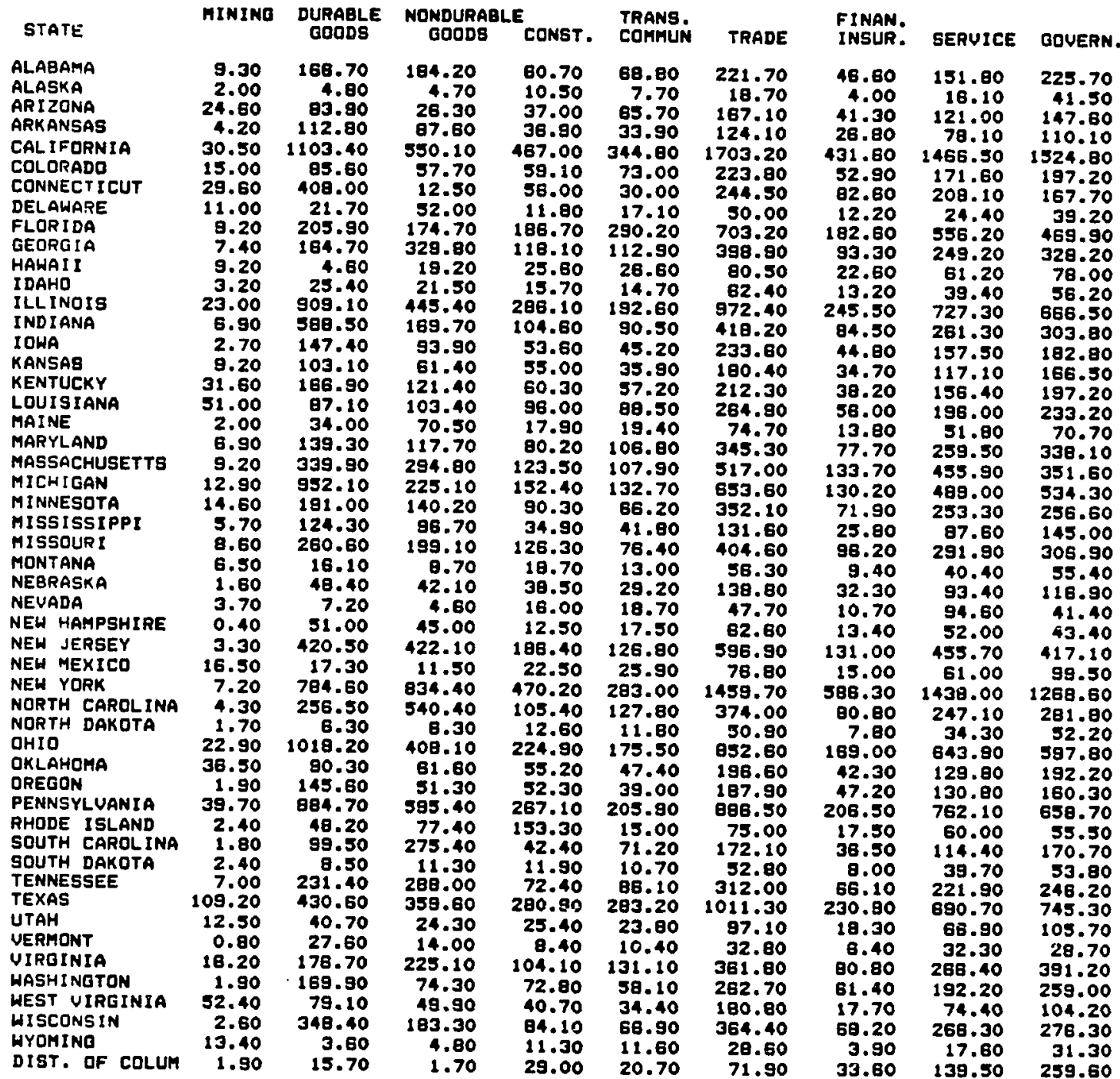


TABLE XX (continued)

U.S.: TOTAL EMPLOYMENT

1974

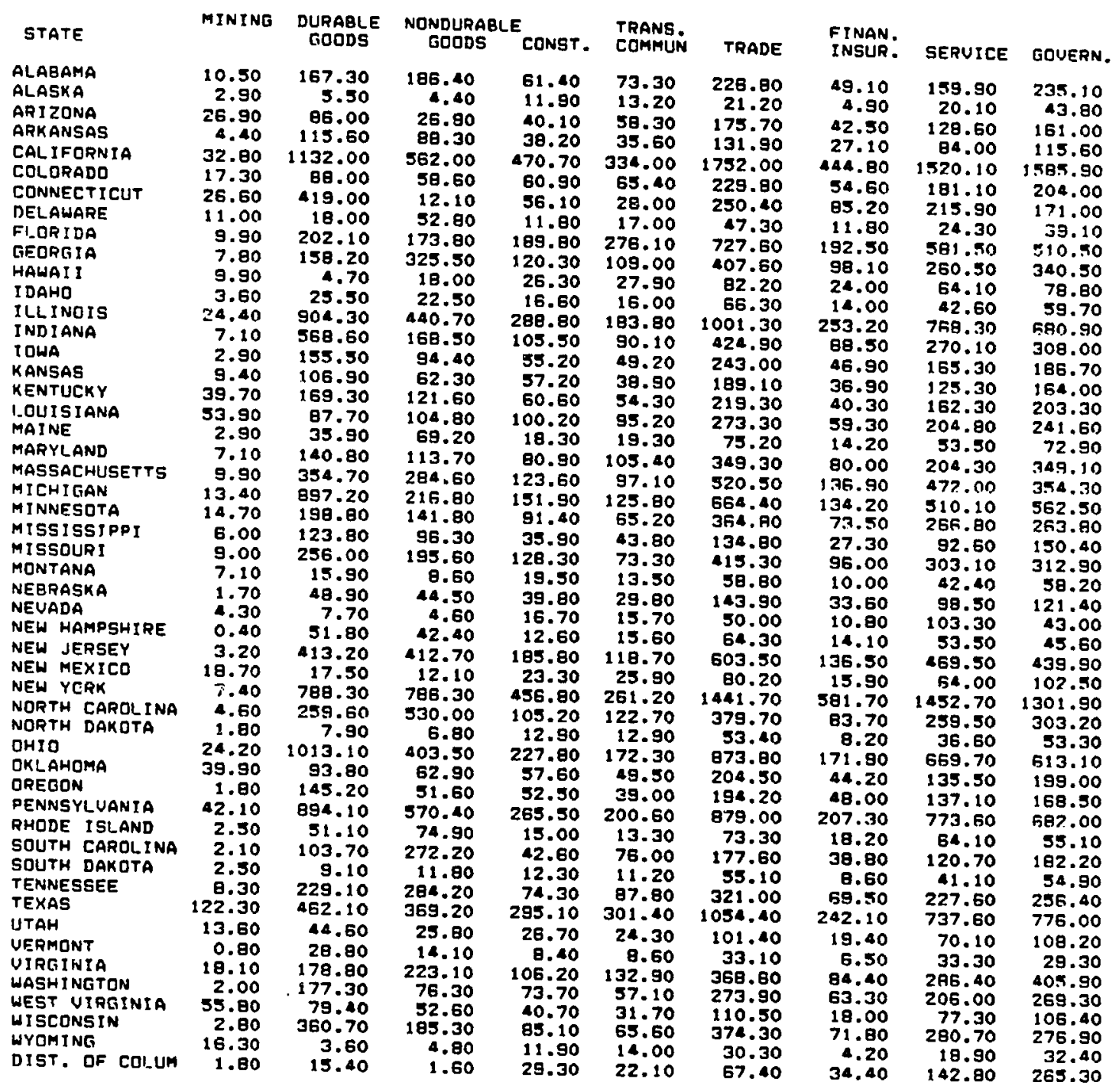


TABLE $x \times$ (continued)

U.S.: TOTAL EMPLOYMENT

1975

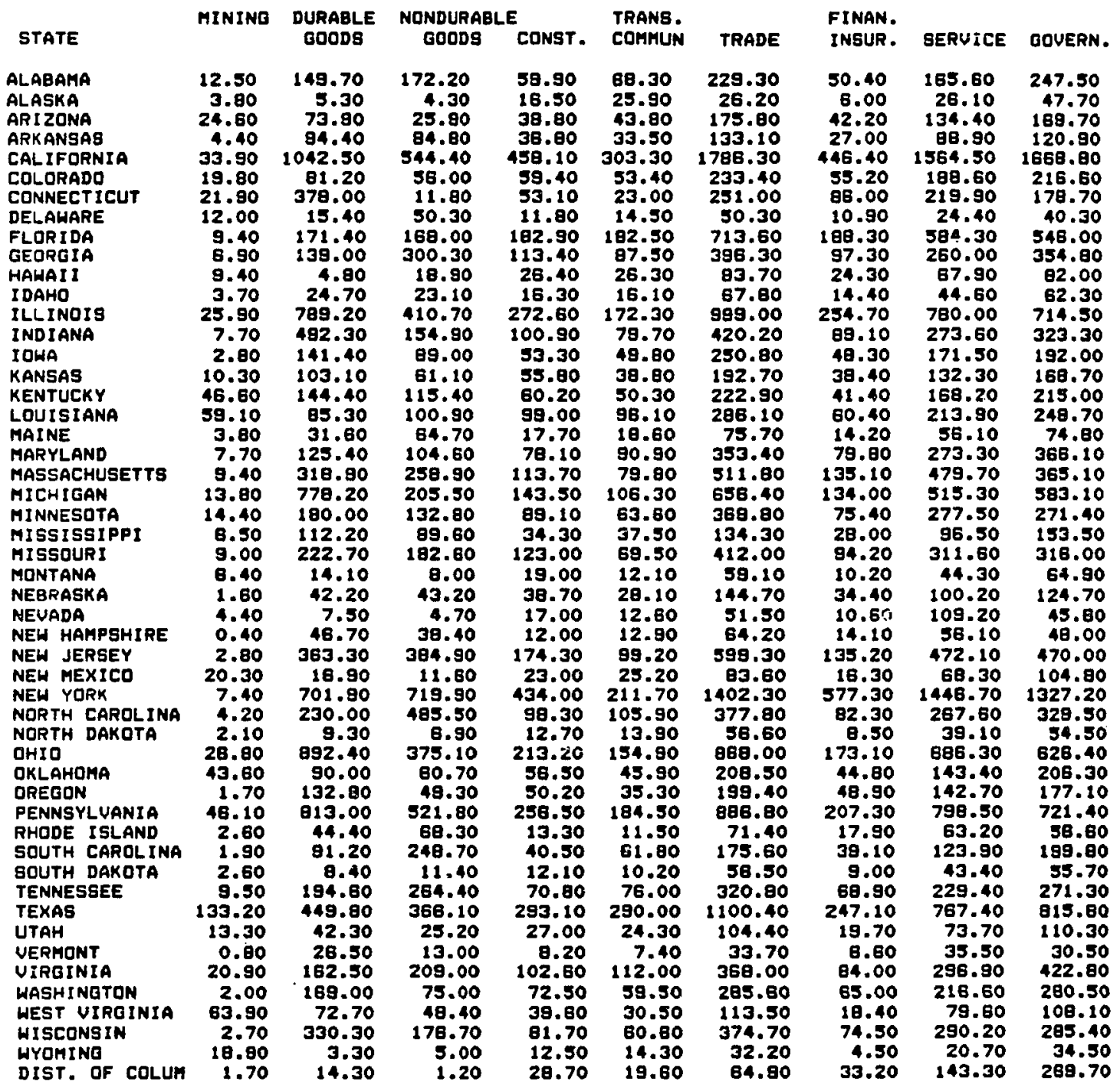


TABLE XX (continuea)

U.S.: TOTAL EMPLOYMENT

1976

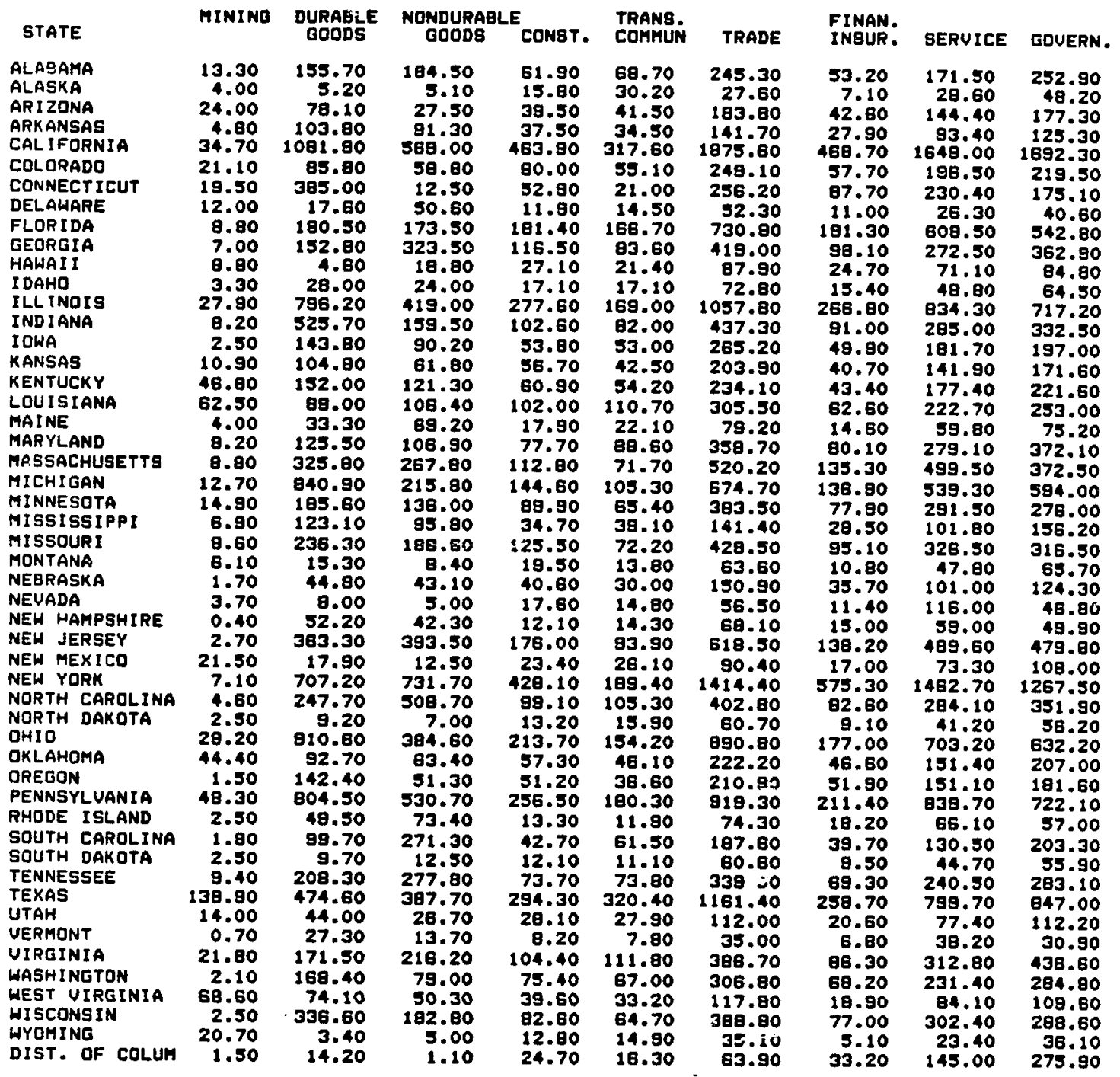


TABLE XX (continued)

U.S.: TOTAL EMPLOYMENT

1977

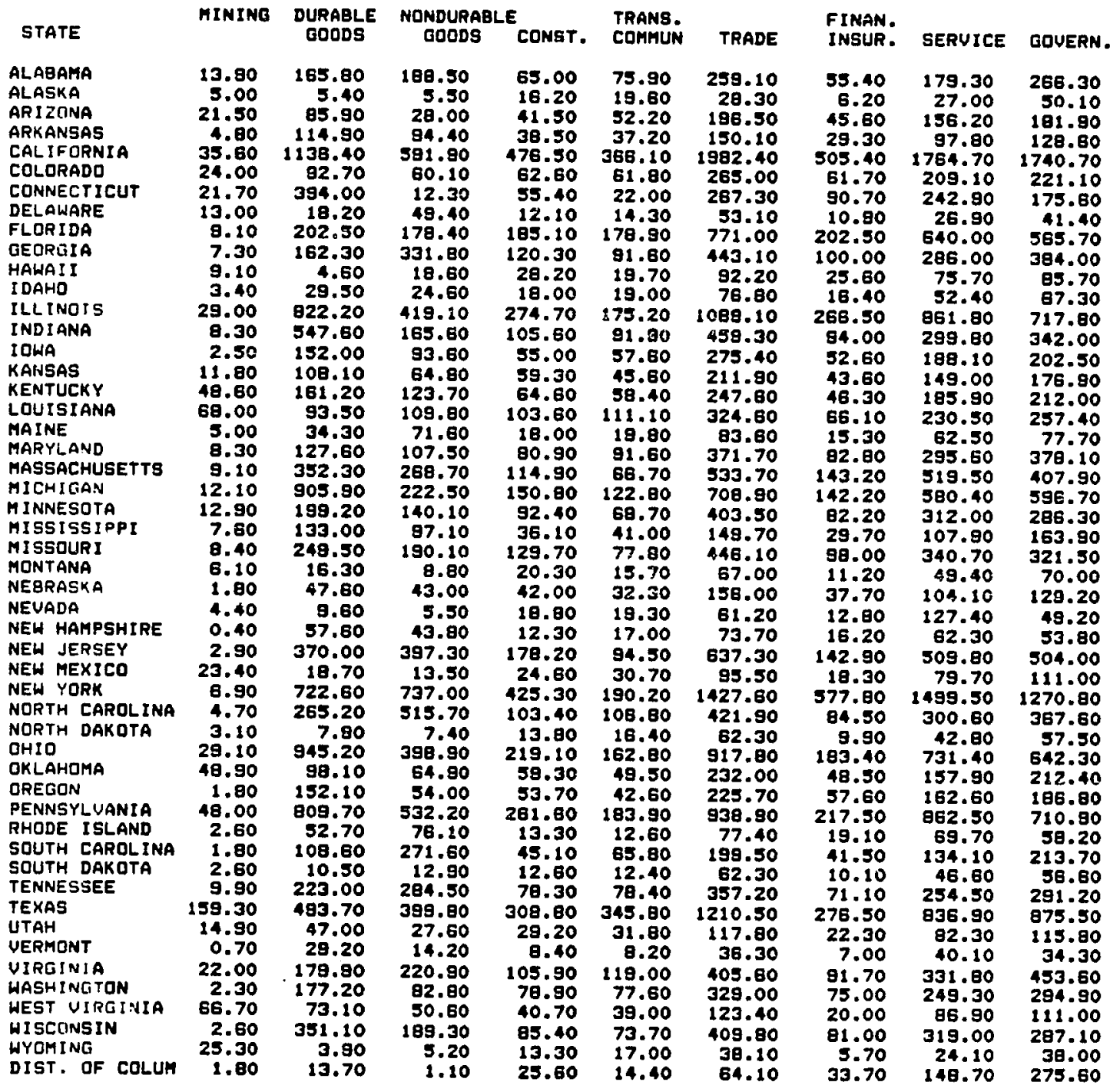


TABLE XX (continued)

U.S.: TOTAL EMPLOYMENT

1978

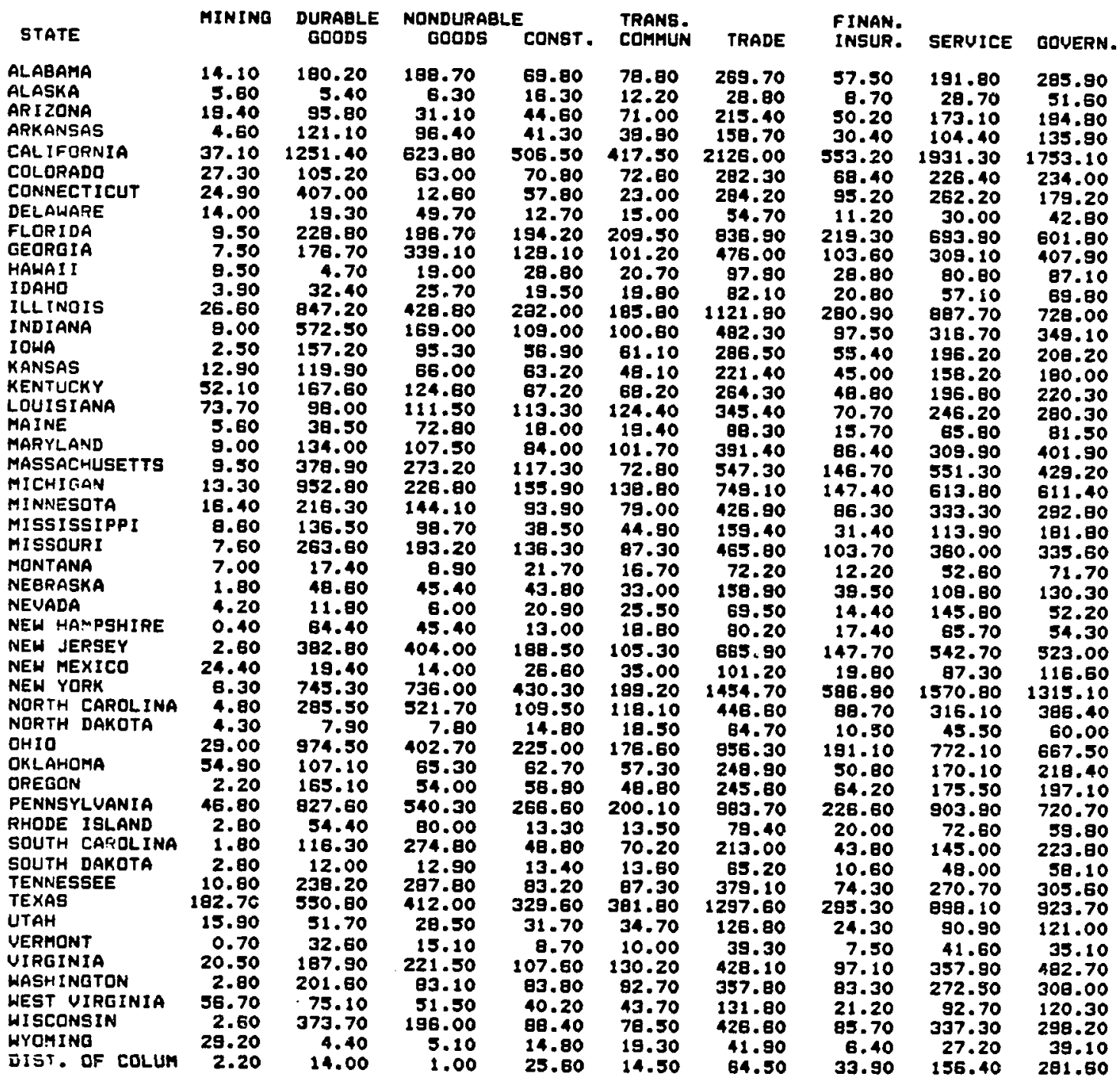


TABLE XX (continued)

U.S.: TOTAL EMPLOYMENT

2979

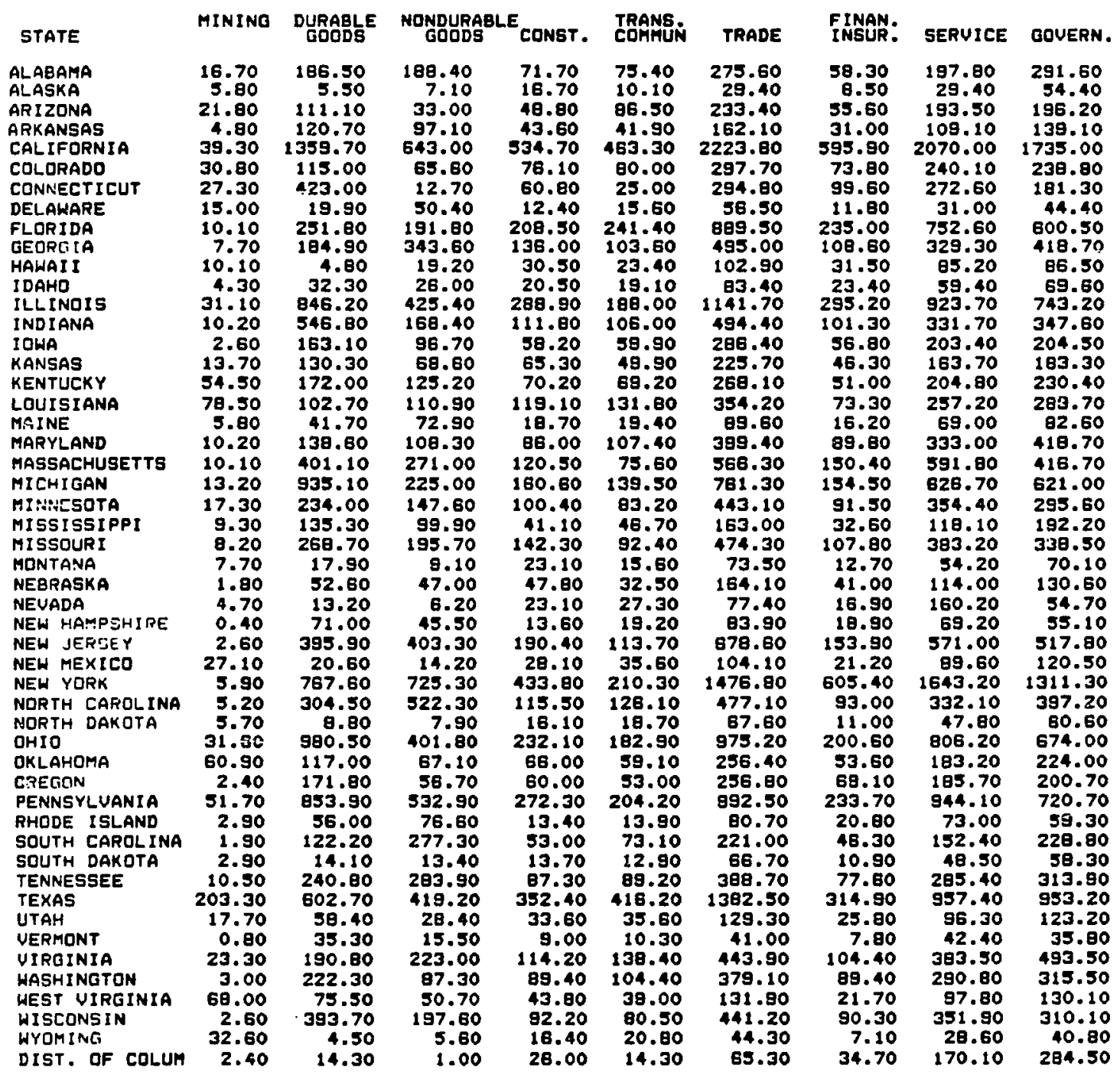


TABLE XX (continued)

U.S.: TOTAL EMPLOYMENT

1980

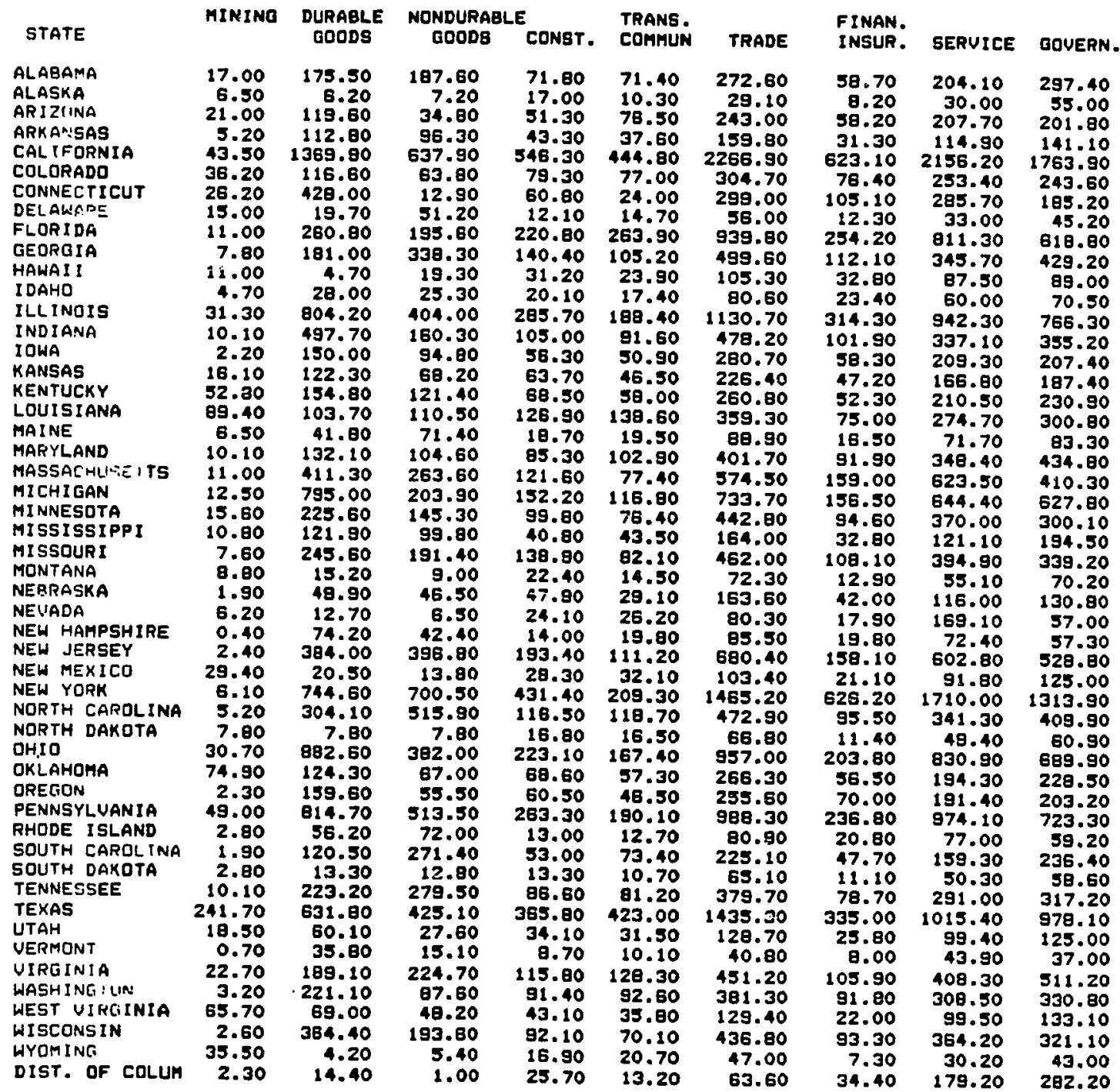


TABLE XX (continued)

U.S.: TOTAL EMPLOYMENT

1981

\begin{tabular}{|c|c|c|c|c|c|c|c|c|c|}
\hline STAT & INING & & & & & TRADE & & & \\
\hline $\begin{array}{l}\text { TLABAMA } \\
\text { ALASKA } \\
\text { ARIZONA } \\
\text { ARKANSAS } \\
\text { GALIFORNIA } \\
\text { OOLORADO } \\
\text { CONMECTICUT } \\
\text { DELAWARE } \\
\text { ILORIDA } \\
\text { OEORGIA } \\
\text { HAWAII } \\
\text { IDAHD } \\
\text { ILLINOIS } \\
\text { INDIANA } \\
\text { IOWA } \\
\text { KANSAS } \\
\text { KENTUCKY } \\
\text { LUISIANA } \\
\text { MAINE } \\
\text { MARYLAND } \\
\text { MASSACHUSETTS } \\
\text { MICHIGAN } \\
\text { MINNESOTA } \\
\text { MISSISSIPPI } \\
\text { MISSOURI } \\
\text { MONTANA } \\
\text { NEBRASKA } \\
\text { NEUADA } \\
\text { NEW HAMPSHIRE } \\
\text { NEW JERSEY } \\
\text { NEW MEXICO } \\
\text { NEW YORK } \\
\text { NORTH CAROLINA } \\
\text { NORTH DAKOTA } \\
\text { OHIO } \\
\text { OKLAHOMA } \\
\text { OREGON } \\
\text { PENNSYLUANIA } \\
\text { RHODE ISLAND } \\
\text { SOUTH CAROLINA } \\
\text { SOUTH DAKOTA } \\
\text { TENNESSEE } \\
\text { TEXAS } \\
\text { UTAH } \\
\text { UERMONT } \\
\text { UIRGINIA } \\
\text { WASHINGTON } \\
\text { WEST UIRGINIA } \\
\text { WISCONSIN } \\
\text { WYOMING } \\
\text { DIST. OF COLUM }\end{array}$ & $\begin{array}{r}15.40 \\
7.70 \\
23.00 \\
5.90 \\
49.00 \\
42.30 \\
26.30 \\
15.80 \\
11.20 \\
7.80 \\
11.20 \\
4.90 \\
26.70 \\
9.00 \\
1.90 \\
19.10 \\
50.50 \\
97.40 \\
7.70 \\
9.00 \\
11.20 \\
12.10 \\
15.70 \\
12.60 \\
6.80 \\
11.50 \\
1.70 \\
7.90 \\
0.40 \\
2.40 \\
31.30 \\
6.30 \\
4.90 \\
10.90 \\
30.30 \\
95.70 \\
2.20 \\
45.20 \\
2.90 \\
1.90 \\
2.90 \\
10.20 \\
289.80 \\
20.20 \\
0.60 \\
21.40 \\
3.10 \\
58.00 \\
2.20 \\
38.20 \\
2.20 \\
\end{array}$ & 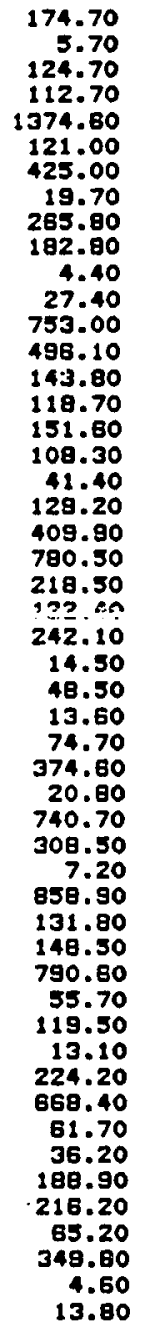 & $\begin{array}{r}197.50 \\
6.30 \\
34.90 \\
97.60 \\
644.20 \\
63.40 \\
12.40 \\
51.20 \\
200.70 \\
337.10 \\
18.80 \\
24.90 \\
382.00 \\
160.80 \\
92.00 \\
69.20 \\
120.50 \\
111.80 \\
71.40 \\
101.80 \\
256.90 \\
197.20 \\
143.70 \\
99.90 \\
185.20 \\
9.00 \\
46.30 \\
6.80 \\
41.70 \\
396.40 \\
13.20 \\
691.20 \\
508.80 \\
8.10 \\
373.60 \\
87.00 \\
54.80 \\
509.20 \\
70.60 \\
268.70 \\
12.70 \\
282.50 \\
439.00 \\
27.80 \\
14.60 \\
223.00 \\
85.70 \\
46.20 \\
193.20 \\
5.50\end{array}$ & $\begin{array}{r}14.40 \\
192.50 \\
29.00 \\
129.30 \\
116.70 \\
17.10 \\
218.40 \\
59.00 \\
59.70 \\
258.30 \\
13.10 \\
53.80 \\
12.80 \\
85.60 \\
383.80 \\
34.50 \\
8.80 \\
116.60 \\
89.30 \\
41.50 \\
90.80 \\
17.90 \\
26.40\end{array}$ & $\begin{array}{r}41.90 \\
98.70 \\
13.40 \\
26.30 \\
25.70 \\
20.10 \\
109.20 \\
33.00 \\
211.40 \\
114.90 \\
14.80 \\
154.20 \\
53.80 \\
37.60 \\
182.50 \\
11.90 \\
71.20 \\
9.90 \\
78.60 \\
431.10 \\
28.30 \\
10.70 \\
115.70 \\
89.70 \\
28.40 \\
60.70 \\
19.20 \\
11.80\end{array}$ & $\begin{array}{r}311.00 \\
303.10 \\
58.40 \\
983.00 \\
503.10 \\
105.50 \\
79.80 \\
1096.60 \\
469.00 \\
274.60 \\
228.20 \\
238.30 \\
369.20 \\
88.70 \\
403.50 \\
575.10 \\
713.30 \\
440.10 \\
163.40 \\
468.30 \\
73.70 \\
162.80 \\
84.80 \\
89.20 \\
690.10 \\
108.80 \\
1463.70 \\
437.30 \\
68.30 \\
946.00 \\
278.30 \\
253.70 \\
986.10 \\
61.40 \\
231.30 \\
64.40 \\
372.80 \\
1508.40 \\
130.20 \\
42.10 \\
462.80 \\
382.70 \\
131.00 \\
432.40 \\
48.70 \\
63.80\end{array}$ & $\begin{array}{r}98.00 \\
11.80 \\
205.20 \\
58.50 \\
68.40 \\
240.60 \\
21.00 \\
49.50 \\
11.30 \\
78.10 \\
346.70 \\
28.30 \\
8.20 \\
108.20 \\
91.40 \\
22.00 \\
95.90 \\
7.50 \\
34.30\end{array}$ & $\begin{array}{r}289.80 \\
33.00 \\
863.40 \\
359.50 \\
89.90 \\
60.00 \\
957.20 \\
341.00 \\
209.20 \\
173.70 \\
214.70 \\
289.10 \\
72.50 \\
387.60 \\
652.40 \\
655.20 \\
381.80 \\
120.90 \\
404.60 \\
58.70 \\
120.80 \\
175.00 \\
76.80 \\
635.20 \\
94.30 \\
1784.30 \\
352.40 \\
51.90 \\
658.20 \\
202.10 \\
192.20 \\
1005.20 \\
81.50 \\
166.20 \\
51.50 \\
308.80 \\
1085.00 \\
103.80 \\
44.50 \\
415.80 \\
317.00 \\
101.20 \\
375.90 \\
32.10 \\
184.30\end{array}$ & $\begin{array}{r}292.70 \\
57.20 \\
199.70 \\
137.80 \\
1763.20 \\
242.90 \\
184.00 \\
44.30 \\
614.80 \\
434.00 \\
89.00 \\
70.10 \\
767.20 \\
347.40 \\
209.90 \\
186.80 \\
227.10 \\
306.20 \\
62.60 \\
421.90 \\
386.50 \\
517.70 \\
298.90 \\
187.40 \\
332.60 \\
70.70 \\
130.50 \\
56.90 \\
56.50 \\
524.20 \\
125.50 \\
1300.10 \\
408.70 \\
60.50 \\
680.20 \\
236.90 \\
202.20 \\
705.40 \\
58.40 \\
234.40 \\
58.20 \\
308.70 \\
994.90 \\
125.00 \\
35.80 \\
509.60 \\
324.20 \\
130.50 \\
319.00 \\
42.96 \\
275.00\end{array}$ \\
\hline
\end{tabular}




\author{
TABLE XXI \\ U.S. UNEMPLOYMENT RATES* BY STATES, 1972-1981
}
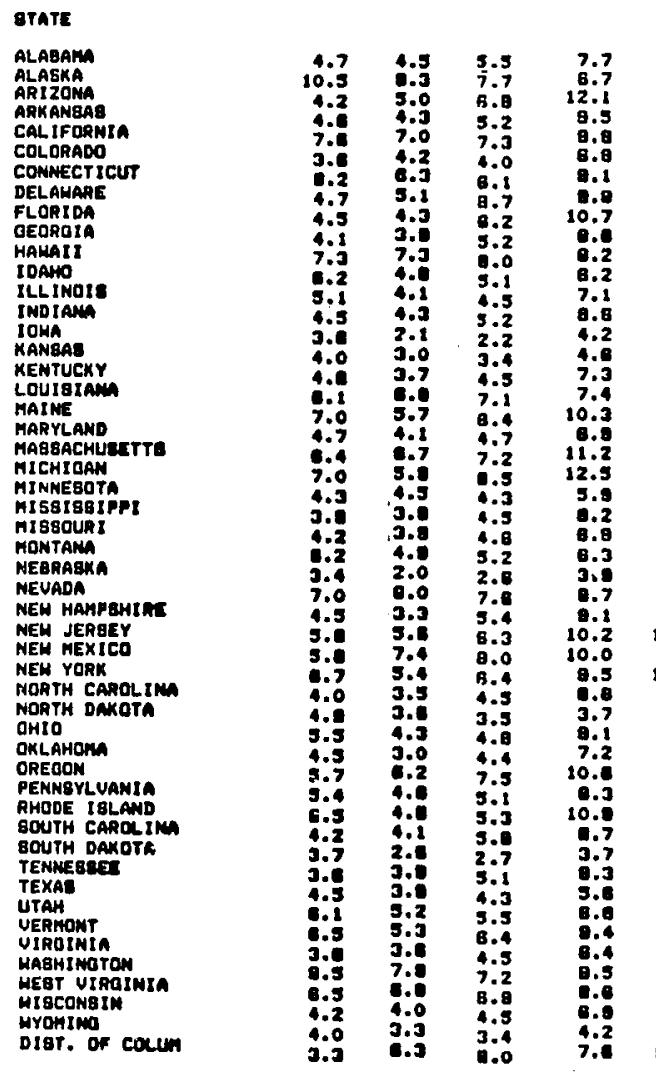

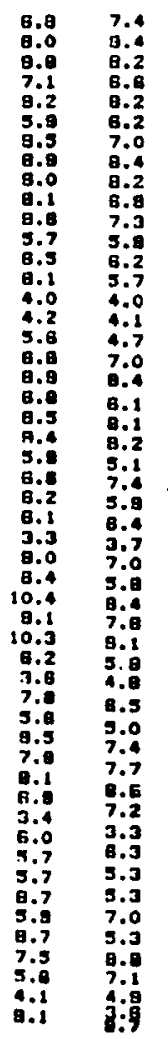
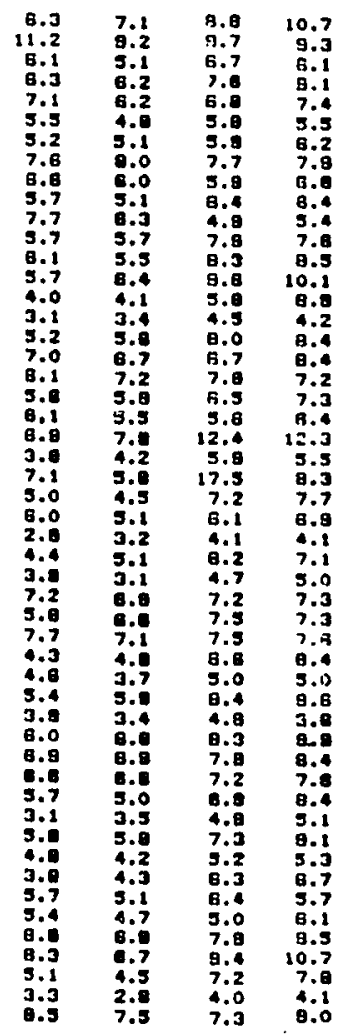

Unemployment as percent of labor force.

Source: U.S. Department of Commerce, Bureau of the Census. Statistical Abstract of the United states, Washington, 
TABLE XXII

U.S. PER CAPITA INCOME BY STATE, 1972-1981

(in dollars)

state

ALABAMA

ALASKA
ARIZONA
ARKANSAB
CALIFOAMIA

CALFOANIA
COLARECTICUT

CONHECTICUT

FLOPIDA
DEAROIA

MaHAII

ILLINOIS
INDIAMA

IOHA

KANSAB
KENUTCKY
LOUIGIAMA

LOUIEIAM MARYLAND

MICHIGAN

Mississippt

MISSOURA

MEVADA

MEN JEREEY

NEH MEXIC

MORTH CAROLINA

OKLAHONA

ORECOON

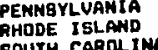

BOUTH CAROLIMA

TENAEBSEE

TEXAB

UERTONT

MASHIMGTON

HIBCoNSIN

DIGT. Of colun

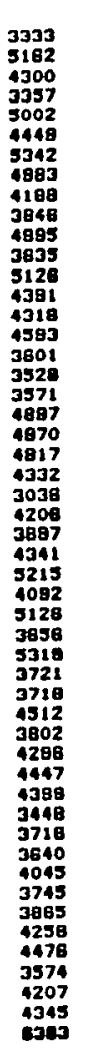

\begin{tabular}{|c|c|c|}
\hline 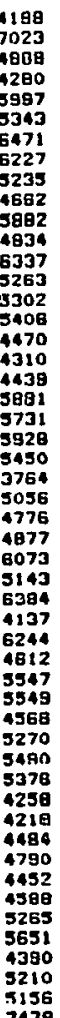 & 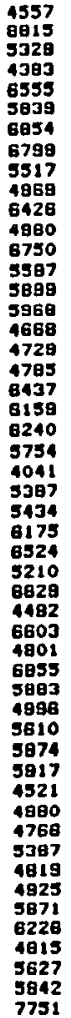 & 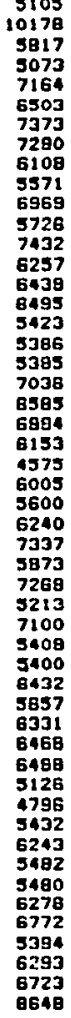 \\
\hline
\end{tabular}

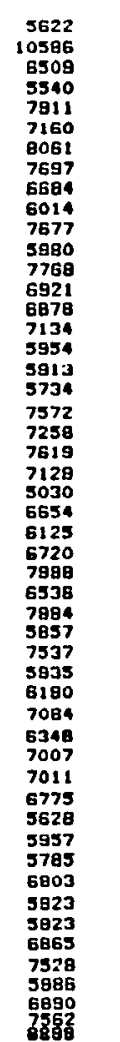

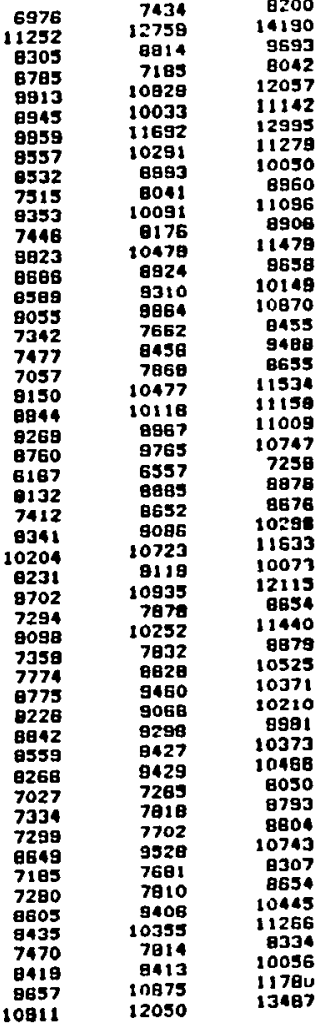

Source: Us, Department of Commerce, Bureau of the Census. Statistical Abstract of the United States, Washington, 
TABLE XXIII

CONSUMER PRICE INDEXES, BY MAJOR GROUPS 1972-1981

$$
1967=100
$$

Year

1972

1973

1974

1975

1976

1977

1978

1979

1980

1981
CPI, AlI Items

125.3

133.1

147.7

161.2

170.5

181.5

195.4

217.4

246.8

272.4

Source: U.S. Department of Commerce, Bureau of the Census. Statistical Abstract of the United States, Washington, D.C., 1972-1984. 
TABLE XXIV

U.S. INDICES OF DIVERSITY

\begin{tabular}{|c|c|c|c|c|}
\hline State & 1972 & 1973 & 1974 & 1975 \\
\hline 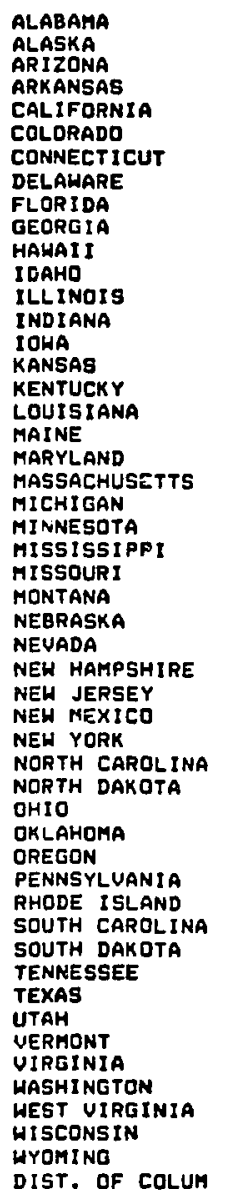 & 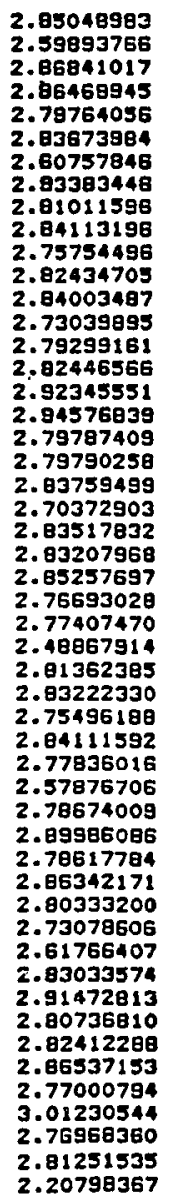 & 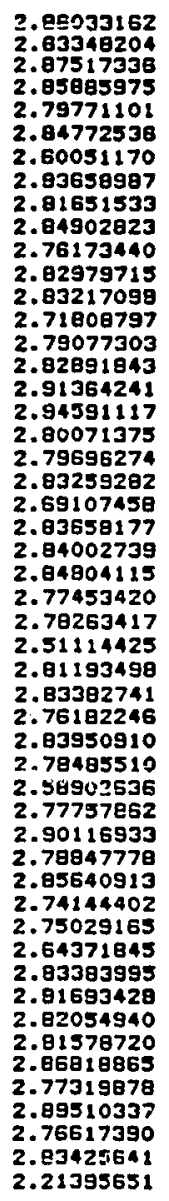 & 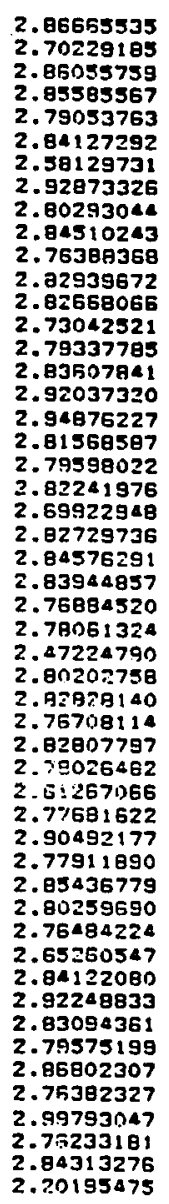 & 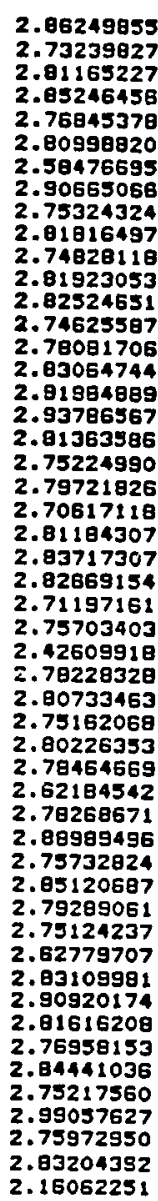 \\
\hline
\end{tabular}


TABLE XXIV (continued)

U.S. INDICES OF DIVERSITY

\begin{tabular}{|c|c|c|c|c|}
\hline State & 1976 & 1977 & 1978 & 1979 \\
\hline $\begin{array}{l}\text { ALABAMA } \\
\text { ALASKA } \\
\text { ARI ZONA } \\
\text { ARKANSAB } \\
\text { CALIFORNIA } \\
\text { COLORADO } \\
\text { CONNECTICUT } \\
\text { DELAWARE } \\
\text { FLORIDA } \\
\text { GEOROIA } \\
\text { HAHAII } \\
\text { IDAHO } \\
\text { ILLINOIS } \\
\text { INDIANA } \\
\text { IOHA } \\
\text { KANSAS } \\
\text { KENTUCKY } \\
\text { LOUISIAMA } \\
\text { MAINE } \\
\text { MARYLAND } \\
\text { MASSACHUSETTS } \\
\text { MICHIGAN } \\
\text { MINNESOTA } \\
\text { MISSISSIPPI } \\
\text { MISSOURI } \\
\text { MONTANA } \\
\text { NEBRASKA } \\
\text { NEUADA } \\
\text { NEW HAMPSHIRE } \\
\text { NEH JERSEY } \\
\text { NEW MEXICO } \\
\text { NEH YORK } \\
\text { NORTH CAROLINA } \\
\text { NORTH DAKOTA } \\
\text { OHIO } \\
\text { OKLAHOMA } \\
\text { OREGON } \\
\text { PENNSYLUANIA } \\
\text { RHODE ISLAND } \\
\text { SOUTH CAROLINA } \\
\text { SOUTH DAKOTA } \\
\text { TENHESSEE } \\
\text { TEXAS } \\
\text { UTAH } \\
\text { UERMONT } \\
\text { UIRGINIA } \\
\text { WASHINGTON } \\
\text { UEST UIRGINIA } \\
\text { HISCONSIN } \\
\text { WYOMING } \\
\text { DIST. OF COLUH }\end{array}$ & 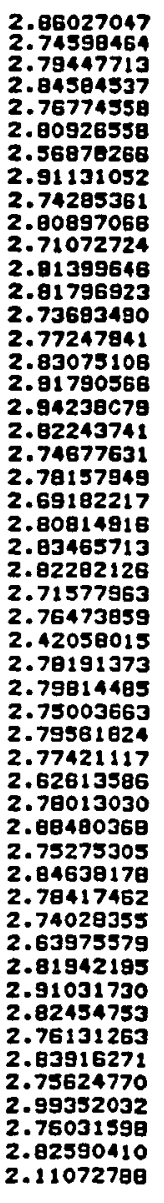 & 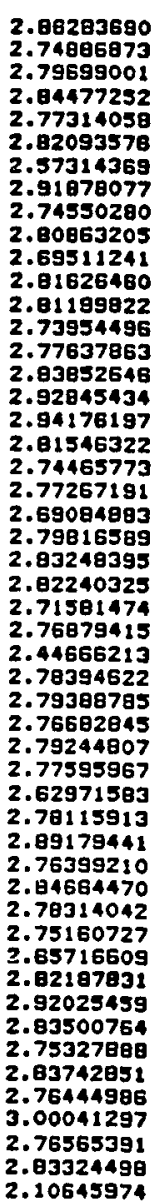 & 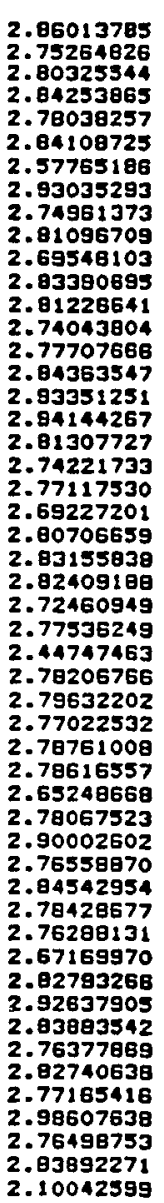 & 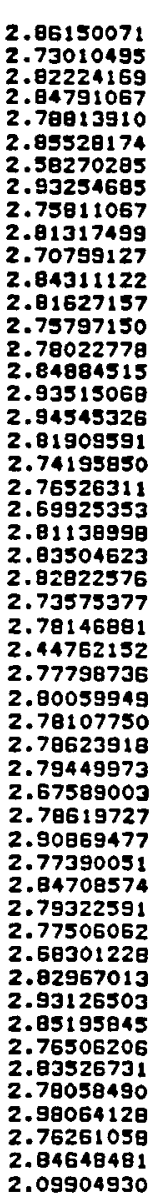 \\
\hline
\end{tabular}


TABLE XXIV (continued)

U.S. INDICES OF DIVERSITY

State

ALABAMA

ALASKA

ARIZONA

ARKANSAS

CALIFORNIA
COLORADO

CONNECTICUT

DELAHARE

FLORIDA

GEORGIA

HALAI

ILLINOIS

INDIANA

INDIAN

KANSAS

KENTUCKY

LOUISIANA

MAINE

MARYLAND

MASSACHUSETTS

MICHIGAN

MINNESOTA

MISSDURI

MONTANA

NEBRASKA

NEUADA

NEW HAMPSHIRE

NEW JERSEY

NEW MEXIC

NORTH CAROLINA

NORTH DAKOTA

OHIO

OKLAHOMA

DREGON

PENNSYLUANIA

RHODE ISLAND

SOUTH CAROLINA

SOUTH DAKOTA

TENNESSEE

TEXAS

UTAH

VERMONT

UIRGINIA

WASHINGTON

WEST UIRGINIA

WISCONSIN

WYOHINO

DIST. Of COLUM
1980

1981

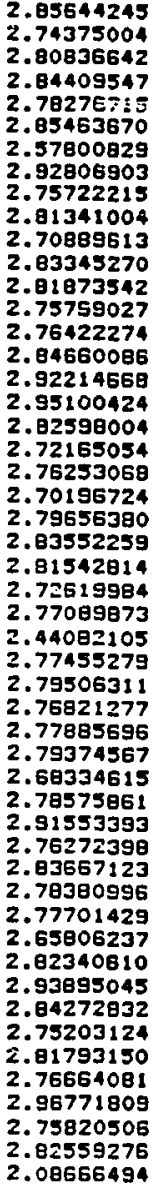

2.05644245

.80836642

2.57800829

2.92806903

2.81341004

2.70889613

2. 1873542

2.75759027

2.

2.95100424

2.

2.72165054

2.70196724

2. 83552259

2.81542814

.72619984

400983

2.77455279

.79506311

2.77885696

.79374567

2.69334615

2.91553393

2.76272390

2.78380995

2.77701429

.04203124

2. 81793150

2.76664081

2.75820506

2.82559276
2.08666494
2.84930390

2.74103270

2.94436339

2. .777.2792

2.077392

2.58232453

2.30232453

2.92822847

2.75506596

2.81151071
2.69501087

2.69501087

2.82876843

2.80854350

2.75325796

2.75212012

2. 84612447

2.90995371

2.95222414

2. 02735780

2.70965735

2.75594103

2.6891655

2.78541076

2.84622788

2. 11201959

2.72963912

2. 75552320

2.44673345

2.76960835

2.78759921

2.76918754

2.77438605

2.80091703

2.80091703

2.69990253

2.77866247

2.91593865

2.74380581

2. 92022126

2.77691549

2.77628524

2.65081400

2.81922749

2.94471392

2. $0395995 \mathrm{~B}$

2.74763703

2. 80416498

2.75786322

2. 94070724

2.94070724

2.74904299

2. 82419920
2.09399805 